Keywords: Hydrogen Kinetics, Hydrogen Storage Vessel Metal Hydride

Retention: Permanent

\title{
Integrated Hydrogen Storage System Model
}

\author{
Bruce J. Hardy
}

November 16, 2007

\begin{tabular}{l} 
Washington Savannah River Company \\
Savannah River Site \\
Aiken, SC 29808 \\
\hline $\begin{array}{l}\text { Prepared for the U.S. Department of Energy } \\
\text { Under Contract Number DEAC09-96-SR18500 }\end{array}$ \\
\hline
\end{tabular}




\section{DISCLAIMER}

This report was prepared for the United States Department of Energy under Contract No. DE-AC09-96SR18500 and is an account of work performed under that contract. Neither the United States Department of Energy, nor WSRC, nor any of their employees makes any warranty, expressed or implied, or assumes any legal liability or responsibility for accuracy, completeness, or usefulness, of any information, apparatus, or product or process disclosed herein or represents that its use will not infringe privately owned rights. Reference herein to any specific commercial product, process, or service by trade name, trademark, name, manufacturer or otherwise does not necessarily constitute or imply endorsement, recommendation, or favoring of same by Washington Savannah River Company or by the United States Government or any agency thereof. The views and opinions of the authors expressed herein do not necessarily state or reflect those of the United States Government or any agency thereof.

Printed in the United States of America

Prepared For the

U.S. Department of Energy 
Keywords: Hydrogen Kinetics, Hydrogen Storage Vessel Metal Hydride

Retention: Permanent

\title{
Integrated Hydrogen Storage System Model
}

\author{
Bruce J. Hardy
}

November 16, 2007

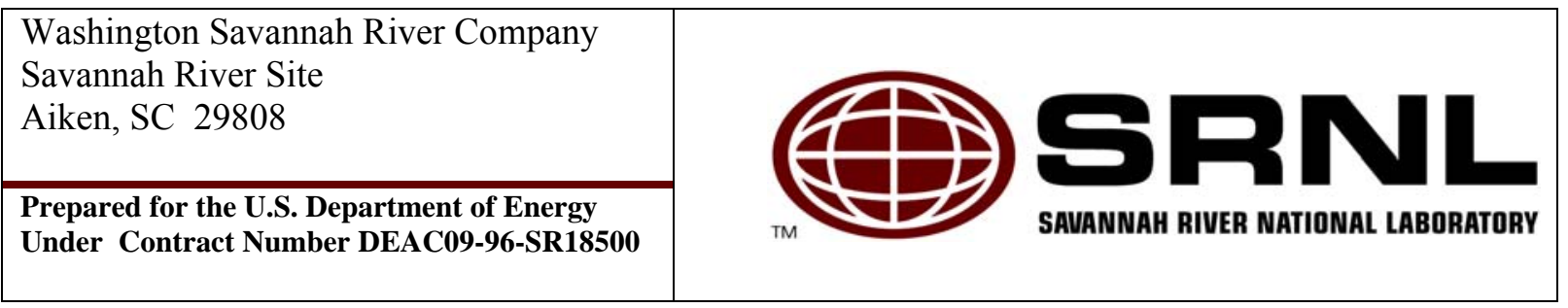




\section{TABLE OF CONTENTS}

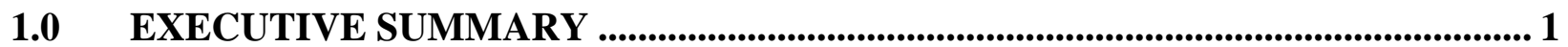

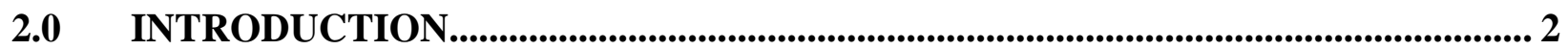

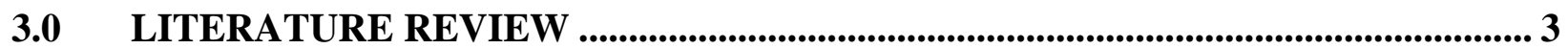

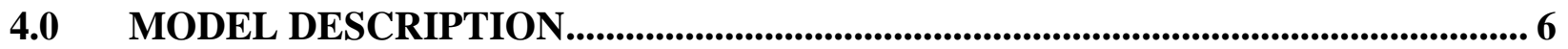

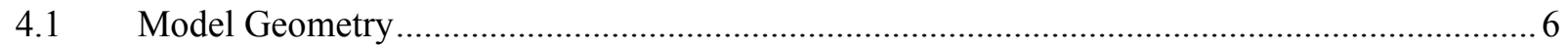

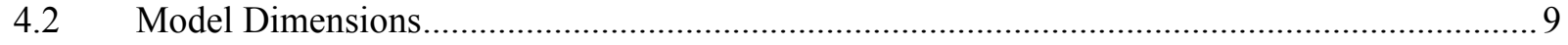

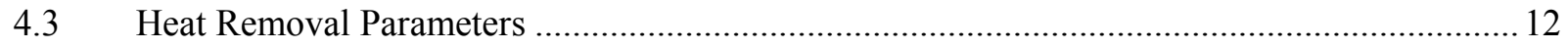

4.4 Governing Equations and Boundary Conditions ….............................................................. 13

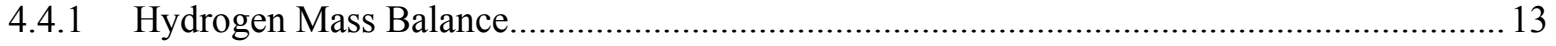

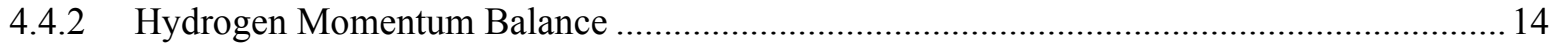

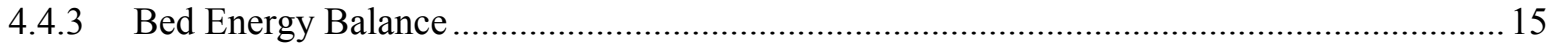

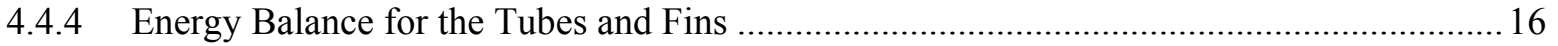

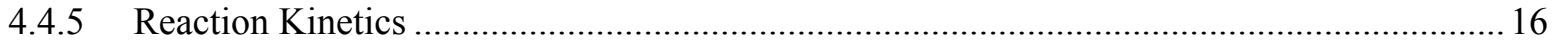

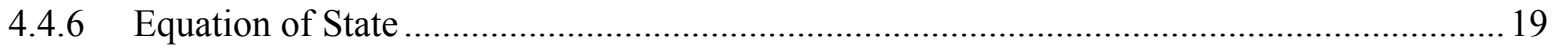

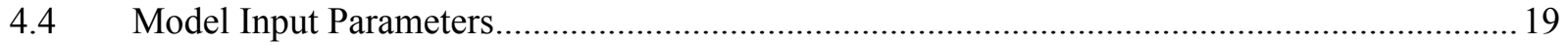

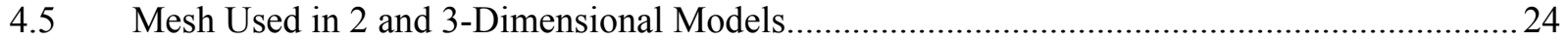

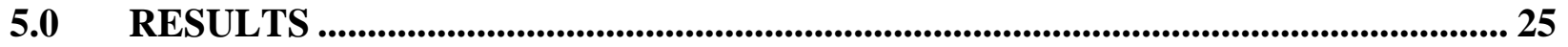

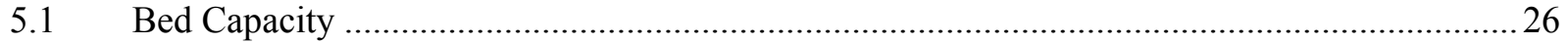

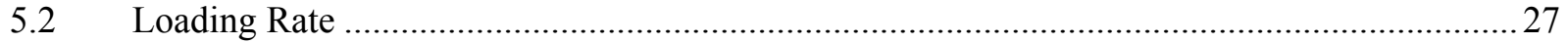

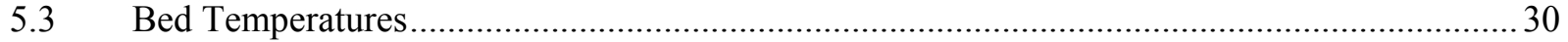

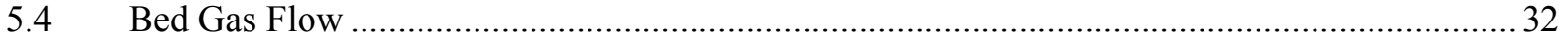

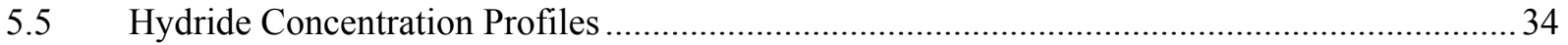

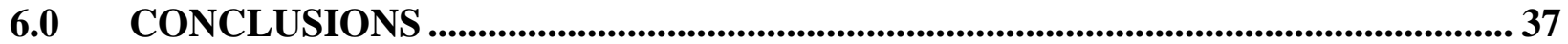

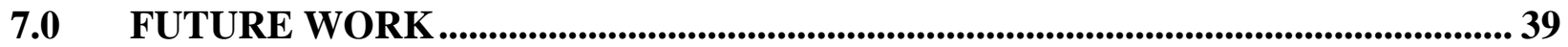

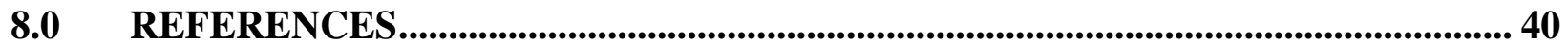

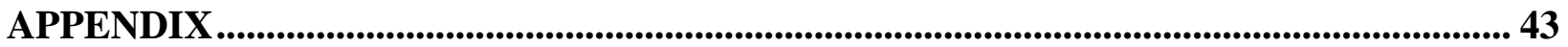

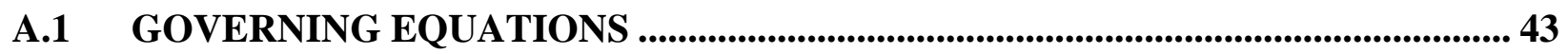

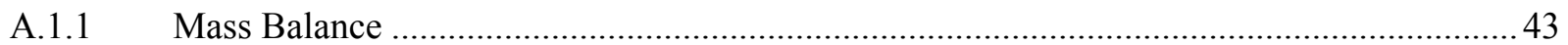

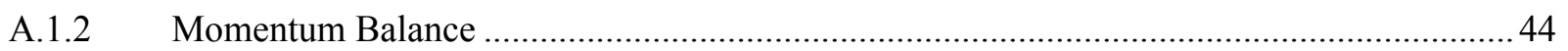

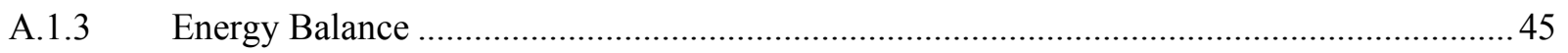

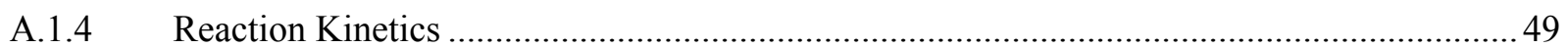

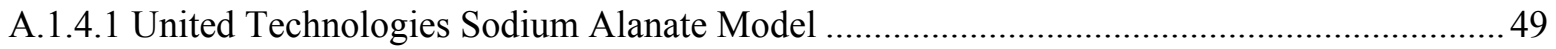




\section{A.2 SYSTEM SCALING AND KINETICS...................................................................... 53}

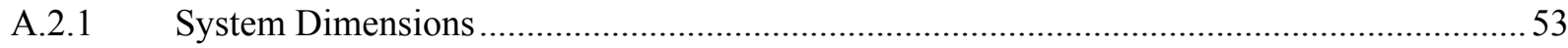

A.2.2 Heat Transfer Requirements For the $\mathrm{NaAlH}_{4}$ System...................................................... 54

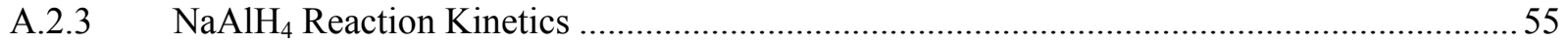

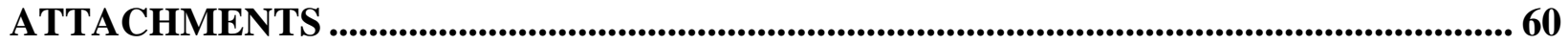

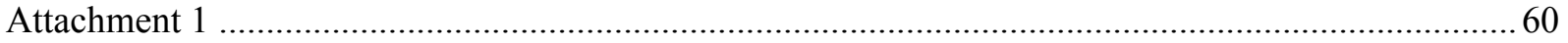

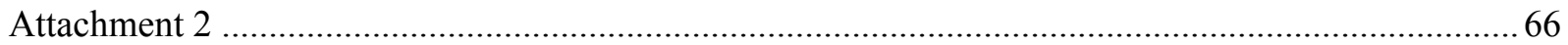

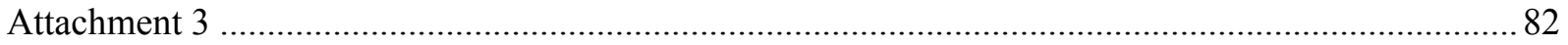




\section{LIST OF FIGURES}

Figure 4.1-1 Illustration of a shell, tube and fin hydride bed configuration developed by the United Technologies Research Center ${ }^{\mathrm{TM}}$, East Hartford, Connecticut.

Figure 4.1-2 $\quad$ Schematic of cross-section for hydride bed. 8

Figure 4.1-3 Geometry used for computations in 2-dimensional COMSOL ${ }^{\circledR}$ model. 8

Figure 4.1-4 Geometry used for computations in 3-dimensional COMSOL ${ }^{\circledR}$ model. 9

$\begin{array}{lll}\text { Figure 4.5-1 } & \text { Two-dimensional mesh. } & 24\end{array}$

Figure 4.5-2 Three-dimensional mesh. 25

Figure 5.2-1 Comparison of the weight fraction of stored hydrogen for the kinetics scoping model and the 2 and 3 -dimensional finite element bed models.

Figure 5.2-2 Comparison of weight fraction of stored hydrogen relative to the theoretical gravimetric capacity of the bed, $w f(t) / 0.056$, for the kinetics scoping model and the 2 and 3-dimensional finite element bed models.

Figure 5.3-1 Isometric and plan views of temperature profile for 3-dimensional model at 40 seconds.

Figure 5.3-2 Comparison between 2-dimensional and 3-dimensional midplane temperature profiles at 30 seconds.

Figure 5.3-3 Comparison between 2-dimensional and 3-dimensional midplane temperature profiles at 60 seconds.

Figure 5.3-4 Comparison between 2-dimensional and 3-dimensional midplane temperature profiles at 120 seconds.

Figure 5.3-5 Comparison between 2-dimensional and 3-dimensional midplane temperature profiles at 720 seconds.

Figure 5.4-1 Hydrogen velocity profile at 10 seconds.

Figure 5.4-2 Hydrogen velocity profile at 40 seconds.

Figure 5.5-1 Comparison of 2-dimensional and 3-dimensional bed midplane hydride concentrations at 40 seconds.

Figure 5.5-2 Comparison of 2-dimensional and 3-dimensional bed midplane hydride concentrations at 60 seconds.

Figure 5.5-3 Comparison of 2-dimensional and 3-dimensional bed midplane hydride concentrations at 120 seconds. 
Figure 5.5-4 Comparison of 2-dimensional and 3-dimensional bed midplane hydride concentrations at 720 seconds.

Figure A.2.1 System dimensions calculated with the scaling tool.

Figure A.2.2 System heat transfer parameters estimated with the scaling tool. 


\section{LIST OF TABLES}

Table 4.2-1 Input to the Geometry Scoping Model 10

Table 4.2-2 Bed Dimensions and Characteristics 11

Table 4.3-1 Input to Heat Removal Scoping Model $\quad 12$

Table 4.3-2 Parameters From Heat Removal Scoping Model 12

$\begin{array}{lll}\text { Table 4.4.5-1 Values for } \mathrm{wf}_{\text {iso }}^{\text {sat }}(\mathrm{T}) & 18\end{array}$

Table 4.4-1 Values of Constants Used in the $\mathrm{NaAlH}_{4}$ Model 20

Table 4.4-1 Values of Constants Used in the $\mathrm{NaAlH}_{4}$ Model (Continued) 21

Table 4.4-2 Global Expressions Used in the $\mathrm{NaAlH}_{4}$ Model 22

Table 4.4-3 Subdomain Expressions Used in the $\mathrm{NaAlH}_{4}$ Model 23

$\begin{array}{lll}\text { Table 4.5-1 } \quad \text { Two-Dimensional Mesh Statistics } & 24\end{array}$

Table 4.5-2 Three-Dimensional Mesh Statistics 25

Table A.1.4.1-1 Constants for the Rate and Equilibrium Expressions 50

$\begin{array}{lll}\text { Table A.1.4.1-2 } \quad \text { Values for } \mathrm{wf}_{\text {iso }}^{\text {sat }}(\mathrm{T}) & 51\end{array}$

\section{LIST OF ACRONYMS}

DAE Differential Algebraic Equation

DOE Department of Energy

UTRC ${ }^{\text {TM }} \quad$ United Technologies Research Center ${ }^{\text {TM }}$ 


\section{NOMENCLATURE}

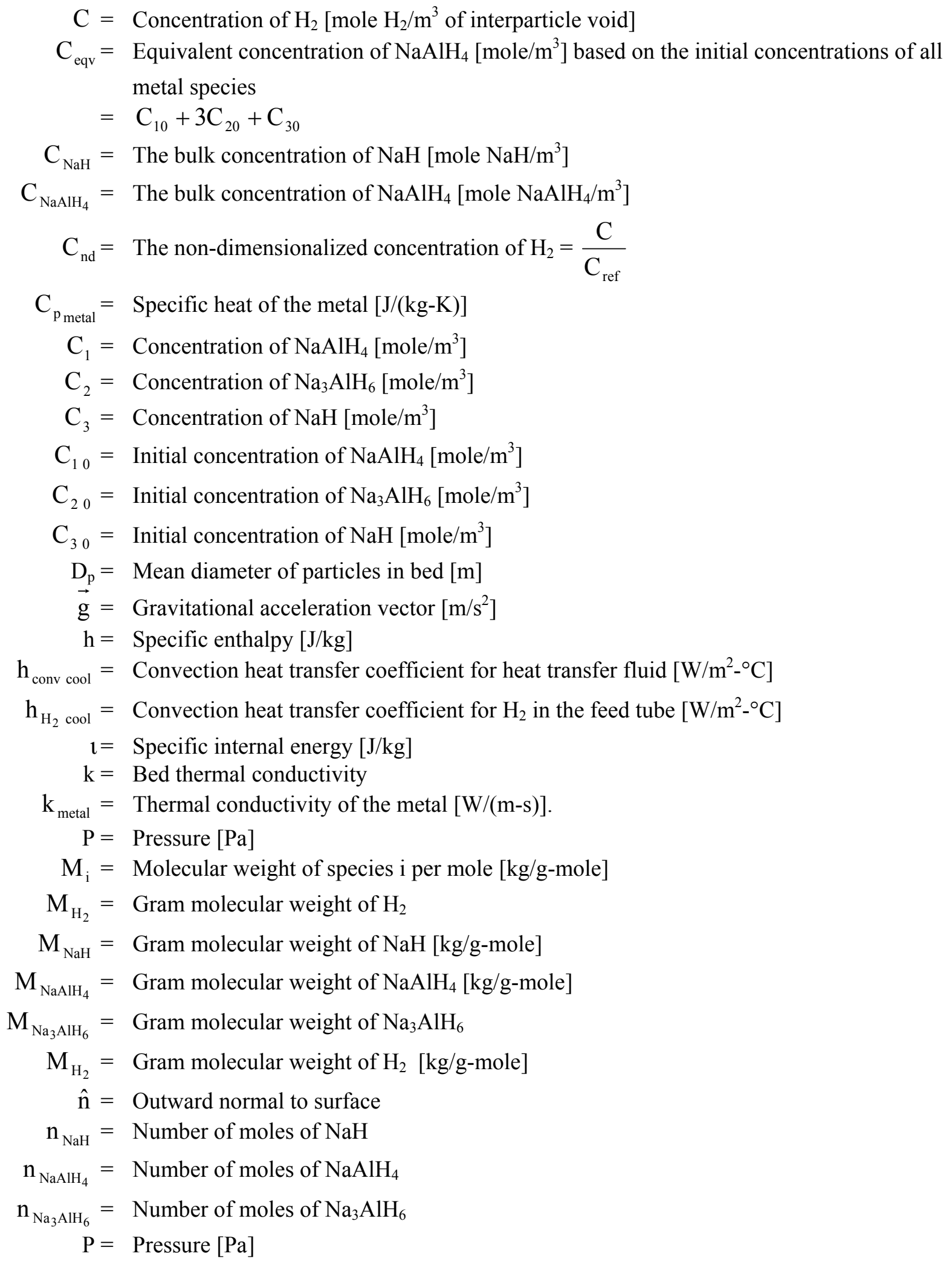




$$
\begin{aligned}
& \mathrm{P}_{\mathrm{nd}}=\frac{\mathrm{P}}{\mathrm{P}_{\mathrm{ref}}}=\text { Non-dimensional pressure } \\
& \mathrm{P}_{\text {ref }}=\text { Reference pressure }[\mathrm{Pa}] \\
& \overrightarrow{\mathrm{q}}^{\prime \prime}=\text { Heat flux vector }\left[\mathrm{W} / \mathrm{m}^{2}\right] \\
& \mathrm{R}=\text { Gas constant } \\
& \mathrm{S}=\text { Surface area }\left[\mathrm{m}^{2}\right] \\
& \mathrm{S}_{\mathrm{H}_{2}}=\text { Rate of } \mathrm{H}_{2} \text { generation per volume of bed from all chemical reactions [ } \mathrm{mol} \mathrm{H}_{2} /\left(\mathrm{m}^{3}-\mathrm{s}\right) \text { ], } \\
& \mathrm{S}_{\mathrm{H}_{2}}>0 \text { if } \mathrm{H}_{2} \text { is produced } \\
& \mathrm{S}_{\mathrm{H}_{2}}<0 \text { if } \mathrm{H}_{2} \text { is removed } \\
& \mathrm{T}_{\text {coolant bulk }}=\text { Bulk temperature of the heat transfer fluid }[\mathrm{K}] \\
& \mathrm{T}_{\mathrm{nd}}=\frac{\mathrm{T}}{\mathrm{T}_{\mathrm{ref}}}=\text { Non-dimensional temperature } \\
& \mathrm{T}_{\mathrm{H}_{2} \text { bulk }}=\text { Bulk temperature of the } \mathrm{H}_{2} \text { in the feed tube }[\mathrm{K}] \\
& \mathrm{T}_{\text {ref }}=\text { Reference temperature }[\mathrm{K}] \\
& \mathrm{T}_{\text {wall }}=\text { Tube wall temperature }[\mathrm{K}] \\
& \mathrm{V}=\text { Volume }\left[\mathrm{m}^{3}\right] \\
& \overrightarrow{\mathrm{v}}=\mathrm{H}_{2} \text { velocity }[\mathrm{m} / \mathrm{s}] \\
& \mathrm{u}=\mathrm{x} \text { component of the velocity, } \overrightarrow{\mathrm{v}}[\mathrm{m} / \mathrm{s}] \\
& \mathrm{u}_{\mathrm{nd}}=\frac{\mathrm{u}}{\mathrm{U}_{\mathrm{ref}}}=\text { Non-dimensional } \mathrm{x} \text {-component of velocity } \\
& \mathrm{U}_{\text {ref }}=\text { Reference velocity }[\mathrm{m} / \mathrm{s}] \\
& \mathrm{v}=\mathrm{y} \text { component of the velocity, } \overrightarrow{\mathrm{v}}[\mathrm{m} / \mathrm{s}] \\
& \mathrm{v}_{\mathrm{nd}}=\frac{\mathrm{V}}{\mathrm{U}_{\mathrm{ref}}}=\text { Non-dimensional y-component of velocity } \\
& \mathrm{w}=\mathrm{z} \text { component of the velocity, } \overrightarrow{\mathrm{v}}[\mathrm{m} / \mathrm{s}] \\
& \mathrm{W}_{\mathrm{nd}}=\frac{\mathrm{W}}{\mathrm{U}_{\mathrm{ref}}}=\text { Non-dimensional z-component of velocity }
\end{aligned}
$$

\section{Greek}

$$
\Delta \mathrm{H}_{\mathrm{i}}=\text { Enthalpy of reaction on a molar basis of species } \mathrm{i}[\mathrm{J} /(\text { mole of } \mathrm{i})]
$$$$
\Delta \mathrm{H}_{\mathrm{rxn} 1}=\text { Heat of per mole of } \mathrm{H}_{2} \text { consumed going to left for reaction } 1
$$$$
=-37 \mathrm{~kJ} /\left(\text { mole }_{2}\right)
$$

$\Delta \mathrm{H}_{\mathrm{rxn} 2}=$ Heat of per mole of $\mathrm{H}_{2}$ consumed going to left for reaction 2

$=-47 \mathrm{~kJ} /\left(\right.$ mole $\left.\mathrm{H}_{2}\right)$

$\rho_{\mathrm{i}}=$ Mass density of species $\mathrm{i}\left[\mathrm{kg} / \mathrm{m}^{3}\right]$

$\rho_{\text {metal }}=$ Density of the metal $\left[\mathrm{kg} / \mathrm{m}^{3}\right]$.

$\varepsilon=$ Void between particles in bed

$\mu=$ Viscosity of $\mathrm{H}_{2}[\mathrm{~Pa}-\mathrm{s}]$ 


$$
\begin{aligned}
& \rho=\text { Mass density }\left[\mathrm{kg} / \mathrm{m}^{3}\right] \\
& \underline{\underline{\tau}}=\text { Stress tensor, having components } \tau_{\mathrm{ij}}\left[\mathrm{N} / \mathrm{m}^{2}\right]
\end{aligned}
$$

\section{Symbols and Operators}

$$
\begin{aligned}
& \left.\frac{v_{\mathrm{H}_{2}}}{v_{\mathrm{NaH}}}\right|_{\mathrm{Rxn} 2}=\text { Ratio of the stoichiometric coefficient of } \mathrm{H}_{2} \text { to } \mathrm{NaH} \text { in reaction } 2=0.5 \\
& \left.\frac{v_{\mathrm{H}_{2}}}{v_{\mathrm{NaAlH}_{4}}}\right|_{\mathrm{Rxn}_{1}}=\text { Ratio of the stoichiometric coefficient of } \mathrm{H}_{2} \text { to } \mathrm{NaAlH}_{4} \text { in reaction } 1=1 \\
& ()_{\mathrm{H}_{2}}=\text { For } \mathrm{H}_{2} \text { gas } \\
& ()_{\mathrm{R}}=\text { For solid phase reactants } \\
& ()_{\mathrm{P}}=\text { For solid phase products } \\
& ()_{\mathrm{I}}=\text { For inert (non-reacting) material, such as metal foam }
\end{aligned}
$$


WSRC-TR-2007-00440

Revision 0

\subsection{EXECUTIVE SUMMARY}

Hydrogen storage is recognized as a key technical hurdle that must be overcome for the realization of hydrogen powered vehicles. Metal hydrides and their doped variants have shown great promise as a storage material and significant advances have been made with this technology. In any practical storage system the rate of $\mathrm{H}_{2}$ uptake will be governed by all processes that affect the rate of mass transport through the bed and into the particles. These coupled processes include heat and mass transfer as well as chemical kinetics and equilibrium. However, with few exceptions, studies of metal hydrides have focused primarily on fundamental properties associated with hydrogen storage capacity and kinetics.

A full understanding of the complex interplay of physical processes that occur during the charging and discharging of a practical storage system requires models that integrate the salient phenomena. For example, in the case of sodium alanate, the size of $\mathrm{NaAlH}_{4}$ crystals is on the order of $300 \mathrm{~nm}$ and the size of polycrystalline particles may be approximately 10 times larger $(\sim 3,000 \mathrm{~nm})$. For the bed volume to be as small as possible, it is necessary to densely pack the hydride particles. Even so, in packed beds composed of $\mathrm{NaAlH}_{4}$ particles alone, it has been observed that the void fraction is still approximately $50-60 \%$. Because of the large void fraction and particle to particle thermal contact resistance, the thermal conductivity of the hydride is very low, on the order of $0.2 \mathrm{~W} / \mathrm{m}-{ }^{\circ} \mathrm{C}$, Gross, Majzoub, Thomas and Sandrock [2002]. The chemical reaction for hydrogen loading is exothermic. Based on the data in Gross [2003], on the order of $10^{8} \mathrm{~J}$ of heat of is released for the uptake of $5 \mathrm{~kg}$ of $\mathrm{H}_{2}$ and complete conversion of $\mathrm{NaH}$ to $\mathrm{NaAlH}_{4}$. Since the hydride reaction transitions from hydrogen loading to discharge at elevated temperatures, it is essential to control the temperature of the bed. However, the low thermal conductivity of the hydride makes it difficult to remove the heat of reaction, especially in the relatively short target refueling times, see Attachment 3 .

This document describes a detailed numerical model for general metal hydride beds that couples reaction kinetics with heat and mass transfer, for both hydriding and dehydriding of the bed. The detailed model is part of a comprehensive methodology for the design, evaluation and modification of hydrogen storage systems. In Hardy [2007], scoping models for reaction kinetics, bed geometry and heat removal parameters are discussed. The scoping models are used to perform a quick assessment of storage systems and identify those which have the potential to meet DOE performance targets. The operational characteristics of successful candidate systems are then evaluated with the more detailed models discussed in this document.

The detailed analysis for hydrogen storage systems is modeled in either 2 or 3-dimensions, via the general purpose finite element solver COMSOL Multiphysics ${ }^{\circledR}$. The two-dimensional model serves to provide rapid evaluation of bed configurations and physical processes, while the threedimensional model, which requires a much longer run time, is used to investigate detailed effects that do not readily lend themselves to two-dimensional representations. The model is general and can be adapted to any geometry or storage media. In this document, the model is applied to a modified cylindrical shell and tube geometry with radial fins perpendicular to the axis, see Figures 4.1-1 and 4.1-2. Sodium alanate, $\mathrm{NaAlH}_{4}$, is used as the hydrogen storage medium. The model can be run on any DOS, LINUX or Unix based system. 
WSRC-TR-2007-00440

Revision 0

\subsection{INTRODUCTION}

It is acknowledged that a critical function of a hydrogen storage system is meeting the DOE refueling goal of three minutes, see Attachment 3. The rapid fueling rate, coupled with the high heat of reaction on uptake, requires a heat dissipation rate on the order of $111 \mathrm{~kW}$ per kilogram of stored $\mathrm{H}_{2}$ in sodium aluminum hydride, $\mathrm{NaAlH}_{4}$. Metal hydride (and other) hydrogen storage systems have a number of physical phenomena that work against one another. For example, the rate of hydrogen uptake for hydrides decreases exponentially, and reverses, as temperatures increase beyond a particular value (e.g. $390 \mathrm{~K}$ for $\mathrm{NaAlH}_{4}$ ). In view of the target charging time and the very large quantity of heat released during the uptake process (on the order of $10^{8} \mathrm{~J}$ for conversion of $\mathrm{NaH}$ to $\mathrm{NaAlH}_{4}$ for the uptake of $5 \mathrm{~kg}$ of $\mathrm{H}_{2}$ ), a high rate of heat transfer must be maintained for the uptake reaction to proceed at an acceptable rate. However, most hydrides also possess low material, and even lower, bulk thermal conductivities. Bed thermal conductivities have been enhanced by embedding the hydride into metal foam, but this reduces the volumetric and gravimetric capacities of the system, as defined in Attachment 3. The goals for volumetric and gravimetric capacity, as well as for the refueling rate, adds additional constraints to the design of the system. To ensure adequate mass transfer rates within the hydride crystals, the polycrystalline particles must have small transport length scales, yielding high surface area to volume ratios. But, in a practical bed the particle size must be sufficiently large to permit an adequate flowrate of hydrogen to supply the demand during the loading and discharge phases. For example, individual $\mathrm{NaAlH}_{4}$ crystals have a length scale of approximately $300 \mathrm{~nm}$ and the polycrystalline particles comprising the bed have length scales of approximately $3000 \mathrm{~nm}$. Particles in this size range meet both the requirements for rapid transport within the hydride and flow through the bed.

It is difficult and expensive to design experiments that fully measure the complex processes occurring during the loading and discharge of hydrogen from a storage media, let alone perform sensitivity studies for a complete system. Moreover, any such experiments would be limited to a particular hydride and system design. A much more efficient approach is to evaluate proposed designs for hydrogen storage systems through the use of numerical models that couple heat and mass transport with the reaction kinetics occurring in the bed. By systematically combining scoping models that quickly evaluate whether a storage system has the potential to meet DOE performance targets with more sophisticated models that provide more detailed predictions of operational performance, the most promising designs can be efficiently identified. The scoping models not only eliminate designs that perform poorly relative to target criteria, but also can be used to identify design improvements and provide input to the more time consuming sophisticated models. The detailed models can be used to perform sensitivity studies and to identify design improvements. Those systems that appear most likely to approach the performance objectives can then be tested as prototypes, greatly reducing the number of necessary experiments. It is perhaps inevitable that deficiencies in available data, required as input to the models, will be discovered. In these instances, experiments can be performed to specifically obtain the necessary data.

Scoping models for hydriding/dehydriding reaction kinetics, bed geometry and heat removal parameters, for generalized storage systems are discussed in Hardy [2007]. This document describes a detailed numerical model for general metal hydride beds that couples reaction kinetics with heat and mass transfer, for both hydriding and dehydriding of the bed. The detailed model is part of a comprehensive methodology for the design, evaluation and modification of hydrogen storage systems. The detailed analysis for hydrogen storage systems is conducted in either 2 or 3 - 
dimensions, via the general purpose finite element solver COMSOL Multiphysics ${ }^{\circledR}$. The twodimensional model serves to provide rapid evaluation of bed configurations and physical processes, while the three-dimensional model, which requires a much longer run time, is used to investigate effects that do not readily lend themselves to two-dimensional representations. The model is general and can be adapted to any geometry or storage media. In this document, however, the model is applied to sodium alanate, $\mathrm{NaAlH}_{4}$, with its associated kinetics and equilibrium equations, and to a particular bed geometry.

\subsection{LITERATURE REVIEW}

In the past, a number of numerical models have been developed for metal hydride beds. These models have attempted to address, at least in part, the coupled phenomena occurring as the bed is charged with or discharges hydrogen. The models, however, tended to be either of limited scope, addressing either a limited number of physical phenomena, simplifying the phenomena or simplifying the bed geometry. A survey of these models is presented in this section.

El-Osery [1984a] developed a one-dimensional transient model for a granular Ti-Fe bed, which approximated the system as an azimuthally symmetric cell in cylindrical geometry, having only radial dependence. The model considered heat conduction in the portion of the cell comprising the bed and convection from the bed surface. It was applied to heat removal during the exothermic chemical reaction that occurred during the charging process and to heating by convection at the external surface to discharge the stored hydrogen. In El-Osery [1984b] this simple model was extended to a variety of geometric configurations represented as onedimensional cells in their respective coordinate geometries. An elaboration of the model was presented in El-Osery [1986].

A model for the discharging reaction in a $\mathrm{LaNi}_{5} \mathrm{H}_{6}$ bed was developed in El-Osairy, et. al. [1992a]. The bed was in the form of a 1-dimensional porous channel with hydrogen introduced at one end. The bed was adiabatic along its sides, with a specified solid phase temperature at the inlet and with a temperature gradient of zero at the exit. Further, it was assumed that the bed was subject to fixed uniform $\mathrm{H}_{2}$ pressure. This one-dimensional, transient model considered the bed to be composed of gas and solid phases, each having separate energy and mass balances that were coupled through convection heat transfer and interphase mass conservation. Temperaturedependent reaction rates for $\mathrm{H}_{2}$ uptake, and the subsequent heat of reaction, were used in the model. El-Osairy, et. al. [1992b] applied the model to a variety of channel configurations, some of which replaced the adiabatic conditions on the sides for the channel with forced convection cooling. The model was applied to $\mathrm{FeTiH}_{1.6}$ and $\mathrm{Mg}_{2} \mathrm{NiH}_{4}$ beds in El-Osairy, et. al. [1993]. By modifying the reaction rate to apply to $\mathrm{H}_{2}$ discharge, El-Osery, et. al. [1993] applied the model to the discharge of the bed. In this model, dehydriding was effected by circulating heated $\mathrm{H}_{2}$ through the bed. Heat transfer from the gas to the solid phase was used to control the endothermic chemical reaction. El-Gammal, et. al. [1993] applied the model to dehydriding annular cylinders composed of $\mathrm{LaNi}_{5} \mathrm{H}_{6}$, where heated gas is passed through the porous media and over its exterior surfaces.

Aldas, et. al. [2002] developed a model based on the PHOENICS ${ }^{\circledR}$ general purpose finite volume Computational Fluid Dynamics (CFD) software to investigate heat and mass transfer in porous metal hydride bed. The transient spatial dependence for hydride formation was predicted by the model. They found that coolant flowrate affected the temperature distribution in the system but did not significantly change the amount of hydrogen absorbed. PHOENICS ${ }^{\circledR}$ was also used by 
Biligi and Ataer [1996] to model the transient temperature and $\mathrm{H}_{2}$ uptake by a porous $\mathrm{LaNi}_{5}$ bed. The bed was an annulus having a length of $30 \mathrm{~mm}$, and inner and outer radii of $10 \mathrm{~mm}$ and $20 \mathrm{~mm}$, respectively. Because of the bed geometry, the model was axisymmetric. Bed porosity was fixed at $50.5 \%$. The model was used to calculate the transient temperature and hydrogen content for the annular configuration. The model addressed the mass and energy balance within the bed. The momentum balance was given by Darcy's law. Cooling by the heat transfer fluid was invoked as a boundary condition. The energy balance assumed the solid and $\mathrm{H}_{2}$ phases to have the same local temperature. It appears that the convection terms in mass balance equation should have been multiplied by the porosity; however, this might have been a typographical error. The rate of $\mathrm{H}_{2}$ uptake by the metal was determined from a reaction kinetics equation and the equilibrium Van't Hoff equation. The model had the potential for generalization to other geometries and metals.

Gopal and Murthy [1992] developed a one-dimensional model for heat and mass transfer in an annular bed, which was charged with hydrogen on its inner surface and cooled at its outer surface. The model was used to obtain correlations for a range of bed alloys and operating conditions. The correlations were then demonstrated for a lanthanum-rich mischmetal $(\mathrm{Lm})$ bed alloyed with nickel and aluminum, $\mathrm{LmNi}_{4.7} \mathrm{Al}_{0.3}$. The authors later conducted experiments on a cylindrical metal bed using porous $\mathrm{MnNi}_{4.5} \mathrm{Al}_{0.5}$, Gopal and Murthy [1995]. In the experiments, hydrogen uptake and release was measured for various coolant temperatures. Although good agreement was obtained between their measured heat and mass transfer rates, and those predicted by their 1992 model, there was a discrepancy between measured and predicted bed temperatures.

Mat and Kaplan [2001] and Aldas and Mat [2002] conducted a numerical analysis of hydride formation in a porous metal bed of $\mathrm{LaNi}_{5} \mathrm{Sn}_{0.2}$, having the shape of a finite length cylinder. The model addressed heat, mass and chemical reactions in the bed. Predictions made by Mat and Kaplan's model agreed well with the experimental data of Mayer, et. al. [1987].

A numerical model that calculated the pressure and temperature histories associated with $\mathrm{H}_{2}$ desorption from a lanthanum-rich mischmetal $(\mathrm{Lm})$ hydride bed alloyed with nickel and aluminum, $\mathrm{Lm}_{1.06} \mathrm{Ni}_{4.96} \mathrm{Al}_{0.04}$, was developed by Gadre, Ebner, Al-Muhtaseb and J. Ritter [2003]. The models were able to predict the P-T behavior of the hydride bed at low discharge rates. However, at higher discharge rates none of the modeling scenarios were able to properly predict the behavior of the bed. The authors postulated that this was the result of a more complex the heat transfer process at higher discharge rates, and that the simplified assumptions employed by the model were insufficient for this regime.

Askri, Jemini and Nasrallah [2004] developed a transient model for a $\mathrm{LiNi}_{5}$ bed in a closed vessel. The governing equations included those for mass, momentum and energy. $\mathrm{LiNi}_{5}$ kinetics and equilibrium equations were used to determine the rate and extent of the reaction. The system of equations was solved numerically using the Control Volume based Finite Element Method (CVFEM) in a computer program developed by the authors. The vessel had the form of a vertical cylinder in which the metal hydride occupied the lower part of the vessel, with a gas space present above the bed. A heat transfer fluid, in contact with the external walls of the vessel, was used to control the temperature of the bed and gas space. The effect of the ratio of the bed height to radius on the rate of hydrogen desorption was investigated. In a comparison with experimental results, the model slightly under-predicted the transient hydrogen pressure during desorption.

Ha, et. al [2004] developed a two dimensional mathematical model for transient heat and mass transfer within a metal hydride bed using the finite volume method. In this analysis, the relation between hydrogen uptake and the bed thermal conductivity, diameter, and heat transfer fins was 
investigated. Darcy's Law was used to relate the pressure gradient to the superficial velocity in the bed. The equation of state was the ideal gas law. Uptake kinetics were modeled via an Arrhenius-type expression, for which a two-step absorption mechanism was postulated. The first step of the uptake reaction was a nucleation and growth process. The second step was diffusion through a hydrogen layer that formed on the hydride. The results of the model indicated that the fractional hydrogen uptake during the first nucleation step is quite rapid and rather invariant with temperature, but is strongly affected by the difference between the actual gas pressure and the hydrogen equilibrium pressure. The second step, however, was found to be strongly affected by temperature, implying that the overall system performance can be greatly improved by the implementation of thermal management and heat transfer controls.

Mazumdar, Gopal and Bhattacharyya [2005] used a steady-state thermodynamic model to predict the performance of a metal hydride refrigeration system. Four metal hydrides were considered: $\mathrm{MnNi}_{4.5} \mathrm{Al}_{0.5}, \mathrm{LaNi}_{5}, \mathrm{TiFe}_{0.85} \mathrm{Mn}_{0.15}, \mathrm{Zr}_{0.9} \mathrm{Ti}_{0.1} \mathrm{Cr}_{0.55} \mathrm{Fe}_{1.45}$. The thermodynamic model utilized the basic thermo-physical properties of the metal hydride including the density, thermal conductivity, specific heat, the equilibrium pressure of $\mathrm{H}_{2}$ for a given hydride, as well as, the material composition and geometry of the bed and heat transfer fins (via standard heat transfer relationships). The objective of the model was to determine the effect that these properties had on the performance of the compressor and its ability to cool the system. Heat and mass transfer were not solved for within the physical domain of the hydride bed.

Kikkinides, Georgiadis and Stubos [2006] modeled a $\mathrm{LaNi}_{5}$ bed using the equations for heat and mass transfer in two-dimensional axisymmetric cylindrical geometry. Predicitions of the model were compared with data taken by Jemini and Nasrallah [1995], Nasrallah and Jemini [1997], and Jemini, Nasrallah and Lamloumi [1999]. In the model, it was assumed that the velocity of hydrogen was constant within the bed, and the hydrogen temperature and density were dependent on time. The resulting system of differential algebraic equations (DAE's) was solved using the commercial software package gPROMS ${ }^{\circledR}$. The model was used to evaluate the time required for the system to reach $99 \%$ of its hydrogen capacity for several heat exchange configurations. Model assumptions included: ideal gas behavior for hydrogen and equal solid and gas phase temperatures in the bed. The hydrogen mass balance included radial dispersion, with the relation between the gas velocity and pressure gradient in the bed given by the Blake-Kozeny equation. It was found that $\mathrm{H}_{2}$ absorption time could be minimized through the use of a cooling ring that split the bed, radially, into two approximately, equal portions. By using this configuration the model indicated that the time required for absorption could be reduced to approximately $60 \%$ of that when only an outer cooling jacket was used.

Transient, two dimensional models for the loading of hydrogen into a sodium alanate bed having a shell, tube and fin configuration, see Figure 4.1-1, were developed by Mosher, et.al [2007]. The models coupled heat transfer and reaction kinetics, including heat of reaction, but did not include mass transfer of the hydrogen through the bed. To accommodate the effect of the fin, which is an axial layer, in the two-dimensional (radial and azimuthal) heat transfer model, the bed thermal conductivity was modified. The model compared reasonably well with data obtained from a scaled experiment. 
WSRC-TR-2007-00440

Revision 0

\subsection{MODEL DESCRIPTION}

The model developed in this document applies to a general metal hydride bed, which is governed by the physical processes occurring as hydrogen is loaded into or discharged from the hydride.

The model includes:

1. Gas flow within the bed (interstitial flow), which depends on:

a. The pressure gradient (or gas phase $\mathrm{H}_{2}$ concentration gradient) in the bed.

b. The void fraction and effective particle diameter.

2. Heat transfer, essential to control the bed temperature, which is governed by:

a. Exothermic and endothermic reactions occurring during uptake and release of $\mathrm{H}_{2}$, respectively.

b. The effective bed thermal conductivity.

c. Convection heat transfer within the bed.

d. System boundary conditions and geometry.

e. Thermal contact for various components of the bed.

3. Reaction kinetics for hydriding and dehydriding reactions.

a. Dependence of reaction rates on temperature, $\mathrm{H}_{2}$ pressure and composition of the solid phase.

b. Dependence of reaction equilibrium on the state of the system.

A model that captures the physical phenomena listed above was built using the COMSOL

Multiphysics $^{\circledR}$, version 3.3.0.405, finite element software, COMSOL [2006].

Assumptions made in the model are:

1 Only hydrogen is allowed to flow in the system.

2 The bed does not expand or contract. This assumption is especially significant because all materials proposed for hydrogen storage undergo significant expansion during hydrogen loading.

3 The thermal properties of the bed do not change with the amount of hydrogen loading.

4 The thermal properties of the bed do not vary with temperature.

5 The characteristics of the bed are unaffected by the number of loading-unloading cycles. That is, bed aging is neglected.

6 Heat transfer from the bed occurs only via the heat transfer fluid (in the cooling tubes), by convection to the hydrogen in the feed tubes, and by homogeneous heat exchange with the hydrogen flowing through the bed.

7 The solid material and hydrogen have the same instantaneous temperature at all locations within the bed.

8 The thermal conductivity, specific heat and viscosity of hydrogen do not vary with pressure over the operational regime of the storage system.

9 The tubes and fins are composed of 6063 T83 aluminum.

10 Thermal contact between the bed and the cooling tubes, the bed and the fin, and the fin and the cooling tubes is good, i.e. neglect thermal contact resistance.

11 The bed void fraction remains constant and uniform throughout.

12 The bed fills the entire volume of the space between the fins and tubes.

13 The bulk temperature of the heat exchange fluid and the hydrogen supplied to the bed is constant and uniform.

14 The hydrogen flows (circulates) through the feed tubes.

15 For this system, the equation of state for hydrogen is given by the ideal gas law.

16 Axial end effects have negligible impact on the performance of the storage system.

\subsection{Model Geometry}


In this work, the detailed 2 and 3-dimensional finite element models are applied to the analysis of sodium alanate, $\mathrm{NaAlH}_{4}$, bed. The storage system has the configuration of a cylindrical shell, tube and fin heat exchange. The bed is divided by an array of fins that are normal to the axis and extend in the radial direction. The fins are press-fit to coolant tubes that are parallel to the axis. Figure 4.1-1 shows a storage system developed and tested by the United Technologies Research

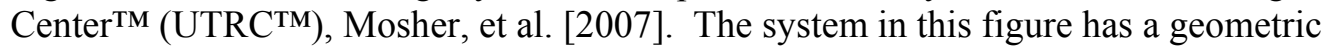
configuration that is similar to the system modeled in this document. However, the system modeled in the current analysis does not possess the same dimensions as the bed displayed in the Figure 4.1-1.

The bed modeled in this document has 9 coolant tubes and 8 tubes used for the injection of hydrogen, see Figure 4.1-2. The model focuses on a layer of hydride material located at sufficient distance from the axial ends of the bed, that the axial boundary conditions are periodic from the midplane of one fin to the midplane of the next adjacent fin. Therefore, axial symmetry conditions can be applied to the midplane of the hydride layer and the midplane of the fin. Further, there are planes of azimuthal symmetry, as shown in Figure 4.1-2. The geometry used for the 2-dimensional COMSOL ${ }^{\circledR}$ model is shown in Figure 4.1-3 and the geometry used in the 3dimensional model is shown in Figure 4.1-4.

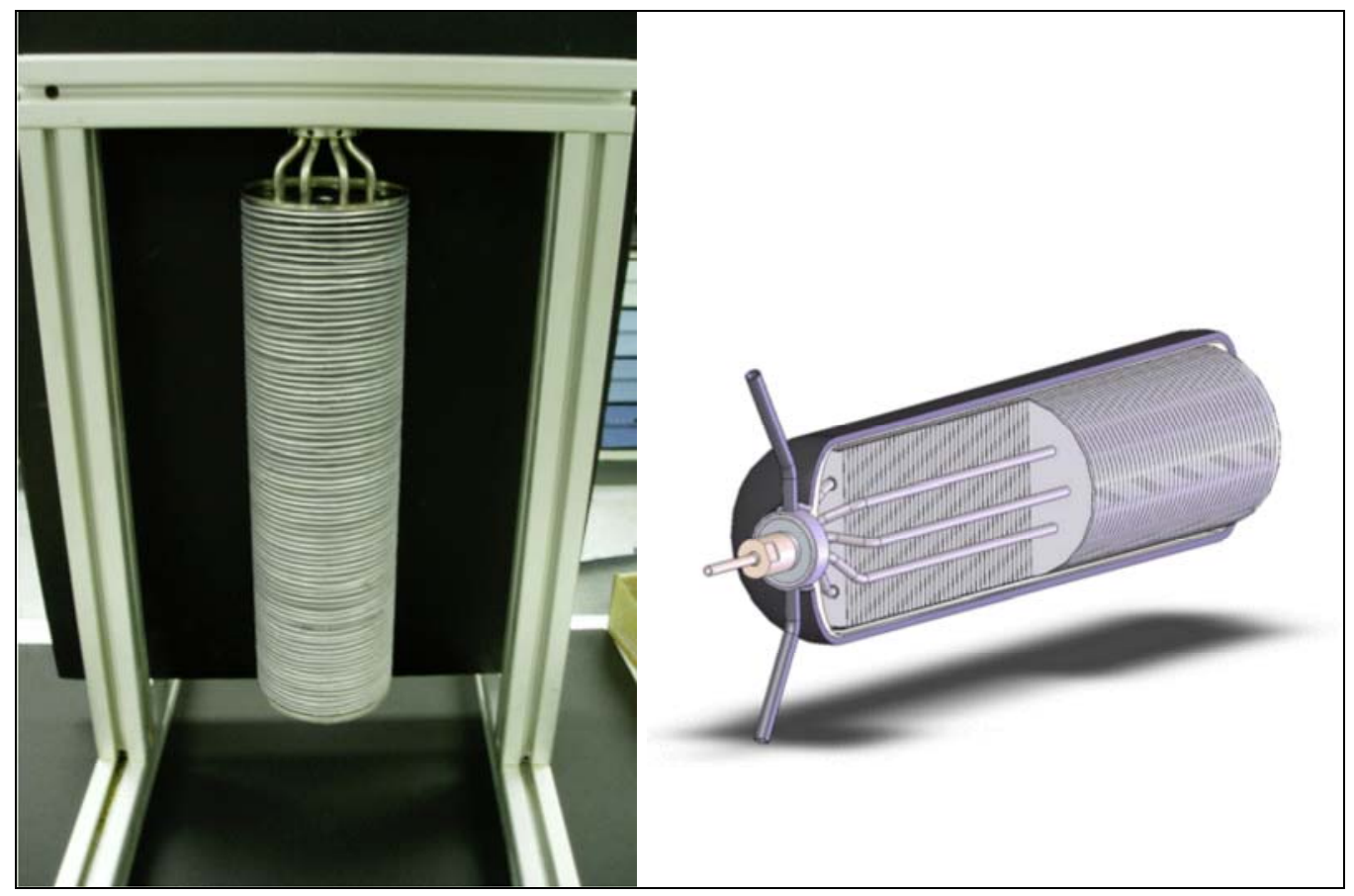

Figure 4.1-1 Illustration of a shell, tube and fin hydride bed configuration developed by the United Technologies Research Center ${ }^{\mathrm{TM}}$, East Hartford, Connecticut. 
WSRC-TR-2007-00440

Revision 0

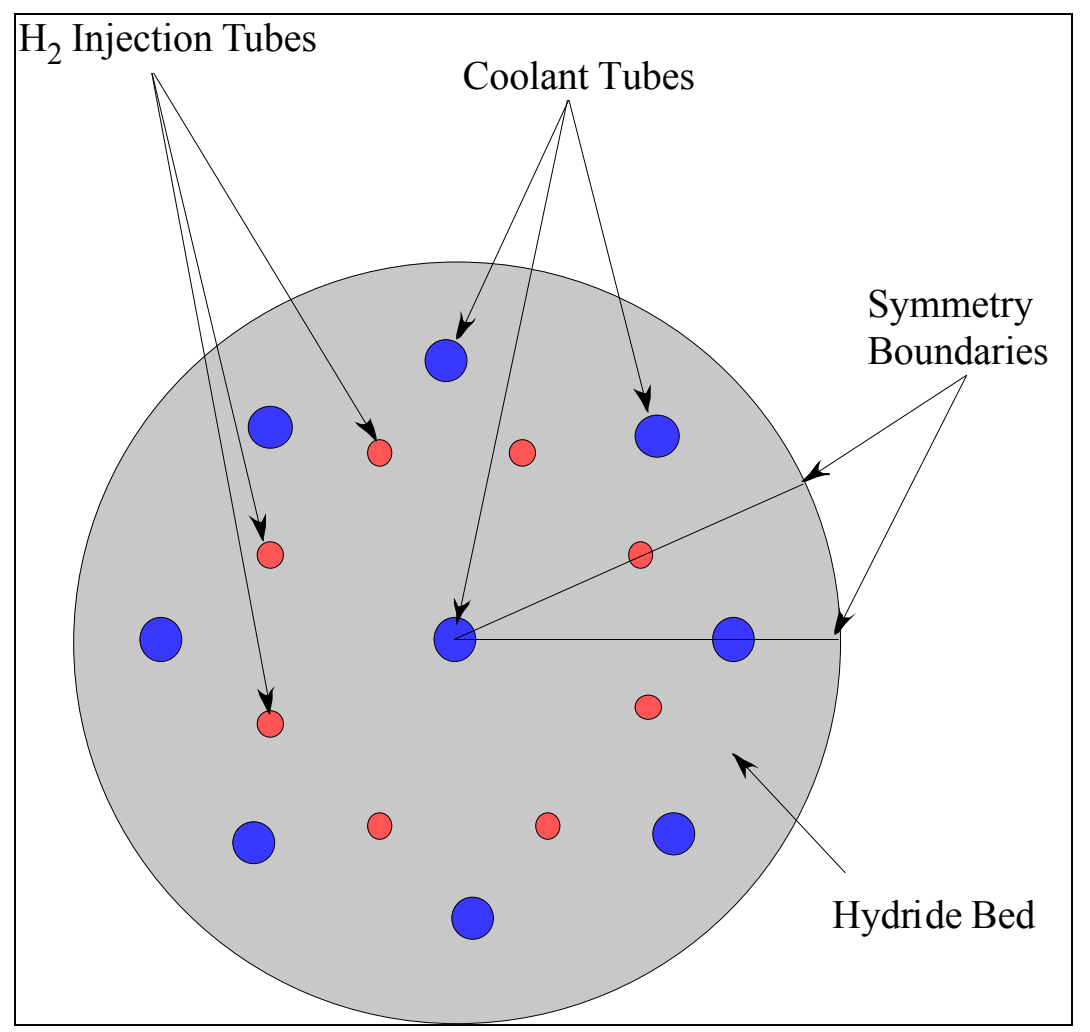

Figure 4.1-2 Schematic of cross-section for hydride bed.

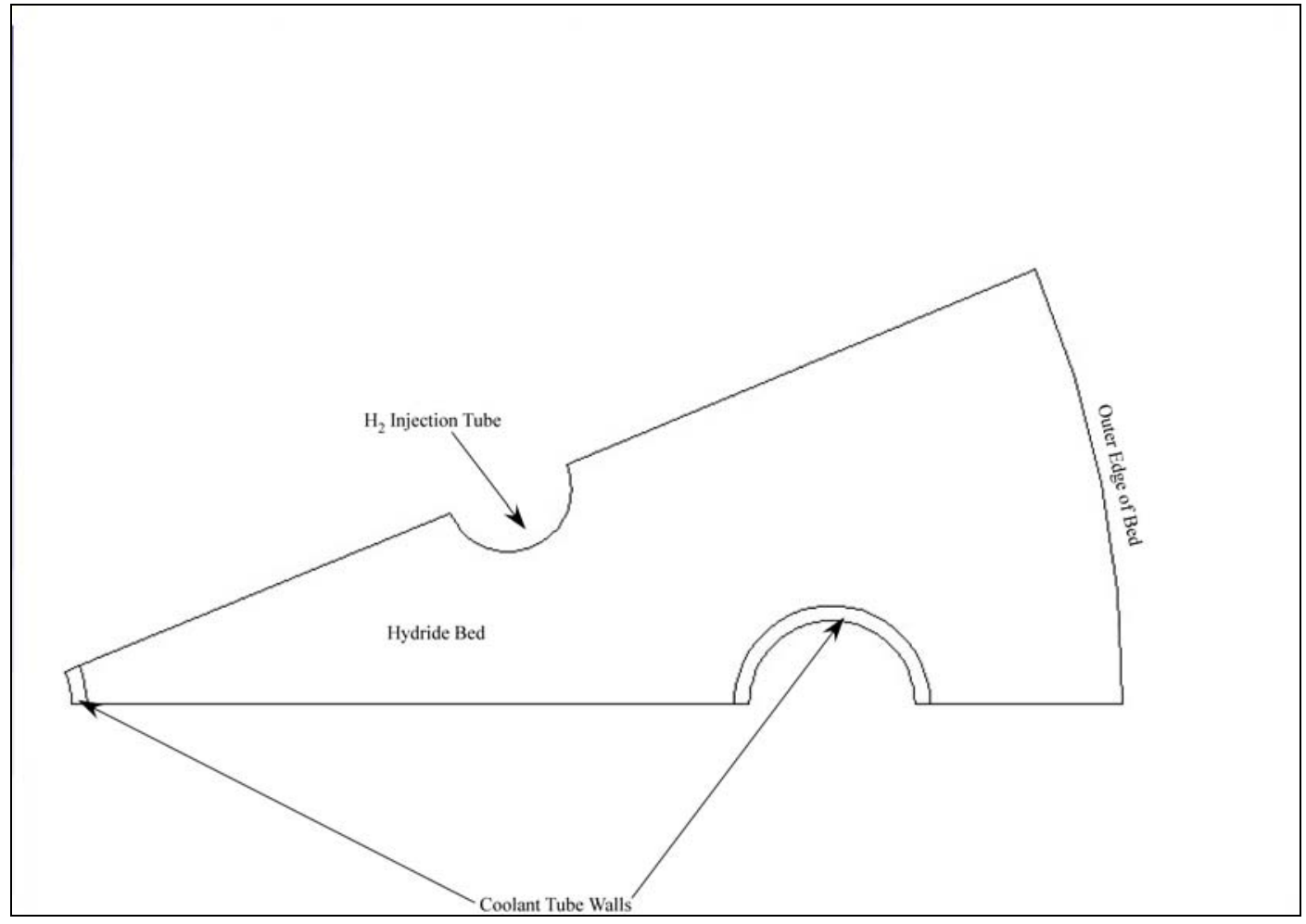

Figure 4.1-3 Geometry used for computations in 2-dimensional COMSOL ${ }^{\circledR}$ model. 
WSRC-TR-2007-00440

Revision 0

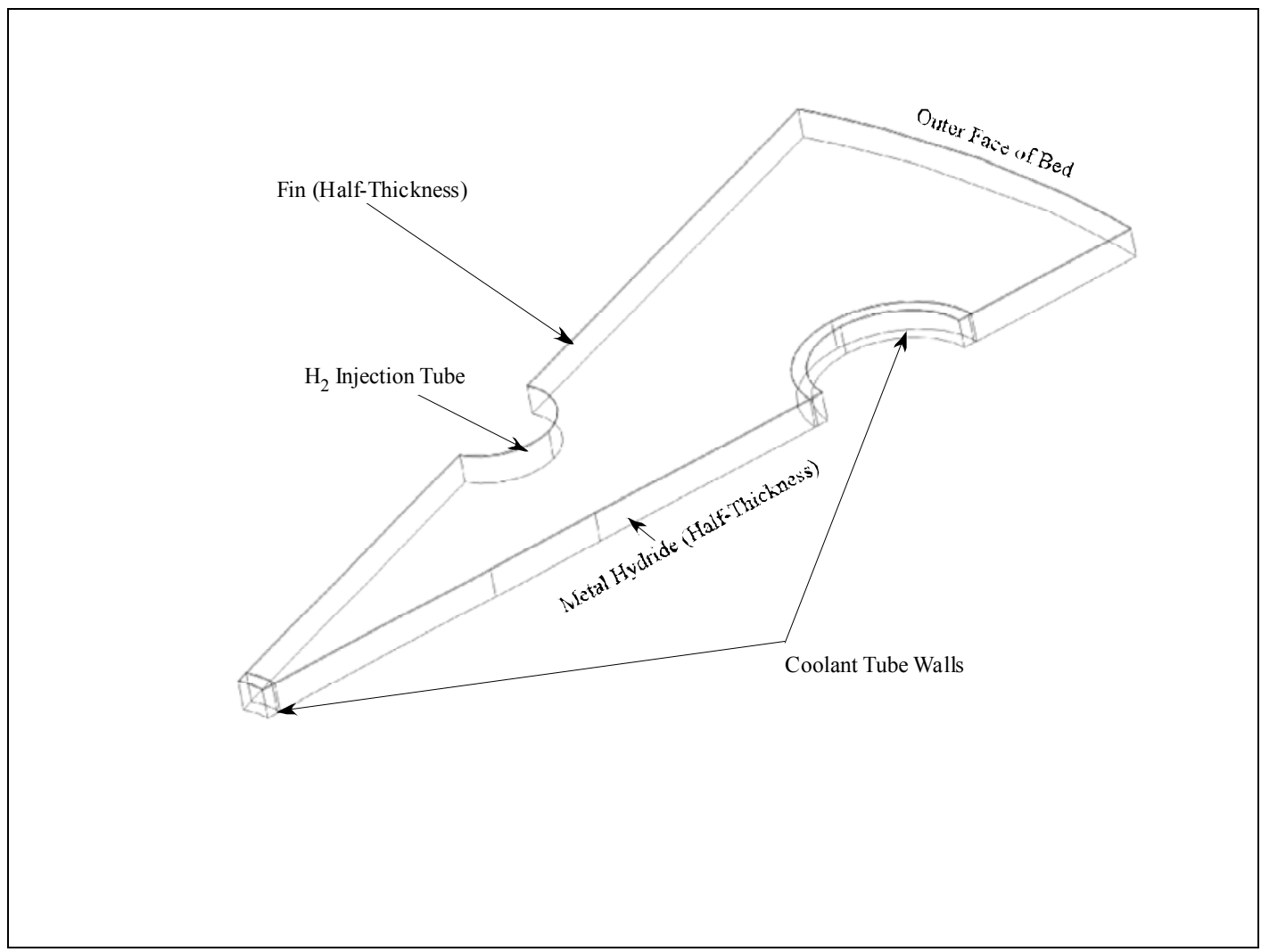

Figure 4.1-4 Geometry used for computations in 3-dimensional COMSOL ${ }^{\circledR}$ model.

\subsection{Model Dimensions}

The dimensions (length scales) of the storage system were calculated with the geometry scoping model described in Hardy [2007]. Input to the scoping model, for application to the finned shell and tube heat exchanger, is listed in Table 4.2-1 and the calculated dimensions are listed in Table 4.2-2. 
WSRC-TR-2007-00440

Revision 0

Table 4.2-1 Input to the Geometry Scoping Model

\begin{tabular}{|c|c|}
\hline Parameter & Value \\
\hline Mass of recoverable $\mathrm{H}_{2}$ to be stored in vessel & $1000.00 \mathrm{~g}$ \\
\hline $\begin{array}{l}\text { Practical ratio of moles } \mathrm{H}_{2} \text { to moles } \mathrm{NaAlH}_{4} \text { that can } \\
\text { be stored in } 12 \text { minutes }\end{array}$ & 1.5 \\
\hline Bulk density of $\mathrm{NaAlH}_{4}$ powder & $0.72 \mathrm{~g} / \mathrm{cm}^{3}$ \\
\hline Hydride bed diameter, no walls & $23.00 \mathrm{~cm}$ \\
\hline Concentration of $\mathrm{NaAlH}_{4}$ & $13,333.33 \mathrm{~mole} / \mathrm{m}^{3}$ \\
\hline Diameter of coolant tubes & $1.91 \mathrm{~cm}$ \\
\hline Diameter of $\mathrm{H}_{2}$ injection tubes & $1.27 \mathrm{~cm}$ \\
\hline Number of coolant tubes & 9 \\
\hline Number of $\mathrm{H}_{2}$ injection tubes & 8 \\
\hline Thickness of fin plates & $0.0313 \mathrm{~cm}$ \\
\hline Approximate spacing between fin plates & $0.64 \mathrm{~cm}$ \\
\hline Tube wall thickness & $0.12 \mathrm{~cm}$ \\
\hline $\begin{array}{l}\text { Density of tube material (6061-T6 Al from table on pg } \\
6-11 \text { of Avallone and Baumeister [1987]) }\end{array}$ & $2.70 \mathrm{~g} / \mathrm{cm}^{3}$ \\
\hline $\begin{array}{l}\text { Density of fin material (6061-T6 Al from table on pg } \\
\text { 6-11 of Avallone and Baumeister [1987]) }\end{array}$ & $2.70 \mathrm{~g} / \mathrm{cm}^{3}$ \\
\hline $\begin{array}{l}\text { Material density of porous insert for } \mathrm{H}_{2} \text { delivery } \\
\text { (6061-T6 Al from table on pg 6-11 of Avallone and } \\
\text { Baumeister [1987]) }\end{array}$ & $2.70 \mathrm{~g} / \mathrm{cm}^{3}$ \\
\hline Void fraction of porous insert for $\mathrm{H}_{2}$ delivery & 0.70 \\
\hline $\begin{array}{l}\text { Density of tank material (Composite @ } \\
0.054191 \mathrm{bm} / \mathrm{in}^{3} \text { ) }\end{array}$ & $1.50 \mathrm{~g} / \mathrm{cm}^{3}$ \\
\hline $\begin{array}{l}\text { Density of liner material (6061-T6 Al from table on } \\
\text { pg 6-11 of Avallone and Baumeister [1987]) }\end{array}$ & $2.70 \mathrm{~g} / \mathrm{cm}^{3}$ \\
\hline Assume $1 / 16$ in gap between bed $\&$ liner & $0.159 \mathrm{~cm}$ \\
\hline Assume $1 / 32$ in thick liner & $0.079 \mathrm{~cm}$ \\
\hline Tank wall thickness at $50 \mathrm{bar} w /$ safety factor & $0.132 \mathrm{~cm}$ \\
\hline
\end{tabular}


WSRC-TR-2007-00440

Revision 0

Table 4.2-2 Bed Dimensions and Characteristics

\begin{tabular}{|c|c|}
\hline Feature & Value \\
\hline Required length of hydride only & $65.62 \mathrm{~cm}$ \\
\hline Total number of fin plates, including end plates & 105 \\
\hline Total length of bed, no vessel & $68.90 \mathrm{~cm}$ \\
\hline Actual spacing of plates & $0.63 \mathrm{~cm}$ \\
\hline Mass of bed; including fins, tubes \& $\mathrm{NaAlH}_{4}$ & $24642.84 \mathrm{~g}$ \\
\hline Volume of bed without vessel \& liner & $36237.36 \mathrm{~cm}^{3}$ \\
\hline Overall length of vessel & $92.64 \mathrm{~cm}^{3}$ \\
\hline Total volume of coolant tubes & $431.70 \mathrm{~cm}^{3}$ \\
\hline $\begin{array}{l}\text { Total volume of plate fins, including part of fin } \\
\text { extruded over the outside of the coolant tubes }\end{array}$ & $1358.11 \mathrm{~cm}^{3}$ \\
\hline Total volume of gap including semi-spherical ends & $6899.97 \mathrm{~cm}^{3}$ \\
\hline Total volume of liner & $266.38 \mathrm{~cm}^{3}$ \\
\hline Total volume of tank material & $445.52 \mathrm{~cm}^{3}$ \\
\hline Total volume of $\mathrm{H}_{2}$ injection tubes & $698.22 \mathrm{~cm}^{3}$ \\
\hline Moles of $\mathrm{H}_{2}$ to be stored in vessel & $496.03 \mathrm{mols}$ \\
\hline Moles of $\mathrm{NaAlH}_{4}$ required for vessel & 330.69 mols \\
\hline Mass of $\mathrm{NaAlH}_{4}$ required for vessel & $17857.28 \mathrm{~g}$ \\
\hline Volume of NaAlH4 required to store hydrogen & $24801.77 \mathrm{~cm}^{3}$ \\
\hline Total area of coolant tube holes & $27.36 \mathrm{~cm}^{2}$ \\
\hline Total area of $\mathrm{H}_{2}$ injection tube holes & $10.13 \mathrm{~cm}^{2}$ \\
\hline With Outer Vessel \& Liner & $0.041 \mathrm{~kg} \mathrm{H}_{2} / \mathrm{Kg}$ Total \\
\hline With Outer Vessel \& Liner & $0.028 \mathrm{~kg} \mathrm{H}_{2} / \mathrm{L}$ Total \\
\hline $\begin{array}{l}\text { Radial location of center of coolant tube. optimized } \\
\text { for hydride area to cooling surface ratio. }\end{array}$ & $8.55 \mathrm{~cm}$ \\
\hline $\begin{array}{l}\text { Angle at center of coolant tube formed by intersection } \\
\text { of tube center radius and tube inner wall }\end{array}$ & 3.04 radians \\
\hline $\begin{array}{l}\text { Arc length along inner wall of coolant tube from } \\
\text { intersections of tube center radius and tube inner wall }\end{array}$ & $2.52 \mathrm{~cm}$ \\
\hline $\begin{array}{l}\text { Cross-sectional area of bed, inside the radius to the } \\
\text { center of the coolant tubes, less interior of coolant } \\
\text { tubes }\end{array}$ & $209.13 \mathrm{~cm}^{2}$ \\
\hline $\begin{array}{l}\text { Cross-sectional area of bed, outside the radius to the } \\
\text { center of the coolant tubes, less interior of coolant } \\
\text { tubes }\end{array}$ & $176.82 \mathrm{~cm}^{2}$ \\
\hline $\begin{array}{l}\text { Sum of arc lengths of inner wall of all coolant tubes } \\
\text { inside the radius to the center of the cooling tubes }\end{array}$ & $25.37 \mathrm{~cm}$ \\
\hline $\begin{array}{l}\text { Sum of arc lengths of inner wall of all coolant tubes } \\
\text { outside the radius to the center of the cooling tubes }\end{array}$ & $21.45 \mathrm{~cm}$ \\
\hline Gravimetric Capacity of the System & $0.041 \mathrm{~kg} \mathrm{H} / \mathrm{kg}$ \\
\hline Volumetric Capacity of the System & $0.028 \mathrm{~kg} \mathrm{H}_{2} / \mathrm{L}$ \\
\hline
\end{tabular}




\subsection{Heat Removal Parameters}

Typical coolant flow velocities, convection heat transfer coefficients, pressure drops over the length of the coolant channels and the change in coolant temperature over the length of the coolant channels were estimated with the system heat removal scoping model described in Hardy [2007]. The hydrogen storage material was $\mathrm{TiCl}_{3}$ catalyzed $\mathrm{NaAlH}_{4}$, which followed the reaction in Equation 4.4.5-1. The dimensions (length scales) of the coolant tubes, mass of $\mathrm{NaAlH}_{4}$, mass of stored $\mathrm{H}_{2}$, number of coolant tubes, etc., were passed directly from the geometry scoping model. The remaining input to the heat removal scoping model is listed in Table 4.3-1 and calculated parameters are listed in Table 4.3-2. The coolant used in the model was Dowtherm $\mathrm{T}^{\circledR}$, see Attachment 1 of Hardy [2007]; the thermal properties of this heat transfer fluid are listed in Table 4.3-1.

\section{Table 4.3-1 Input to Heat Removal Scoping Model}

\begin{tabular}{|c|c|}
\hline Parameter & Value \\
\hline $\begin{array}{l}\Delta \mathrm{H}_{\text {Rxn1 }} \text { (Enthalpy of Reaction 1, see } \\
\text { Eq. 4.4.5-1) Ref. Gross, et. al. [2002] }\end{array}$ & $37.00 \mathrm{~kJ} / \mathrm{mol} \mathrm{H}_{2}$ \\
\hline $\begin{array}{l}\Delta \mathrm{H}_{\text {Rxn2 }} \text { (Enthalpy of Reaction 2, see } \\
\text { Eq. 4.4.5-1) Ref. Gross, et. al. [2002] }\end{array}$ & $47.00 \mathrm{~kJ} / \mathrm{mol} \mathrm{H}_{2}$ \\
\hline Charging Time & $180.00 \mathrm{sec}$ \\
\hline Wall Temperature & $90.00^{\circ} \mathrm{C}$ \\
\hline Coolant Liquid Density & $0.82 \mathrm{~g} / \mathrm{cm}^{3}$ \\
\hline Coolant Liquid Themal Conductivity & $\begin{array}{c}1.04 \mathrm{E}-03 \mathrm{~W} /(\mathrm{cm} \\
\left.{ }^{\circ} \mathrm{C}\right)\end{array}$ \\
\hline Coolant Viscosity & $3.00 \mathrm{E}-02 \mathrm{~g} /(\mathrm{cm} \mathrm{s})$ \\
\hline Coolant Specific Heat & $2.30 \mathrm{~J} /\left(\mathrm{g}{ }^{\circ} \mathrm{C}\right)$ \\
\hline Coolant Prandtl Number & 66.52 \\
\hline
\end{tabular}

Table 4.3-2 Parameters From Heat Removal Scoping Model

\begin{tabular}{|l|c|}
\hline \multicolumn{1}{|c|}{ Parameter } & Value \\
\hline \hline $\begin{array}{l}\Delta \mathrm{H}_{\text {overall }} \text { (Overall Enthalpy of Reaction, } \\
\text { see Eq. 4.4.5-1) }\end{array}$ & $40.33 \mathrm{~kJ} / \mathrm{mol} \mathrm{H}_{2}$ \\
\hline $\begin{array}{l}\text { Total Amount of Heat to be Removed } \\
\text { for Mass of Stored Hydrogen in Table } \\
4.2-1\end{array}$ & $20,006.61 \mathrm{~kJ}$ \\
\hline $\begin{array}{l}\text { Heat Removal Rate Based on Total } \\
\text { Heat to be Removed and the Charging } \\
\text { Time in Table 4.3-1 }\end{array}$ & $111,147.85 \mathrm{~W}$ \\
\hline Wall Heat Flux on Coolant Tube & $3.45 \mathrm{E}+01 \mathrm{~W} / \mathrm{cm}^{2}$ \\
\hline $\begin{array}{l}\text { Convection Heat Transfer Coefficient } \\
\text { by Diitus-Boelter Correlation, Ref } \\
\text { Holman [1976] }\end{array}$ & $0.4922 \mathrm{~W} /\left(\mathrm{cm}^{2}{ }^{\circ} \mathrm{C}\right)$ \\
\hline Coolant Mass Flux, Per Tube & $1030.04 \mathrm{~g} /\left(\mathrm{cm}^{2} \mathrm{~s}\right)$ \\
\hline Coolant Velocity & $1260.73 \mathrm{~cm} / \mathrm{s}$ \\
\hline Re & 56861.02 \\
\hline $\begin{array}{l}\text { Pressure Drop Over Length of Coolant } \\
\text { Tube }\end{array}$ & $1.18 \mathrm{E}+01 \mathrm{psi}$ \\
\hline $\begin{array}{l}\text { Bulk Coolant Temperature Increase } \\
\text { Over Length of Coolant Tube }\end{array}$ & $2.42{ }^{\circ} \mathrm{C}$ \\
\hline
\end{tabular}




\subsection{Governing Equations and Boundary Conditions}

Both the 2 and 3-dimensional models consist of a set of governing equations together with their input parameters and a mesh for the section of the hydride bed. Details of all equations used in the model are discussed in Appendix A.1.

\subsubsection{Hydrogen Mass Balance}

The mass (mole) balance for hydrogen flowing through the bed is given by

$$
\frac{\partial \mathrm{C}_{\mathrm{nd}}}{\partial \mathrm{t}}+\nabla \cdot\left(\mathrm{C}_{\mathrm{nd}} \overrightarrow{\mathrm{v}}\right)=\frac{1}{\mathrm{C}_{\mathrm{ref}}}\left(\frac{\mathrm{S}_{\mathrm{H}_{2}}}{\varepsilon}\right)
$$

where: $\quad \mathrm{S}_{\mathrm{H}_{2}}=$ Rate of $\mathrm{H}_{2}$ generation per volume of bed [mole $\mathrm{H}_{2} /\left(\mathrm{m}^{3}-\mathrm{s}\right)$ ]

$\varepsilon=$ Void fraction (porosity) of particle bed

$\overrightarrow{\mathrm{v}}=$ Mean interstitial $\mathrm{H}_{2}$ velocity $[\mathrm{m} / \mathrm{s}]$

$\mathrm{C}_{\mathrm{nd}}=$ The non-dimensionalized concentration of $\mathrm{H}_{2}=\frac{\mathrm{C}}{\mathrm{C}_{\mathrm{ref}}}$

$\mathrm{C}=$ Concentration of $\mathrm{H}_{2}$ in the void space of the bed $\left[\mathrm{mole} / \mathrm{m}^{3}\right]$.

$\mathrm{C}_{\text {ref }}=$ The reference $\mathrm{H}_{2}$ concentration in the void space, $\mathrm{C}_{\text {ref }}\left[\mathrm{mole} / \mathrm{m}^{3}\right]$

$\nabla=$ Gradient $[1 / \mathrm{m}]$.

For example, in a sodium alanate bed the $\mathrm{H}_{2}$ uptake/discharge reaction occurs via a two-step reaction given by the chemical balance equation

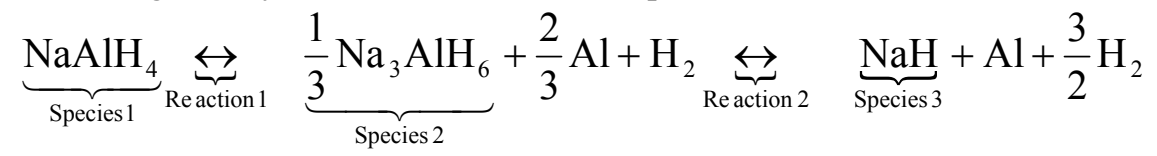

In this case, the source rate for hydrogen is

$\mathrm{S}_{\mathrm{H}_{2}}=\left.\frac{v_{\mathrm{H}_{2}}}{v_{\mathrm{NaH}}}\right|_{\mathrm{Rxn} 2} \frac{\partial \mathrm{C}_{\mathrm{NaH}}}{\partial \mathrm{t}}-\left.\frac{v_{\mathrm{H}_{2}}}{v_{\mathrm{NaAlH}_{4}}}\right|_{\mathrm{Rxn1}} \frac{\partial \mathrm{C}_{\mathrm{NaAlH}_{4}}}{\partial \mathrm{t}}$

where: $\left.\frac{v_{\mathrm{H}_{2}}}{v_{\mathrm{NaH}}}\right|_{\mathrm{Rxn} 2}=$ Ratio of the stoichiometric coefficient of $\mathrm{H}_{2}$ to $\mathrm{NaH}$ in reaction $2=0.5$

$$
\begin{aligned}
\left.\frac{v_{\mathrm{H}_{2}}}{v_{\mathrm{NaAlH}_{4}}}\right|_{\mathrm{Rxn1}} & =\text { Ratio of the stoichiometric coefficient of } \mathrm{H}_{2} \text { to } \mathrm{NaAlH}_{4} \text { in reaction } 1=1 \\
\mathrm{C}_{\mathrm{NaH}} & =\text { The bulk concentration of } \mathrm{NaH}\left[\mathrm{mole} / \mathrm{m}^{3}\right] \\
\mathrm{C}_{\mathrm{NaAlH}_{4}} & =\text { The bulk concentration of } \mathrm{NaAlH} \mathrm{H}_{4}\left[\mathrm{~mole} / \mathrm{m}^{3}\right] .
\end{aligned}
$$

Mass balance boundary conditions applied to the model are:

$\nabla \cdot\left(\mathrm{C}_{\mathrm{nd}} \overrightarrow{\mathrm{V}}\right)=0 \quad$ (on all walls and surfaces of symmetry)

and 
$\mathrm{C}_{\mathrm{nd}}=\frac{\mathrm{P}_{\text {inj }} \mathrm{T}_{\text {ref }}}{\mathrm{P}_{\text {ref }} \mathrm{T}_{\text {wall }}}$ (where the $\mathrm{H}_{2}$ feed tube wall joins the bed)

where: $\quad \mathrm{P}_{\text {inj }}=\mathrm{H}_{2}$ pressure in the feed tube $[\mathrm{Pa}]$

$\mathrm{T}_{\text {ref }}=$ Reference temperature $[\mathrm{K}]$

$\mathrm{P}_{\text {ref }}=$ Reference pressure $[\mathrm{Pa}]$

$\mathrm{T}_{\text {wall }}=$ Feed tube wall temperature $[\mathrm{K}]$.

\subsubsection{Hydrogen Momentum Balance}

The components of velocity, effectively the momentum balance, are obtained from the BlakeKozeny equation, see Bird, Stewart and Lightfoot [1960]. Modifying the Blake-Kozeny equation to give the mean interstitial velocity, rather than the superficial velocity, gives:

$$
\begin{aligned}
& \mathrm{u}=-\frac{\mathrm{D}_{\mathrm{p}}{ }^{2}}{150 \mu}\left(\frac{\varepsilon}{1-\varepsilon}\right)^{2} \frac{\partial \mathrm{P}}{\partial \mathrm{x}} \\
& \mathrm{v}=-\frac{\mathrm{D}_{\mathrm{p}}{ }^{2}}{150 \mu}\left(\frac{\varepsilon}{1-\varepsilon}\right)^{2} \frac{\partial \mathrm{P}}{\partial \mathrm{y}} \\
& \mathrm{w}=-\frac{\mathrm{D}_{\mathrm{p}}{ }^{2}}{150 \mu}\left(\frac{\varepsilon}{1-\varepsilon}\right)^{2} \frac{\partial \mathrm{P}}{\partial \mathrm{z}}
\end{aligned}
$$

where $\quad \mathrm{u}, \mathrm{v}, \mathrm{w}=\mathrm{x}, \mathrm{y}$ and $\mathrm{z}$ components of the mean interstitial velocity, $\overrightarrow{\mathrm{v}}$, respectively

$[\mathrm{m} / \mathrm{s}]$

$$
\begin{aligned}
\mathrm{D}_{\mathrm{p}} & =\text { Mean diameter of particles in bed }[\mathrm{m}] \\
\mu & =\text { Viscosity of } \mathrm{H}_{2}[\mathrm{~Pa}-\mathrm{s}] \\
\mathrm{P} & =\text { Pressure }[\mathrm{Pa}]
\end{aligned}
$$

Divide by $\mathrm{U}_{\text {ref }}$ to non-dimensionalize the components of velocity in Eqs. 4.4.1-1 to get the nondimensionalized velocities

$$
\begin{aligned}
& \mathrm{u}_{\mathrm{nd}}=-\frac{\mathrm{D}_{\mathrm{p}}^{2}}{150 \mu}\left(\frac{\varepsilon}{1-\varepsilon}\right)^{2} \frac{\mathrm{P}_{\mathrm{ref}}}{\mathrm{U}_{\mathrm{ref}}} \frac{\partial \mathrm{P}_{\mathrm{nd}}}{\partial \mathrm{x}} \\
& \mathrm{v}_{\mathrm{nd}}=-\frac{\mathrm{D}_{\mathrm{p}}^{2}}{150 \mu}\left(\frac{\varepsilon}{1-\varepsilon}\right)^{2} \frac{\mathrm{P}_{\mathrm{ref}}}{\mathrm{U}_{\text {ref }}} \frac{\partial \mathrm{P}_{\mathrm{nd}}}{\partial \mathrm{y}} \\
& \mathrm{w}_{\mathrm{nd}}=-\frac{\mathrm{D}_{\mathrm{p}}{ }^{2}}{150 \mu}\left(\frac{\varepsilon}{1-\varepsilon}\right)^{2} \frac{\mathrm{P}_{\mathrm{ref}}}{\mathrm{U}_{\text {ref }}} \frac{\partial \mathrm{P}_{\mathrm{nd}}}{\partial \mathrm{z}}
\end{aligned}
$$

where: $U_{\text {ref }}=$ Reference velocity $[\mathrm{m} / \mathrm{s}]$.

$$
\begin{aligned}
& \mathrm{u}_{\mathrm{nd}}=\frac{\mathrm{u}}{\mathrm{U}_{\mathrm{ref}}}=\text { Non-dimensional x-component of the mean interstitial velocity. } \\
& \mathrm{v}_{\mathrm{nd}}=\frac{\mathrm{v}}{\mathrm{U}_{\mathrm{ref}}}=\text { Non-dimensional y-component of the mean interstitial velocity. }
\end{aligned}
$$




$$
\begin{aligned}
\mathrm{w}_{\mathrm{nd}} & =\frac{\mathrm{W}}{\mathrm{U}_{\text {ref }}}=\text { Non-dimensional z-component of the mean interstitial velocity. } \\
\mathrm{P}_{\mathrm{ref}} & =\text { Reference pressure }[\mathrm{Pa}] \\
\mathrm{P}_{\mathrm{nd}} & =\frac{\mathrm{P}}{\mathrm{P}_{\mathrm{ref}}}=\text { Non-dimensional pressure. }
\end{aligned}
$$

Since the velocities are given explicitly in terms of the pressure gradient, there is no need to apply boundary conditions to the momentum balance.

\subsubsection{Bed Energy Balance}

It is assumed that, at a given location, both the hydrogen contained within the voids of the bed, and the solid material comprising the bed, have the same instantaneous temperature. Thus, in the sense of temperature, the solid and gas phases of the bed are assumed homogeneous. Because hydrogen flows through the bed, it transports thermal energy by convection. The enthalpies of reaction occurring during the uptake and release of hydrogen constitute a heat source that is assumed to be uniformly distributed over the volume occupied by the bed. The bed energy balance treats both the solid and gas phases as a homogeneous region, and is given by

$$
\begin{gathered}
\rho_{\text {bed }} \mathrm{C}_{\mathrm{p} \text { bed }} \frac{\partial \mathrm{T}_{\mathrm{nd}}}{\partial \mathrm{t}}-\nabla \cdot \mathrm{k} \nabla \mathrm{T}_{\mathrm{nd}}=-\varepsilon \rho_{\mathrm{H}_{2}} \mathrm{C}_{\mathrm{p}} \mathrm{H}_{2}\left(\frac{\partial \mathrm{T}_{\mathrm{nd}}}{\partial \mathrm{t}}+\overrightarrow{\mathrm{v}} \cdot \nabla \mathrm{T}_{\mathrm{nd}}\right)+\frac{1}{\mathrm{~T}_{\text {ref }}}\left(\frac{\partial \mathrm{P}}{\partial \mathrm{t}}+\varepsilon \overrightarrow{\mathrm{v}} \cdot \nabla \mathrm{P}\right) \\
+\frac{1}{\mathrm{~T}_{\text {ref }}} \text { Source }
\end{gathered}
$$

where: $\quad$ Source $=$ Heat of reaction $\left[\mathrm{W} / \mathrm{m}^{3}\right]=-\left(\sum_{\mathrm{i}}\left[\frac{1}{\mathrm{M}_{\mathrm{i}}} \frac{\partial \rho_{\mathrm{i}}}{\partial \mathrm{t}} \Delta \mathrm{H}_{\mathrm{i}}\right]\right)$

$$
\begin{aligned}
\mathrm{M}_{\mathrm{i}} & =\text { Molecular weight of species i per mole }[\mathrm{kg} / \mathrm{g} \text {-mole }] \\
\rho_{\mathrm{i}} & =\text { Bulk mass density of species } \mathrm{i}\left[\mathrm{kg} / \mathrm{m}^{3}\right] \\
\mathrm{C}_{\mathrm{p} \mathrm{i}} & =\text { Specific heat of species } \mathrm{i}[\mathrm{J} / \mathrm{kg}] \\
\Delta \mathrm{H}_{\mathrm{i}} & =\text { Enthalpy of reaction on a molar basis of species } \mathrm{i}[\mathrm{J} /(\mathrm{mol} \text { of } \mathrm{i})] \\
\rho_{\text {bed }} \mathrm{C}_{\mathrm{p} \text { bed }} & =\rho_{\text {Solid Reactan ts }} \mathrm{C}_{\mathrm{p} \text { Solid Reac tan ts }}+\rho_{\text {Solid Products }} \mathrm{C}_{\mathrm{p} \text { Solid Products }} \\
\mathrm{T}_{\text {ref }} & =\text { Reference temperature }[\mathrm{K}] \\
\mathrm{T}_{\mathrm{nd}} & =\frac{\mathrm{T}}{\mathrm{T}_{\text {ref }}}=\text { Non-dimensional temperature } \\
\mathrm{k} & =\text { Bed thermal conductivity } \\
\mathrm{P} & =\text { Pressure }[\mathrm{Pa}]
\end{aligned}
$$

The boundary conditions for the energy balance are:

$\hat{\mathrm{n}} \cdot \nabla \cdot\left(\mathrm{k} \nabla \mathrm{T}_{\mathrm{nd}}\right)=0 \quad$ (thermal insulation, on all exterior boundaries and surfaces of symmetry)

$\hat{\mathrm{n}} \cdot \nabla \cdot\left(\mathrm{k} \nabla \mathrm{T}_{\mathrm{nd}}\right)=-\mathrm{h}_{\mathrm{H}_{2} \text { cool }}\left(\frac{\mathrm{T}_{\text {wall }}-\mathrm{T}_{\mathrm{H}_{2} \text { bulk }}}{\mathrm{T}_{\mathrm{Ref}}}\right) \quad$ (on the walls of the $\mathrm{H}_{2}$ feed tubes) 
WSRC-TR-2007-00440

Revision 0

where: $\quad \hat{\mathrm{n}}=$ Outward normal to surface

$\mathrm{h}_{\mathrm{H}_{2} \text { cool }}=$ Convection heat transfer coefficient for $\mathrm{H}_{2}$ in the feed tube $\left[\mathrm{W} / \mathrm{m}^{2}-^{\circ} \mathrm{C}\right]$

$\mathrm{T}_{\text {wall }}=$ Tube wall temperature $[\mathrm{K}]$

$\mathrm{T}_{\mathrm{H}_{2} \text { bulk }}=$ Bulk temperature of the $\mathrm{H}_{2}$ in the feed tube $[\mathrm{K}]$.

\subsubsection{Energy Balance for the Tubes and Fins}

The energy balance within the metal composing the fins and tubes is

$\mathrm{k}_{\text {metal }} \nabla^{2} \mathrm{~T}=\rho_{\text {metal }} \mathrm{C}_{\mathrm{p}_{\text {metal }}} \frac{\partial \mathrm{T}}{\partial \mathrm{t}}$

where: $\quad \mathrm{k}_{\text {metal }}=$ Thermal conductivity of the metal $[\mathrm{W} /(\mathrm{m}-\mathrm{s})]$.

$\rho_{\text {metal }}=$ Density of the metal $\left[\mathrm{kg} / \mathrm{m}^{3}\right]$.

$\mathrm{C}_{\mathrm{p}_{\text {metal }}}=$ Specific heat of the metal $[\mathrm{J} /(\mathrm{kg}-\mathrm{K})]$

The boundary conditions applied to the metal tube and fins are:

$\nabla \cdot\left(\mathrm{k}_{\text {metal } 1} \nabla \mathrm{T}_{\text {metal 1 }}\right)=\nabla \cdot\left(\mathrm{k}_{\text {metal } 2} \nabla \mathrm{T}_{\text {metal 2 }}\right) \quad$ (at the interfaces between the fins and tubes)

$\nabla \cdot\left(\mathrm{k}_{\text {metal }} \nabla \mathrm{T}_{\text {metal }}\right)=\nabla \cdot\left(\mathrm{k}_{\text {bed }} \nabla \mathrm{T}_{\text {bed }}\right) \quad$ (at the interface between the bed and the metal)

$\hat{\mathrm{n}} \cdot \nabla \cdot\left(\mathrm{k}_{\text {metal }} \nabla \mathrm{T}_{\text {metal }}\right)=-\mathrm{h}_{\text {conv cool }}\left(\mathrm{T}_{\text {wall }}-\mathrm{T}_{\text {coolant bulk }}\right) \quad$ (on the walls of the cooling tubes)

where: $\quad \hat{\mathrm{n}}=$ Outward normal to surface

$\mathrm{h}_{\text {conv cool }}=$ Convection heat transfer coefficient for heat transfer

fluid $\left[\mathrm{W} / \mathrm{m}^{2}-{ }^{\circ} \mathrm{C}\right]$

$\mathrm{T}_{\text {wall }}=$ Tube wall temperature $[\mathrm{K}]$

$\mathrm{T}_{\text {coolant bulk }}=$ Bulk temperature of the heat transfer fluid $[\mathrm{K}]$

\subsubsection{Reaction Kinetics}

Chemical kinetics depend on the material used as a storage media. Thus, to permit the kinetics equations to be easily modified, they are cast as a separate module within the set of governing equations defined in COMSOL Multiphysics ${ }^{\circledR}$. At present, the model can accept kinetics models in the form of differential-algebraic equations or as tabulated data (which can be fit using a cubic spline).

The particular storage system examined in this report consisted of a bed that was converted from $\mathrm{NaH}$ to sodium aluminum hydride, $\mathrm{NaAlH}_{4}$, as given by Equation 4.4.5-1, when loaded with hydrogen. Specifically, the hydride used in the bed is $\mathrm{TiCl}_{3}$ catalyzed $\mathrm{NaAlH}_{4}$. As discussed in Appendx A.2, the United Technologies Research Center ${ }^{\mathrm{TM}}$ (UTRC) developed an empirical kinetics model for this material.

$\underbrace{\mathrm{NaAlH}_{4}}_{\text {Species1 }} \underbrace{\leftrightarrow}_{\text {Reaction1 }} \underbrace{\frac{1}{3} \mathrm{Na}_{3} \mathrm{AlH}_{6}}_{\text {Species2 }}+\frac{2}{3} \mathrm{Al}+\mathrm{H}_{2} \underbrace{\leftrightarrow}_{\text {Reaction } 2} \underbrace{\mathrm{NaH}}_{\text {Species3 }}+\mathrm{Al}+\frac{3}{2} \mathrm{H}_{2}$ 
Forward and reverse reaction rates for each reaction were fit to data using the following expressions:

$$
\begin{aligned}
& r_{1 F} \equiv C_{\text {eqv }} A_{1 F} \exp \left[-\frac{E_{1 F}}{R T}\right]\left[\frac{P(C, T)-P_{\text {eq } 1}(T)}{P_{\text {eq } 1}(T)}\right] \\
& r_{1 B} \equiv-C_{\text {eqv }} A_{1 B} \exp \left[-\frac{E_{1 B}}{R T}\right]\left[\frac{P_{\text {eq } 1}(T)-P(C, T)}{P_{\text {eq } 1}(T)}\right] \\
& r_{2 F} \equiv-C_{\text {eqv }} A_{2 F} \exp \left[-\frac{E_{2 F}}{R T}\right]\left[\frac{P(C, T)-P_{\text {eq } 2}(T)}{P_{\text {eq } 2}(T)}\right] \\
& r_{2 B} \equiv C_{\text {eqv }} A_{2 B} \exp \left[-\frac{E_{2 B}}{R T}\right]\left[\frac{P_{\text {eq2 }}(T)-P(C, T)}{P_{\text {eq } 2}(T)}\right]
\end{aligned}
$$

where: $\quad \mathrm{C}=$ Concentration of $\mathrm{H}_{2}$ [mole $\mathrm{H}_{2} / \mathrm{m}^{3}$ of interparticle void]

$$
\mathrm{C}_{\text {eqv }}=\text { Equivalent concentration of } \mathrm{NaAlH}_{4}\left[\mathrm{~mole} / \mathrm{m}^{3}\right] \text { based on the initial }
$$
concentrations of all metal species (concentration of bed fully converted to tetrahydride form)

$$
=\mathrm{C}_{10}+3 \mathrm{C}_{20}+\mathrm{C}_{30}
$$

$\mathrm{C}_{10}=$ Initial concentration of $\mathrm{NaAlH}_{4}\left[\mathrm{~mole} / \mathrm{m}^{3}\right]$

$\mathrm{C}_{20}=$ Initial concentration of $\mathrm{Na}_{3} \mathrm{AlH}_{6}\left[\mathrm{~mole} / \mathrm{m}^{3}\right]$

$\mathrm{C}_{30}=$ Initial concentration of $\mathrm{NaH}\left[\mathrm{mole} / \mathrm{m}^{3}\right]$.

$\mathrm{P}_{\text {eq1 }}(\mathrm{T})$ and $\mathrm{P}_{\text {eq2 }}(\mathrm{T})$ are the $\mathrm{H}_{2}$ pressures, in $\mathrm{Pa}$, in equilibrium with the $\mathrm{NaAlH}_{4}$ and the $\mathrm{Na}_{3} \mathrm{AlH}_{6}$ metal hydrides, respectively, at temperature $\mathrm{T}$, in $[\mathrm{K}]$. These relations are given by the van't Hoff equations:

$$
\begin{aligned}
& \mathrm{P}_{\text {eq1 }}(\mathrm{T})=10^{5} \exp \left[\frac{\Delta \mathrm{H}_{4}}{\mathrm{RT}}-\frac{\Delta \mathrm{S}_{4}}{\mathrm{R}}\right] \\
& \mathrm{P}_{\text {eq2 }}(\mathrm{T})=10^{5} \exp \left[\frac{\Delta \mathrm{H}_{2}}{\mathrm{RT}}-\frac{\Delta \mathrm{S}_{2}}{\mathrm{R}}\right]
\end{aligned}
$$

The reference for this model, contained in Appendix A.2, proposes the kinetics equations

$$
\frac{\mathrm{dC}_{1}}{\mathrm{dt}}= \begin{cases}\mathrm{r}_{1 \mathrm{~F}}\left[\frac{3 \mathrm{C}_{2}(\mathrm{t})}{\mathrm{C}_{\text {eqv }}}-\mathrm{C}_{2 \mathrm{sat}}(\mathrm{T})\right]^{\chi_{1 \mathrm{~F}}} & \text { if } \mathrm{P} \geq \mathrm{P}_{\text {eq1 }}(\mathrm{T}) \\ \mathrm{r}_{1 \mathrm{~B}}\left[\frac{\mathrm{C}_{1}(\mathrm{t})}{\mathrm{C}_{\text {eqv }}}\right]^{\chi_{1 \mathrm{~B}}} & \text { if } \mathrm{P}<\mathrm{P}_{\text {eq1 }}(\mathrm{T}) \text { and } \mathrm{C}_{1}(\mathrm{t}) \geq 0\end{cases}
$$

and 


$$
\frac{\mathrm{dC}_{3}}{\mathrm{dt}}= \begin{cases}\mathrm{r}_{2 \mathrm{~F}}\left[\frac{\mathrm{C}_{3}(\mathrm{t})}{\mathrm{C}_{\text {eqv }}}-\mathrm{C}_{3 \mathrm{sat}}(\mathrm{T})\right]^{\chi_{2 \mathrm{~F}}} & \text { if } \mathrm{P} \geq \mathrm{P}_{\mathrm{eq} 2}(\mathrm{~T}) \\ \mathrm{r}_{2 \mathrm{~B}}\left[\frac{3 \mathrm{C}_{2}(\mathrm{t})}{\mathrm{C}_{\text {eqv }}}\right]^{\chi_{2 \mathrm{~B}}} & \text { if } \mathrm{P}<\mathrm{P}_{\mathrm{eq} 2}(\mathrm{~T}) \text { and } \mathrm{C}_{2}(\mathrm{t}) \geq 0\end{cases}
$$

By Eq. 4.4.5-1

$\frac{\mathrm{dC}_{2}}{\mathrm{dt}}=-\frac{1}{3}\left(\frac{\mathrm{dC}_{1}}{\mathrm{dt}}+\frac{\mathrm{dC}_{3}}{\mathrm{dt}}\right)$ or $\mathrm{C}_{2}=\mathrm{C}_{20}-\frac{1}{3}\left[\left(\mathrm{C}_{1}-\mathrm{C}_{10}\right)+\left(\mathrm{C}_{3}-\mathrm{C}_{30}\right)\right]$

where: $\quad \mathrm{C}_{1}=$ Concentration of $\mathrm{NaAlH}_{4}\left[\mathrm{~mole} / \mathrm{m}^{3}\right]$

$\mathrm{C}_{2}=$ Concentration of $\mathrm{Na}_{3} \mathrm{AlH}_{6}\left[\mathrm{~mole} / \mathrm{m}^{3}\right]$

$\mathrm{C}_{3}=$ Concentration of $\mathrm{NaH}\left[\mathrm{mole} / \mathrm{m}^{3}\right]$

$\mathrm{C}_{2 \text { sat }}(\mathrm{T})$ and $\mathrm{C}_{3 \text { sat }}(\mathrm{T})$, in $\left[\mathrm{mole} / \mathrm{m}^{3}\right]$, were estimated by UTRC in Appendix A.2 as

$\mathrm{C}_{2 \text { sat }}(\mathrm{T})=0$

$\mathrm{C}_{3 \text { sat }}(\mathrm{T})=\mathrm{r}_{\text {sat }}\left(1-\frac{\mathrm{wf}_{\text {iso }}^{\mathrm{sat}}(\mathrm{T})}{0.056}\right)$

where: $\quad r_{\text {sat }}=\operatorname{Max}\left[1,\left(1-\frac{0.0373}{0.056-\mathrm{wf}_{\text {iso }}^{\text {sat }}(\mathrm{T})}\right)\right]$

The values for $\mathrm{wf}_{\text {iso }}^{\text {sat }}(\mathrm{T})$, the saturation hydrogen weight fraction for loading at a fixed temperature T, are listed in Table 4.4.5-1. The $\mathrm{COMSOL}^{\circledR}$ fits this data via a cubic spline, with extrapolated values fixed at the endpoints.

\section{Table 4.4.5-1}

Values for $\mathrm{wf}_{\text {iso }}^{\text {sat }}(\mathrm{T})$

\begin{tabular}{|c|c|}
\hline $\mathbf{T}(\mathbf{K})$ & $\mathrm{wf}_{\text {iso }}^{\text {sat }}(\mathrm{T})$ \\
\hline \hline 353.15 & 0.021 \\
\hline 363.15 & 0.023 \\
\hline 373.15 & 0.029 \\
\hline 393.15 & 0.022 \\
\hline 413.15 & 0.018 \\
\hline
\end{tabular}


The weight fraction of $\mathrm{H}_{2}$ contained in the sodium alanate metal, based on Eq. 4.4.5-1, is defined as

$$
\begin{aligned}
\text { wf } & =\frac{\text { Mass of } \mathrm{H}_{2} \text { contained in the metal hydride at time } \mathrm{t}\left(\mathrm{kg} \mathrm{H}_{2}\right)}{\text { Mass of the bed fully converted to tetrahydride form }(\mathrm{kg} \mathrm{NaAlH})} \\
& =\frac{1.5 \mathrm{C}_{1}+0.5 \mathrm{C}_{2}}{\mathrm{C}_{\text {eqv }}} \frac{\mathrm{M}_{\mathrm{H}_{2}}}{\mathrm{M}_{\mathrm{NaAlH}_{4}}}
\end{aligned}
$$

where: $\quad \mathrm{M}_{\mathrm{Na}_{3} \mathrm{AlH}_{6}}=$ Gram molecular weight of $\mathrm{Na}_{3} \mathrm{AlH}_{6}[\mathrm{~kg} / \mathrm{g}$-mole $]$

$\mathrm{M}_{\mathrm{H}_{2}}=$ Gram molecular weight of $\mathrm{H}_{2}[\mathrm{~kg} / \mathrm{g}$-mole $]$.

For sodium alanate, the reaction heat term for the energy balance, Eq. 4.4.3-1 is

Source $=\frac{\mathrm{dC}_{1}}{\mathrm{dt}} \Delta \mathrm{H}_{\mathrm{rxn} 1}-0.5 \frac{\mathrm{dC}_{3}}{\mathrm{dt}} \Delta \mathrm{H}_{\mathrm{rxn} 2}$

where by Gross [2003]:

$$
\begin{aligned}
\Delta \mathrm{H}_{\mathrm{rxn} 1} & =\text { Heat of per mole of } \mathrm{H}_{2} \text { consumed going to left for reaction } 1 \\
& =-37 \mathrm{~kJ} /\left(\text { mole } \mathrm{H}_{2}\right) \\
\Delta \mathrm{H}_{\mathrm{rxn} 2} & =\text { Heat of per mole of } \mathrm{H}_{2} \text { consumed going to left for reaction } 2 \\
& =-47 \mathrm{~kJ} /\left(\text { mole } \mathrm{H}_{2}\right)
\end{aligned}
$$

\subsubsection{Equation of State}

Over the range of operating temperatures and pressures for the storage system, hydrogen behaves as an ideal gas. Hence, the ideal gas law, in the form of Eq. 4.4.6-1, constitutes the equation of state for the gas phase.

$$
\mathrm{P}=\mathrm{C}_{\mathrm{H}_{2}} \mathrm{RT}
$$

where: $\mathrm{C}_{\mathrm{H}_{2}}=$ Concentration of $\mathrm{H}_{2}$ gas $\left(\mathrm{mole} / \mathrm{m}^{3}\right)$.

$$
\mathrm{R}=\text { Gas constant }
$$

\subsection{Model Input Parameters}

Table 4.4-1 contains the constant values or expressions used in the COMSOL ${ }^{\circledR}$ model for the $\mathrm{NaAlH}_{4}$ bed. Global expressions used by $\mathrm{COMSOL}^{\circledR}$ are listed in Table 4.4-2. Finally, subdomain expressions, applied only to the metal hydride bed, are listed in Table 4.4-3 
WSRC-TR-2007-00440

Revision 0

Table 4.4-1 Values of Constants Used in the $\mathrm{NaAlH}_{4}$ Model

\begin{tabular}{|c|c|c|}
\hline Description of Parameter & Expression or Value & $\begin{array}{l}\text { Variable Notation } \\
\text { Used in COMSOL }^{\circledR}\end{array}$ \\
\hline Reference Pressure [Pa], Atmospheric Pressure & 101325 & Pref \\
\hline Reference Speed $[\mathrm{m} / \mathrm{s}]$ & 0.1 & Uref \\
\hline Reference Length $[\mathrm{m}] \sim$ Bed Radius & 0.1 & Lref \\
\hline Reference Concentration $\left[\mathrm{mol} / \mathrm{m}^{3}\right]$ & Pref/(R*Tref) & Cref \\
\hline Reference Temperature $[\mathrm{K}]$ & 300 & Tref \\
\hline Reference $\mathrm{H}_{2}$ Density $\left[\mathrm{kg} / \mathrm{m}^{3}\right]$ & M_H2*Cref & rho_ref \\
\hline Initial $\mathrm{H}_{2}$ Concentration $\left[\mathrm{mol} / \mathrm{m}^{3}\right]$ & $\mathrm{P} 0 /(\mathrm{R} * \mathrm{~T} 0)$ & $\mathrm{C} 0$ \\
\hline Bed Particle Diameter [m] & $3 \mathrm{E}-7$ & $\mathrm{Dp}$ \\
\hline Bed Void Fraction & 0.5 & epsilon \\
\hline g-molecular weight of $\mathrm{NaAlH}_{4}[\mathrm{~kg} / \mathrm{mol}]$ & $54 / 1000$ & M_NaAlH4 \\
\hline g-molecular weight of $\mathrm{H}_{2}[\mathrm{~kg} / \mathrm{mol}]$ & $2.016 / 1000$ & M_H2 \\
\hline Gas Constant [J/mol-K] & 8.314 & $\mathrm{R}$ \\
\hline Initial Pressure $[\mathrm{Pa}]$ & 101325 & $\mathrm{P} 0$ \\
\hline Initial Bed Temperature [K] & 373 & T0 \\
\hline Temperature of Injected $\mathrm{H}_{2}[\mathrm{~K}]$ & 373 & Tinj \\
\hline Velocity of Injected $\mathrm{H}_{2}$ in Feed Tube $[\mathrm{m} / \mathrm{s}]$ & 14 & Vinj \\
\hline Inner Diameter of $\mathrm{H}_{2}$ Injection Tube [m] & 0.0127 & Dinj \\
\hline Concentration for Exit Pressure [Pa] & $\mathrm{C} 0$ & Cout \\
\hline Coolant Density $\left[\mathrm{kg} / \mathrm{m}^{3}\right]$; For DowTherm $\mathrm{T}^{\mathbb{R}}$ & 820.0 & rho_cool \\
\hline $\begin{array}{l}\text { Coolant Thermal Conductivity }\left[\mathrm{W} / \mathrm{m}^{\circ} \mathrm{C}\right] \text {; For } \\
\text { DowTherm T }\end{array}$ & 0.325 & k_cool \\
\hline $\begin{array}{l}\text { Coolant Specific Heat }[\mathrm{J} / \mathrm{kg} \mathrm{K}] \text {; For } \\
\text { DowTherm } \mathrm{T}^{\circledR}\end{array}$ & 820.0 & Cp_cool \\
\hline Coolant Viscosity [Pa-s]; For DowTherm $\mathrm{T}^{\mathbb{B}}$ & $3.0 \mathrm{e}-3$ & mu_cool \\
\hline Coolant Tube Diameter $[\mathrm{m}]$ & 0.0168 & D_cool \\
\hline Coolant Velocity $[\mathrm{m} / \mathrm{s}]$ & 13.0 & Vcool \\
\hline Coolant Temperature $[\mathrm{K}]$ & 373 & T_cool \\
\hline $\begin{array}{l}\text { Fin-Tube Contact Conductance }\left[\mathrm{W} / \mathrm{m}^{2}{ }^{\circ} \mathrm{C}\right] \\
\text { From Holman }[1976]\end{array}$ & $5.56 \mathrm{e}-4$ & h_contact_tube \\
\hline $\begin{array}{l}\text { Bed-Tube Contact Conductance }\left[\mathrm{W} / \mathrm{m}^{2}{ }^{\circ} \mathrm{C}\right] \\
\text { Estimated }\end{array}$ & $1 e-6$ & h_contact_bed \\
\hline $\begin{array}{l}\text { Bulk Density of Hydride Bed }\left[\mathrm{kg} / \mathrm{m}^{3}\right], \text { Mosher, } \\
\text { et. el. [2007] }\end{array}$ & 720.0 & rho_bed \\
\hline $\begin{array}{l}\text { Thermal Cond of Hydride Bed [W/m K]; used } \\
\text { sand from Avallone and Baumeister [1987], } \\
\text { Table 4.4.4 }\end{array}$ & 0.325 & k_bed \\
\hline $\begin{array}{l}\text { Specific Heat of Hydride Bed [J/kg K]; for sand } \\
\text { from Avallone and Baumeister [1987], Table } \\
4.2 .25\end{array}$ & 820.0 & Cp_bed \\
\hline $\begin{array}{l}\text { Density of } 6063-\mathrm{T} 83 \text { Aluminum } \\
\text { (Tubes \& Fins) }\left[\mathrm{kg} / \mathrm{m}^{3}\right] \text {; from Avallone and } \\
\text { Baumeister [1987], and } \mathrm{COMSOL}^{\circledR} \text { material } \\
\text { data }\end{array}$ & 2700 & \\
\hline $\begin{array}{l}\text { Thermal conductivity of } \\
6063-\mathrm{T} 83 \text { Aluminum (Tubes \& Fins) } \\
{[\mathrm{W} /(\mathrm{m}-\mathrm{K})] \text {; from COMSOL }{ }^{\circledR} \text { material data }}\end{array}$ & 201 & \\
\hline $\begin{array}{l}\text { Heat capacity of } \\
6063-\mathrm{T} 83 \text { Aluminum }(\text { Tubes \& Fins })[\mathrm{J} /(\mathrm{kg}- \\
\mathrm{K})] \text {; from COMSOL }{ }^{\mathbb{}} \text { material data }\end{array}$ & 900 & \\
\hline Test Source $\left[\mathrm{W} / \mathrm{m}^{3}\right]$ & $4.48 \mathrm{e} 6$ & S0 \\
\hline
\end{tabular}


WSRC-TR-2007-00440

Revision 0

Table 4.4-1 Values of Constants Used in the $\mathrm{NaAlH}_{4}$ Model (Continued)

\begin{tabular}{|c|c|c|}
\hline Description of Parameter & Expression or Value & $\begin{array}{l}\text { Variable Notation } \\
\text { Used in COMSOL }\end{array}$ \\
\hline $\begin{array}{l}\text { Time [s] to Reach } 90 \% \text { of Full Heat Source } \\
\text { Strength (S0) }\end{array}$ & 60 & tau \\
\hline $\begin{array}{l}\text { Constant in Time-Dependent Heat Source } \\
\text { Expression, Source }\end{array}$ & $-\log (0.1) / \operatorname{tau}$ & $\mathrm{a}$ \\
\hline Forward Rate Constant for Reaction 1 & $1 \mathrm{e} 8$ & A1F \\
\hline $\begin{array}{l}\text { Forward Activation Energy for Reaction } 1 \\
{[\mathrm{~kJ} / \mathrm{mol}]}\end{array}$ & 80 & E1F \\
\hline Backward Rate Constant for Reaction 1 & $4 \mathrm{e} 12$ & A1B \\
\hline $\begin{array}{l}\text { Backward Activation Energy for Reaction } 1 \\
{[\mathrm{~kJ} / \mathrm{mol}]}\end{array}$ & 110 & E1B \\
\hline Exponent for Reaction 1 & 2 & Chil \\
\hline Forward Rate Constant for Reaction 2 & $1.5 \mathrm{e} 5$ & $\mathrm{~A} 2 \mathrm{~F}$ \\
\hline $\begin{array}{l}\text { Forward Activation Energy for Reaction } 2 \\
{[\mathrm{~kJ} / \mathrm{mol}]}\end{array}$ & 70 & E2F \\
\hline Backward Rate Constant for Reaction 2 & $6 \mathrm{e} 12$ & A2B \\
\hline $\begin{array}{l}\text { Backward Activation Energy for Reaction } 2 \\
{[\mathrm{~kJ} / \mathrm{mol}]}\end{array}$ & 110 & E2B \\
\hline Exponent for Reaction 2 & 1 & Chi2 \\
\hline$(\Delta$ Enthalpy for Reaction 1$) / R$ & -4475 & DHR1 \\
\hline$(\Delta$ Entropy for Reaction 1$) / R$ & -14.83 & DSR1 \\
\hline$(\Delta$ Enthalpy for Reaction 2$) / \mathrm{R}$ & -6150 & DHR2 \\
\hline$(\Delta$ Entropy for Reaction 2$) / \mathrm{R}$ & -16.22 & DSR2 \\
\hline Heat of Reaction for Reaction $1\left[\mathrm{~J} / \mathrm{mol} \mathrm{H}_{2}\right]$ & 37000 & DH_rx1 \\
\hline Heat of Reaction for Reaction $2\left[\mathrm{~J} / \mathrm{mol} \mathrm{H}_{2}\right]$ & 47000 & DH_rx2 \\
\hline Initial Concentration of $\mathrm{NaAlH}_{4}\left[\mathrm{~mol} / \mathrm{m}^{3}\right]$ & 0 & $\mathrm{C} 10$ \\
\hline Initial Concentration of $\mathrm{Na}_{3} \mathrm{AlH}_{6}\left[\mathrm{~mol} / \mathrm{m}^{3}\right]$ & 0 & $\mathrm{C} 20$ \\
\hline Initial Concentration of $\mathrm{NaH}\left[\mathrm{mol} / \mathrm{m}^{3}\right]$ & $13,333.33$ & $\mathrm{C} 30$ \\
\hline
\end{tabular}


WSRC-TR-2007-00440

Revision 0

Table 4.4-2 Global Expressions Used in the $\mathrm{NaAlH}_{4}$ Model

\begin{tabular}{|c|c|c|}
\hline Description of Expression & Expression & $\begin{array}{c}\text { Expression Identifier } \\
\text { Used in COMSOL }^{\circledR}\end{array}$ \\
\hline $\begin{array}{l}\mathrm{H}_{2} \text { Viscosity [Pa-s]; } \\
{[\mathrm{TK}]=\mathrm{K} ; \text { Lide and Kehiaian }} \\
{[1994]}\end{array}$ & $\begin{array}{l}5.1899 * 10^{\wedge}-8^{*} \mathrm{TK}-1.23594 * 10^{\wedge}-10^{*} \mathrm{TK}^{\wedge} 2+2.06597 * 10^{\wedge}-13^{*} \mathrm{TK}^{\wedge} 3 \\
-1.30208^{*} 10^{\wedge}-16^{*} \mathrm{TK}^{\wedge} 4\end{array}$ & mu_H2 \\
\hline \multirow[t]{2}{*}{ Density of $\mathrm{H}_{2}\left[\mathrm{~kg} / \mathrm{m}^{3}\right]$} & C*M_H2 & rho_H2 \\
\hline & rho_H2/rho_ref & rho_H2_nd \\
\hline $\begin{array}{l}\text { Thermal Cond for } \mathrm{H}_{2} \\
{[\mathrm{~W} / \mathrm{m} \mathrm{K}] ;[\mathrm{TK}]=\mathrm{K} \text {; Lide }} \\
\text { and Kehiaian }[1994]\end{array}$ & $\begin{array}{l}\left(0.7042^{*} \mathrm{TK}-1.470^{*} 10^{\wedge}-4 * \mathrm{TK}^{\wedge} 2-3.652^{*} 10^{\wedge}-7 * \mathrm{TK}{ }^{\wedge} 3\right. \\
\left.-1.738^{*} 10^{\wedge}-10^{*} \mathrm{TK} \wedge 4\right) / 1000\end{array}$ & k_H2 \\
\hline $\begin{array}{l}\text { Specific Heat for } \mathrm{H}_{2} \\
{[\mathrm{~J} / \mathrm{kg} \mathrm{K}] ;[\mathrm{TK}]=\mathrm{K} ; \text { Lide and }} \\
\text { Kehiaian }[1994]\end{array}$ & $\begin{array}{l}5.1899 * 10^{\wedge}-8^{*} \mathrm{TK}-1.23594 * 10^{\wedge}-10^{*} \mathrm{TK}^{\wedge} 2+2.06597 * 10^{\wedge}-13^{*} \mathrm{TK}^{\wedge} 3 \\
-1.30208^{*} 10^{\wedge}-16^{*} \mathrm{TK}^{\wedge} 4\end{array}$ & $\mathrm{Cp} \_\mathrm{H} 2$ \\
\hline $\begin{array}{l}\text { Time Dependent Pressure } \\
\text { in } \mathrm{H}_{2} \text { Feed Tubes }[\mathrm{Pa}]\end{array}$ & $49 * \mathrm{P} 0 *(1-\exp (-.456 * \mathrm{t}))+\mathrm{P} 0$ & Pinj \\
\hline $\begin{array}{l}\text { Mass Flux of Injected } \mathrm{H}_{2} \\
{\left[\mathrm{~kg} / \mathrm{m}^{2} \mathrm{~s}\right]}\end{array}$ & $\left(\mathrm{Cinj} * \mathrm{M} \_\mathrm{H} 2\right)^{*}$ Vinj & G_H2_inj \\
\hline $\begin{array}{l}\text { Mass Flux of Coolant } \\
{\left[\mathrm{kg} / \mathrm{m}^{2} \mathrm{~s}\right]}\end{array}$ & rho_cool*Vcool & G_cool \\
\hline Prandtl No for Injected $\mathrm{H}_{2}$ & visc_H2(Tinj)*spec_heat_H2(Tinj)/therm_cond_H2(Tinj) & Pr_H2 \\
\hline $\begin{array}{l}\text { Prandtl No for Coolant, } \\
\text { DowTherm T }^{\circledR}\end{array}$ & mu_cool*Cp_cool/k_cool & Pr_cool \\
\hline $\begin{array}{l}\text { Convection Heat transfer } \\
\text { Coefficient for Injected } \mathrm{H}_{2} \\
{\left[\mathrm{~W} / \mathrm{m}^{2} \mathrm{~K}\right] \text {; Holman }[1976]}\end{array}$ & $\begin{array}{l}\left.0.023 * \text { therm_cond_H2(Tinj)/Dinj } *\left(G_{-} H 2 \text { inj } * \text { Dinj } / \text { visc_H2(Tinj) }\right)\right)^{\wedge} 0.8 \\
* \text { Pr_H } 2 \wedge 0.4\end{array}$ & h_conv_H2 \\
\hline $\begin{array}{l}\text { Convection Heat Transfer } \\
\text { Coefficient for Coolant } \\
{\left[\mathrm{W} / \mathrm{m}^{2} \mathrm{~K}\right] \text {; Holman }[1976]}\end{array}$ & $0.023 * \mathrm{k}$ _cool $/ \mathrm{D}$ _cool ${ }^{*}\left(\mathrm{G} \text { _cool }{ }^{*} \mathrm{D} \text { _cool } / \mathrm{mu} \text { _cool }\right)^{\wedge} 0.8^{*} \mathrm{Pr}$-cool${ }^{\wedge} 0.4$ & h_conv_cool \\
\hline $\begin{array}{l}\text { Temperature }[\mathrm{K}] \text { for use in } \\
\text { Functions }\end{array}$ & T_nd*Tref & TK \\
\hline Temperature $[\mathrm{K}]$ & TK & $\mathrm{T}$ \\
\hline
\end{tabular}


WSRC-TR-2007-00440

Revision 0

Table 4.4-3 Subdomain Expressions Used in the $\mathrm{NaAlH}_{4}$ Model

\begin{tabular}{|c|c|c|}
\hline $\begin{array}{c}\text { Description of } \\
\text { Expression }\end{array}$ & Expression & $\begin{array}{c}\text { Expression Identifier } \\
\text { Used in COMSOL }^{\circledR} \\
\end{array}$ \\
\hline Pressure $[\mathrm{Pa}]$ & $\mathrm{C} * \mathrm{R} * \mathrm{TK}$ & $\mathrm{P}$ \\
\hline $\begin{array}{l}\text { Non-Dimensionalized x- } \\
\text { Component of Velocity }\end{array}$ & -Dp^2*Pref*(epsilon/(1-epsilon) $))^{\wedge} 2 * \operatorname{diff}\left(\mathrm{P} \_\right.$nd, $\left.\mathrm{x}\right) /\left(150 * \mathrm{mu} \_\mathrm{H} 2 *\right.$ Uref $)$ & u_nd \\
\hline $\begin{array}{l}\text { Non-Dimensionalized y- } \\
\text { Component of Velocity }\end{array}$ & -Dp^2*Pref*(epsilon/(1-epsilon) $))^{\wedge} 2 * \operatorname{diff}\left(\mathrm{P} \_\right.$nd,y $) /\left(150 * m u \_H 2 * U r e f\right)$ & v_nd \\
\hline $\begin{array}{l}\text { Non-Dimensionalized z- } \\
\text { Component of Velocity }\end{array}$ & -Dp^2*Pref*(epsilon/(1-epsilon) $))^{\wedge} 2 * \operatorname{diff}\left(\mathrm{P} \_\right.$nd, $\left.\mathrm{z}\right) /\left(150 * \mathrm{mu} \_\mathrm{H} 2 *\right.$ Uref $)$ & w_nd \\
\hline $\begin{array}{l}\text { Heat Source Due to } \\
\text { Chemical Reactions }\end{array}$ & C1t*DH_rx1-0.5*C3t*DH_rx2 & Source \\
\hline $\begin{array}{l}\text { Non-Dimensionalized } \\
\text { Pressure }\end{array}$ & P/Pref & P_nd \\
\hline $\begin{array}{l}\text { x-Component of Velocity } \\
{[\mathrm{m} / \mathrm{s}]}\end{array}$ & u_nd*Uref & $\mathrm{u}$ \\
\hline $\begin{array}{l}\mathrm{y} \text {-Component of Velocity } \\
{[\mathrm{m} / \mathrm{s}]}\end{array}$ & V_nd*Uref & $\mathrm{V}$ \\
\hline $\begin{array}{l}\text { z-Component of Velocity } \\
{[\mathrm{m} / \mathrm{s}]}\end{array}$ & w_nd*Uref & $\mathrm{w}$ \\
\hline $\begin{array}{l}\mathrm{H}_{2} \text { Equilibrium Pressure } \\
\text { for Reaction } 1[\mathrm{~Pa}]\end{array}$ & $100000 * \exp (\mathrm{DHR} 1 / \mathrm{TK}-\mathrm{DSR} 1)$ & Peq1 \\
\hline $\begin{array}{l}\mathrm{H}_{2} \text { Equilibrium Pressure } \\
\text { for Reaction } 2[\mathrm{~Pa}]\end{array}$ & $100000 * \exp (\mathrm{DHR} 2 / \mathrm{TK}-\mathrm{DSR} 2)$ & Peq2 \\
\hline $\begin{array}{l}\text { "Saturation } \\
\text { Concentration" for } \\
\mathrm{Na}_{3} \mathrm{AlH}_{6} \text { [equiv units] }\end{array}$ & 0 & C2sat \\
\hline $\begin{array}{l}\text { "Saturation } \\
\text { Concentration" for } \mathrm{NaH} \\
\text { [equiv units] }\end{array}$ & $1-125 * \mathrm{wf}(\mathrm{TK}) / 7$ & C3sat \\
\hline $\begin{array}{l}\text { Concentration of } \\
\mathrm{Na}_{3} \mathrm{AlH}_{6}\left[\mathrm{~mol} / \mathrm{m}^{3}\right]\end{array}$ & $\mathrm{C} 20-(\mathrm{C} 11-\mathrm{C} 10+\mathrm{C} 3-\mathrm{C} 30) / 3$ & $\mathrm{C} 2$ \\
\hline $\begin{array}{l}\text { Basis for Equivalent } \\
\text { Units }\left[\mathrm{mol} / \mathrm{m}^{3}\right]\end{array}$ & $\mathrm{C} 10+3 * \mathrm{C} 20+\mathrm{C} 30$ & Ceqv \\
\hline $\begin{array}{l}\text { Forward Rate for } \\
\text { Reaction } 1\end{array}$ & $\begin{array}{l}\text { A1F*Ceqv*exp(-1000*E1F/(R*TK }))^{*}(\mathrm{P}-\mathrm{Peq} 1) *(3 * \mathrm{C} 2 / \text { Ceqv- } \\
\text { C2sat)^Chi1/Peq1 }\end{array}$ & $\mathrm{r} 1 \mathrm{~F}$ \\
\hline $\begin{array}{l}\text { Backward Rate for } \\
\text { Reaction } 1\end{array}$ & -A1B*Ceqv*exp(-1000*E1B/(R*TK))*(Peq1-P)*(C11/Ceqv $)^{\wedge}$ Chi1/Peq1 & $\mathrm{r} 1 \mathrm{~B}$ \\
\hline $\begin{array}{l}\text { Forward Rate for } \\
\text { Reaction } 2\end{array}$ & $-\mathrm{A} 2 \mathrm{~F}^{*} \mathrm{Ceqv} * \exp \left(-1000^{*} \mathrm{E} 2 \mathrm{~F} /(\mathrm{R} * \mathrm{TK})\right)^{*}(\mathrm{P}-\mathrm{Peq} 2)^{*}(\mathrm{C} 3 / \mathrm{Ceqv}-\mathrm{C} 3 \mathrm{sat})^{\wedge} \mathrm{Chi} 2 / \mathrm{Peq} 2$ & $\mathrm{r} 2 \mathrm{~F}$ \\
\hline $\begin{array}{l}\text { Backward Rate for } \\
\text { Reaction } 2\end{array}$ & A2B $*$ Ceqv $* \exp \left(-1000 * E 2 B /\left(R^{*} T K\right)\right) *($ Peq $2-P) *(3 * C 2 / \text { Ceqv })^{\wedge}$ Chi $2 /$ Peq 2 & $\mathrm{r} 2 \mathrm{~B}$ \\
\hline $\begin{array}{l}\text { H2 Concentration } \\
{\left[\mathrm{mol} / \mathrm{m}^{3}\right]}\end{array}$ & C_nd*Cref & $\mathrm{C}$ \\
\hline $\begin{array}{l}\text { NaALH4 Concentration } \\
{\left[\mathrm{mol} / \mathrm{m}^{3}\right]}\end{array}$ & $\mathrm{C} 1 *(\mathrm{C} 1>0)$ & C11 \\
\hline
\end{tabular}




\subsection{Mesh Used in 2 and 3-Dimensional Models}

The mesh used in the 2-dimensional model is shown in Figure 4.5-1 and the mesh statistics are listed in Table 4.5-1. Similarly, Figure 4.5-2 shows the mesh used in the 3-dimensional model, and its mesh statistics are listed in Table 4.5-2

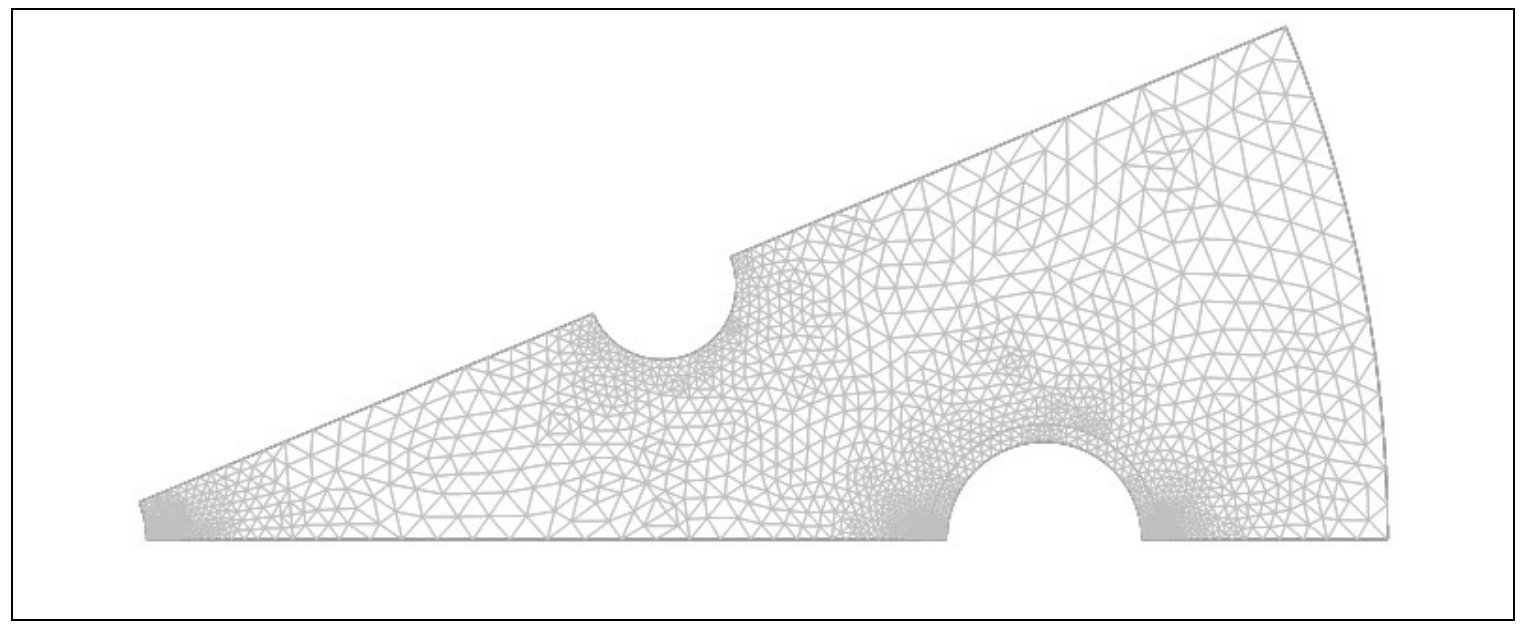

Figure 4.5-1 Two-dimensional mesh.

Table 4.5-1 Two-Dimensional Mesh Statistics

\begin{tabular}{|l|l|}
\hline Number of degrees of freedom & 106,697 \\
\hline Number of mesh points & 7,793 \\
\hline Number of elements & 15,136 \\
\hline Triangular & 15,136 \\
\hline Quadrilateral & 0 \\
\hline Number of boundary elements & 568 \\
\hline Number of vertex elements & 20 \\
\hline Minimum element quality & 0.6474 \\
\hline Element area ratio & $8.09 \mathrm{E}-4$ \\
\hline
\end{tabular}




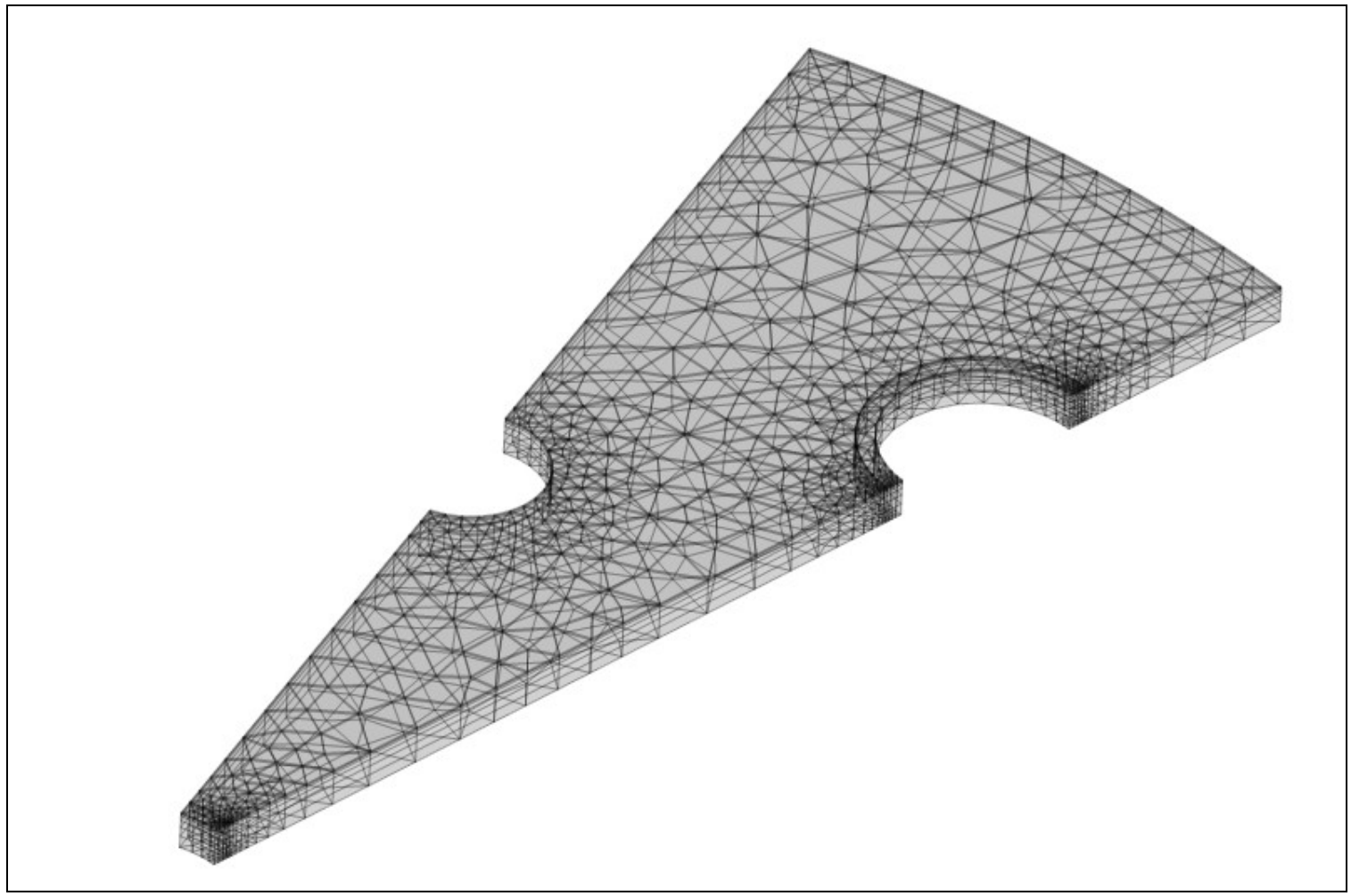

Figure 4.5-2 Three-dimensional mesh.

Table 4.5-2 Three-Dimensional Mesh Statistics

\begin{tabular}{|l|l|}
\hline Number of degrees of freedom & 98,454 \\
\hline Number of mesh points & 4,382 \\
\hline Number of elements & 6,696 \\
\hline Tetrahedral & 0 \\
\hline Prism & 6,696 \\
\hline Hexahedral & 0 \\
\hline Number of boundary elements & 4,332 \\
\hline Triangular & 3,348 \\
\hline Quadrilateral & 984 \\
\hline Number of edge elements & 612 \\
\hline Number of vertex elements & 60 \\
\hline Minimum element quality & 0.055 \\
\hline Element volume ratio & 0 \\
\hline
\end{tabular}

\subsection{RESULTS}

Transient calculations were performed for the loading phase of the sodium alanate bed. Although the state of the bed was conducive to loading, the kinetics equations used in the model were capable of modeling forward and reverse hydriding reactions. Thus, if the exothermic hydriding reactions caused the local temperature to rise sufficiently, dehydriding could be predicted by the model. 
Variables predicted by the model included spatially and time dependent temperature, pressure, molar concentrations of $\mathrm{NaAlH}_{4}, \mathrm{Na}_{3} \mathrm{AlH}_{6}$, and $\mathrm{NaH}$, the three components of gas velocity, gas concentration and/or density, and any parameter that could be computed from the aforementioned variables. The coolant was assumed to be DowTherm $\mathrm{T}^{\mathbb{B}}$, which was at a constant temperature of $373 \mathrm{~K}$ and flowed at a velocity of $13 \mathrm{~m} / \mathrm{s}$. Hydrogen was introduced to the bed through injection tubes that allowed the gas to flow freely into the porous bed. Initially the gas pressure in the tubes and the bed was 1 bar. The pressure in the tubes exponentially approached 50 bar, reaching $99 \%$ of the final value in 10 seconds. As the gas pressure increased, the resulting pressure gradient caused the gas to flow from the interface between the tube and bed into the bed, according to the Blake-Kozeny equations. The gas temperature in the tube was fixed at $373 \mathrm{~K}$.

\subsection{Bed Capacity}

Both the two and three-dimensional $\mathrm{COMSOL}^{\circledR}$ models were applied to a sodium aluminum hydride bed having dimensions derived from the Microsoft Excel ${ }^{\circledR}$ based geometry scoping tool, as discussed in Section 4.2. Underlying the calculations for the bed dimensions was the requirement that the hydride contain $1000 \mathrm{~g}$ of $\mathrm{H}_{2}$, and the assumption that all the hydride was converted from $\mathrm{NaH}$ to $\mathrm{NaAlH}_{4}$ in 3 minutes. However, later investigation with the Mathcad ${ }^{\circledR}$ kinetics scoping model, which utilized the equations in Attachments 1 and 2 for $\mathrm{TiCl}_{3}$ catalyzed $\mathrm{NaAlH}_{4}$, showed that the uptake rate for hydrogen was slow. Even for near optimal loading conditions, with a temperature of $100^{\circ} \mathrm{C}$ and a pressure of 50 bar, a bed starting with pure $\mathrm{NaH}$ only achieved a hydrogen weight fraction (defined in Equation 4.4.5-5) of 0.00238 after 3 minutes, far lower than the theoretical value of 0.056 . For this reason, the run time in the finite element models was increased to 12 minutes, while keeping the heat transfer parameters the same as for the 3 minute charging time. Even with the charging time increased to 12 minutes, the weight fraction of $\mathrm{H}_{2}$ stored in the bed was approximately 0.00794 . This value implies that to store $1000 \mathrm{~g}$ of hydrogen in 12 minutes, the mass of hydride would need to be increased by more than 7 times.

Based on the UTRC TM kinetics equations for $\mathrm{TiCl}_{3}$ catalyzed $\mathrm{NaAlH}_{4}$ in Attachments 1 and 2, the maximum weight fraction of stored hydrogen (the bed gravimetric capacity defined in Equation 5.1.2) loaded at $100^{\circ} \mathrm{C}$ and 50 bar, was approximately 0.029 , rather than the theoretical value of 0.056 discussed in Section 5.2. This difference may, in part, be because the UTRC ${ }^{\text {TM }}$ kinetics equations were fit to data taken over less than 15,000 seconds. At longer periods of time the actual hydrogen weight fraction may be greater than that predicted by the correlations derived by UTRCTM.

From Figure 5.1-1, it can be seen that, according to the UTRC ${ }^{\text {TM }}$ kinetics equations, the weight fraction asymptotically approaches 0.029 as the charging time increases. This applies to a charging temperature of $100^{\circ} \mathrm{C}$ and pressure of 50 bar. The limiting conversion is due to the terms $\mathrm{C}_{\text {sat }} \mathrm{i}(\mathrm{T})$ in the kinetics equations, see Appendix A.1.4. These terms were introduced to improve the comparison of the kinetics model with data over less than 15,000 seconds. However, at very long times the $\mathrm{C}_{\text {sat }} \mathrm{i}(\mathrm{T})$ terms prevent full conversion to the tetrahydride, and perhaps limit the validity of the kinetics model at very long charging times. Because the saturation terms depend on temperature, the fraction of monohydride that can be converted to tetrahydride for long times varies with the system temperature during loading. The weight fraction depends on both the temperature and pressure during the charging process. 
WSRC-TR-2007-00440

Revision 0

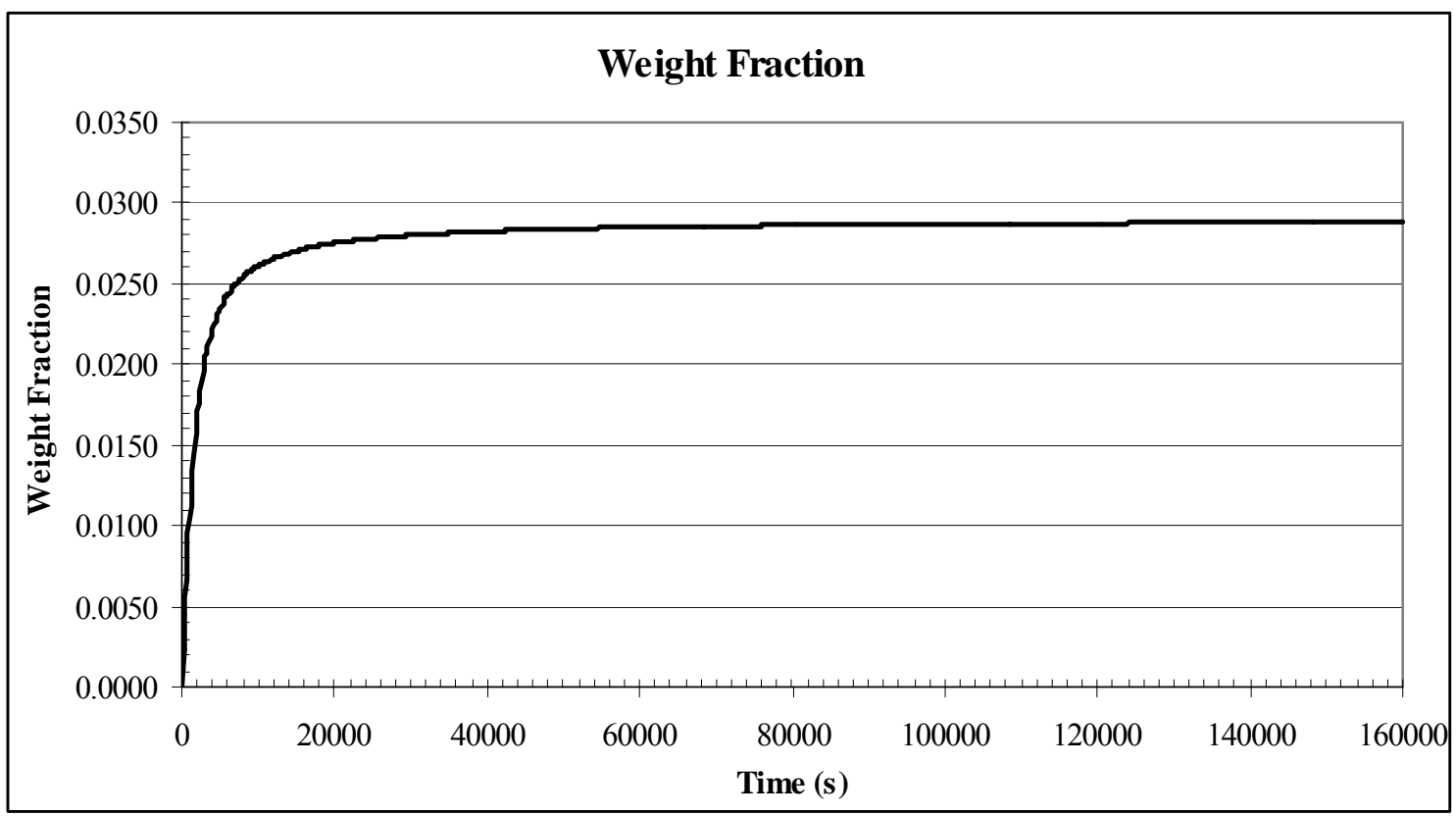

Figure 5.1-1 Bed weight fraction of stored hydrogen, loaded at $100^{\circ} \mathrm{C}$ and 50 bar. Storage in both $\mathrm{NaAlH}_{4}$ and $\mathrm{Na}_{3} \mathrm{AlH}_{6}$ are included.

\subsection{Loading Rate}

Loading rates for the bed are given in terms of the weight fraction of stored hydrogen, $w f(t)$, as opposed to the bed and system gravimetric capacities, $\mathrm{G}_{\text {Bed }}$ and $\mathrm{G}_{\text {System }}$, respectively. These terms are defined as

$w f(t)=\frac{\text { Mass of } \mathrm{H}_{2} \text { contained in the metal hydride at time } \mathrm{t}\left(\mathrm{kg} \mathrm{H}_{2}\right)}{\text { Mass of the bed fully converted to tetrahydride form }\left(\mathrm{kg} \mathrm{NaAlH}_{4}\right)}$

$\mathrm{G}_{\text {Bed }}(\mathrm{t})=\frac{\text { Stoichiometric mass of } \mathrm{H}_{2} \text { used to produce } \mathrm{NaAlH}_{4} \text { from } \mathrm{NaH}\left(\mathrm{kg} \mathrm{H}_{2}\right)}{\text { Mass of the bed fully converted to tetrahydride form }\left(\mathrm{kg} \mathrm{NaAlH} \mathrm{Na}_{4}\right)}$

$\mathrm{G}_{\text {System }}=\frac{\text { Stoichiometric mass of } \mathrm{H}_{2} \text { used to produce } \mathrm{NaAlH}_{4} \text { from } \mathrm{NaH}\left(\mathrm{kg} \mathrm{H}_{2}\right)}{\text { Mass of the system with the bed in tetrahydride form }(\mathrm{kg} \text { system })}$

By Equation 4.4.5-1, the theoretical value of $\mathrm{G}_{\mathrm{Bed}}$ is

$\mathrm{G}_{\mathrm{Bed}}=\frac{\text { Stoichiometric mass of } \mathrm{H}_{2} \text { used to produce } 1 \text { mole of } \mathrm{NaAlH}_{4} \text { from } \mathrm{NaH}}{\text { Mass of } 1 \text { mole of } \mathrm{NaAlH}_{4}}=\frac{1.5 \mathrm{M}_{\mathrm{H}_{2}}}{\mathrm{M}_{\mathrm{NaAlH}_{4}}}=0.0560$

where: $\quad \mathrm{M}_{\mathrm{H}_{2}}=$ Molecular weight of $\mathrm{H}_{2}(\mathrm{~kg} / \mathrm{g}$-mole $)=2.016 \times 10^{-3} \mathrm{~kg} / \mathrm{g}$-mole

$$
\mathrm{M}_{\mathrm{NaAlH}_{4}}=\text { Molecular weight of } \mathrm{NaAlH}_{4}(\mathrm{~kg} / \mathrm{g} \text {-mole })=5.40 \times 10^{-2} \mathrm{~kg} / \mathrm{g} \text {-mole }
$$

In the system model, it was assumed that the bed was initially all $\mathrm{NaH}$, with sufficient $\mathrm{Al}$ to complete the reaction to $\mathrm{NaAlH}_{4}$. The initial bed temperature was assumed to be $100^{\circ} \mathrm{C}$. Three 
models were used to estimate the loading rate for the bed. These were the kinetics scoping model and the 2 and 3-dimensional finite element models.

The 0-dimensional Matlab ${ }^{\circledR}$ based kinetics scoping model predicted the transient weight fraction of stored hydrogen for a bed being loaded at a fixed temperature and pressure; in this case $100^{\circ} \mathrm{C}$ and 50 bar. This model considered only the chemical kinetics of the loading process.

Both the 2 and 3-dimensional finite element $\mathrm{COMSOL}^{\circledR}$ based models also predict the transient bed weight fraction of stored hydrogen. For these models, heat transfer from the bed occurred via conduction through the bed, fins and tube walls, as well as by convection from hydrogen flowing through the porous bed. The bulk coolant temperature was fixed at $100^{\circ} \mathrm{C}$, as was the bulk temperature of hydrogen in the injection tubes.

In the finite element models, the penetration of hydrogen into the bed was driven by an increase in gas pressure in the injection tubes. Within the tubes the hydrogen pressure underwent an asymptotic increase from 1 to 50 bar, rising to within $99 \%$ of 50 bar in 10 seconds. The porous wall of the injection tube allowed hydrogen to penetrate into the hydride bed, which was initially at a pressure of 1 bar. As the pressure in the injection tube increased, the resulting pressure gradient within the packed hydride bed resulted in gas flow, which experienced viscous resistance as it passed into the bed. Hence, at the beginning of the loading phase, the local gas pressure within the bed varied over time. Heat generated by the chemical reactions was transferred to the cooling and gas injection tubes by conduction and to much lesser extent by forced convection as the gas flowed through the bed. Therefore, the local bed temperature varied with time and position. Heat transfer in the 3-dimensional model also consisted of conduction to the axially spaced fins. Of course, this effect was not treated in the 2-dimensional model. Initial bed temperatures, coolant and gas temperatures in the 2 and 3-dimensional models were chosen to optimize the uptake kinetics. It was attempted to select temperatures that were sufficiently high to provide the most rapid uptake reaction rate, but not so high that exothermic reactions would yield bed temperatures that reversed the hydriding reaction.

A comparison of loading rates for the 0 -dimensional kinetics model, and the 2 and 3-dimensional finite element models, in terms of the weight fraction of stored hydrogen, is shown in Figure 5.2-1. For the 0-dimensional kinetics model, the weight fraction of stored hydrogen was point dependent, however, for the 2 and 3-dimensional finite element models, the weight fraction of stored hydrogen depended on location and time. Therefore, for the 2 and 3-dimensional models, the weight fraction of stored hydrogen was expressed as an areal or volume average, respectively. To demonstrate capability, the 2 and 3 dimensional finite element models were run for initial $\mathrm{NaH}$ concentrations of 330.69 and $13,333.33 \mathrm{~mole} / \mathrm{m}^{3}$. Because these models included an energy balance that addressed the heat of reaction, increased initial $\mathrm{NaH}$ concentration resulted in increase transient temperatures, which impacted the rate of hydrogen uptake.

Loading rates predicted by 3-dimensional finite element models, which allowed for the presence of the axially located fins, were essentially identical to those for the 0 -dimensional kinetics model. The higher loading rates for the 2-dimensional finite element model, with an initial $\mathrm{NaH}$ concentration of $330.69 \mathrm{~mole} / \mathrm{m}^{3}$, resulted from higher predicted bed temperatures due to the absence of fins. However, for the larger initial NaH concentration of $13,333.33 \mathrm{~mole} / \mathrm{m}^{3}$, temperatures in the 2-dimensional model were sufficiently high to reduce, and in some locations reverse, the hydriding reactions. This led to the lower loading rate shown in Figure 5.2-1

Figure 5.2-2 shows the transient weight fraction of stored hydrogen relative to bed gravimetric capacity, which had a theoretical value of 0.056 . 


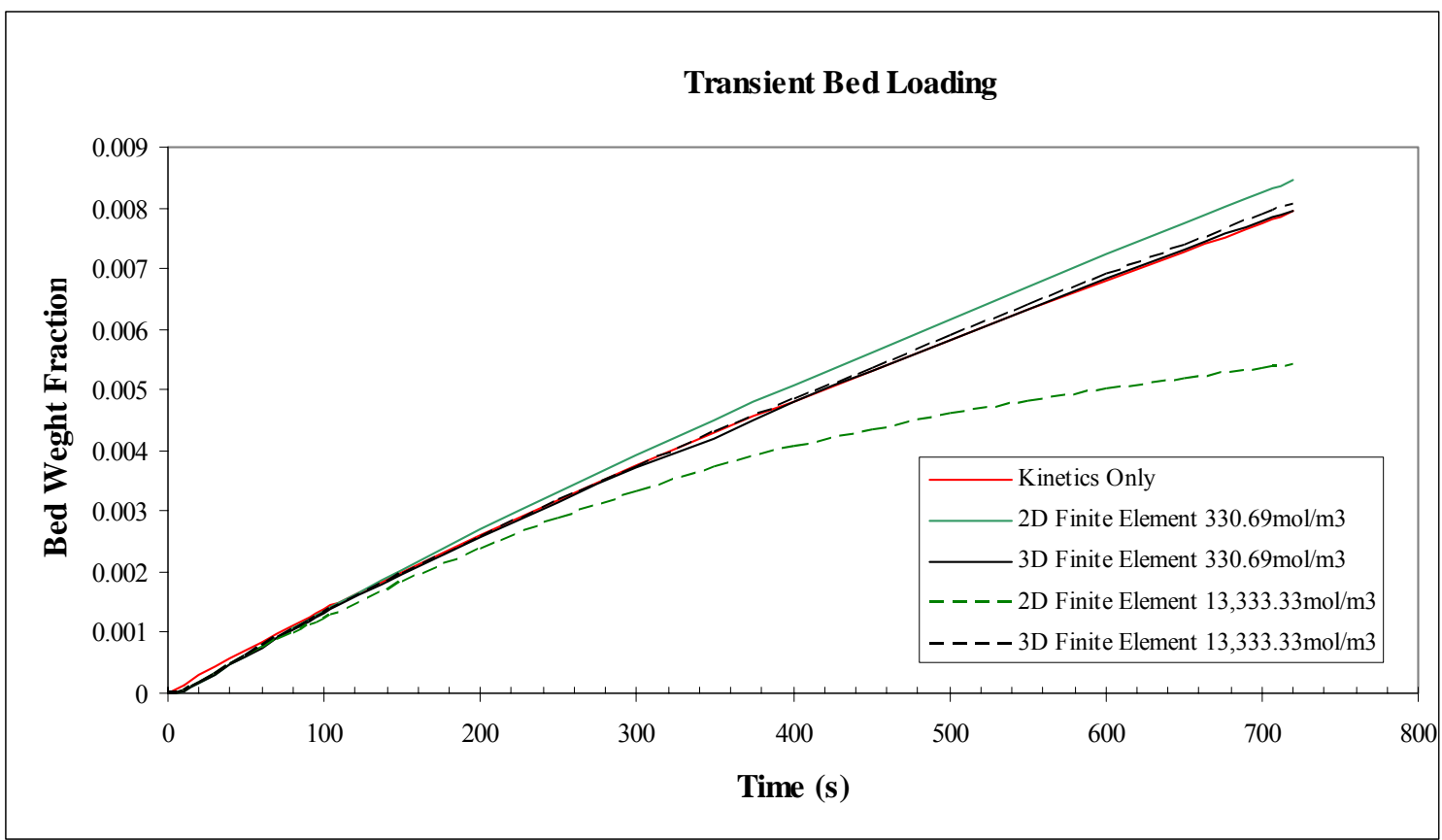

Figure 5.2-1 Comparison of the weight fraction of stored hydrogen for the kinetics scoping model and the 2 and 3-dimensional finite element bed models.

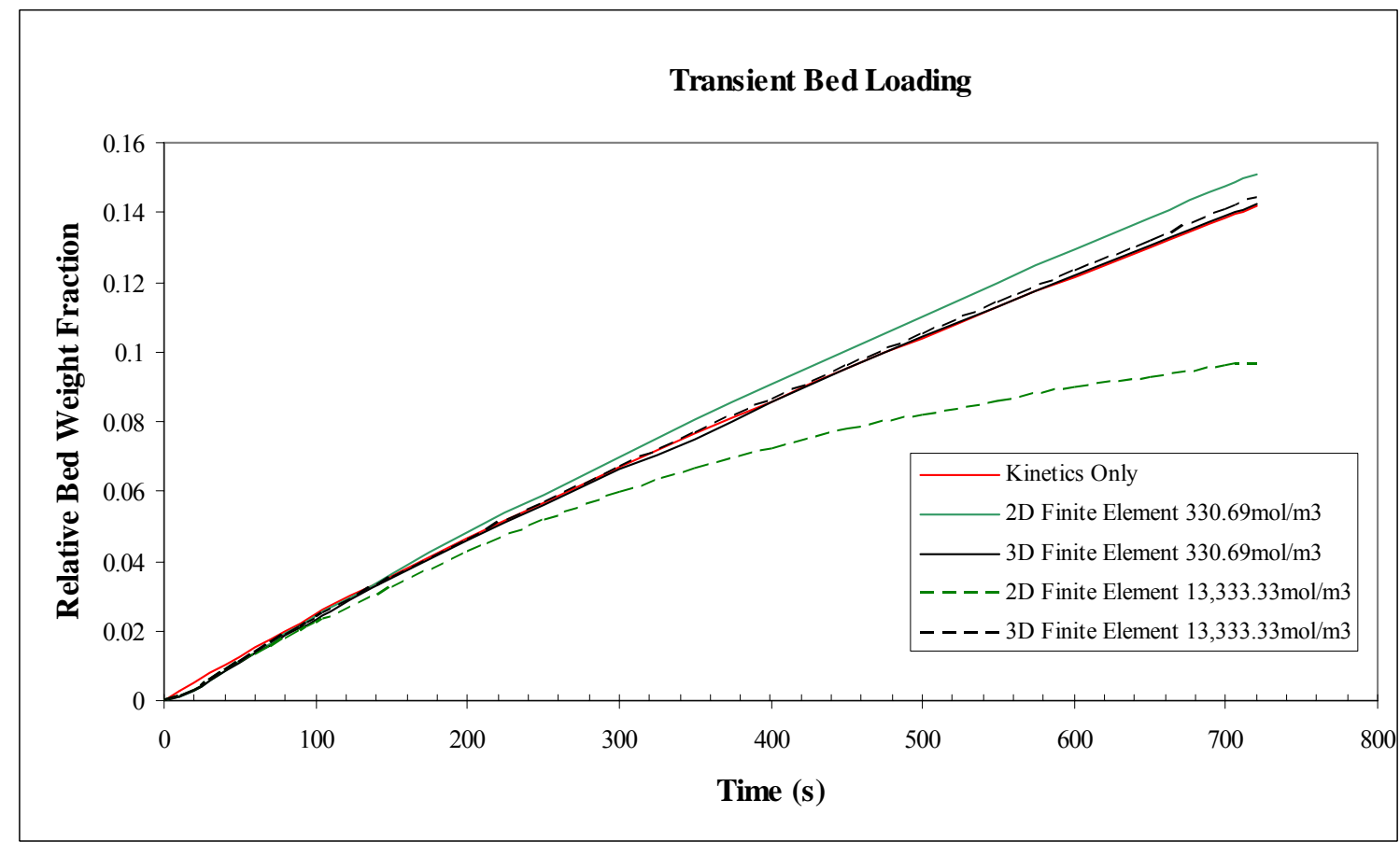

Figure 5.2-2 Comparison of weight fraction of stored hydrogen relative to the theoretical gravimetric capacity of the bed, wf $(\mathrm{t}) / 0.056$, for the kinetics scoping model and the 2 and 3-dimensional finite element bed models. 


\subsection{Bed Temperatures}

Heat generated during the loading of the bed results in a temperature transient that impacts the reaction rates. The low thermal conductivity of the alanate necessitates design features that maintain a relatively short length scale for heat transfer within the bed. The models in this document were developed for shell and tube (the 2-dimensional finite element model) and shell, tube and fin (the 3-dimensional finite element model) configurations.

Figure 5.3-1 shows plan and isometric views of the temperature profile in the 3-dimensional model at 40 second into the loading transient. The image on the left shows the reduction in temperature from the mid-plane of the hydride layer to the midplane of the fin. The plan view, on the right, shows the temperature profile over the midplane of the hydride layer.

Figures 5.3-2 through 5.3-5 compare the transient temperature profile for the 2-dimensional model, which does not have fins, to the temperature profile at the midplane of the hydride layer for the 3-dimensional model. Comparisons were made at 30, 60, 120 and 720 seconds. In these figures, it can be seen that the fins result in a much more uniform temperature profile.
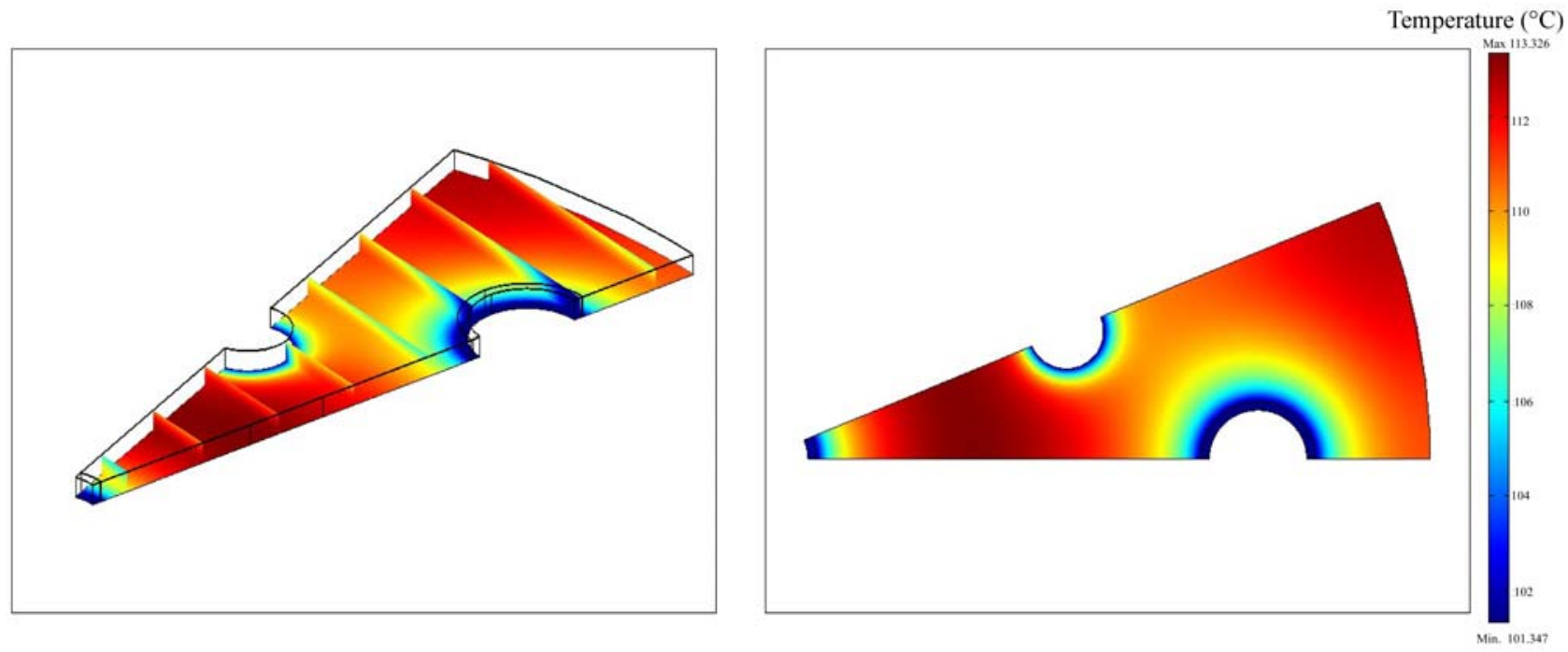

Figure 5.3-1 Isometric and plan views of temperature profile for 3-dimensional model at 40 seconds. 

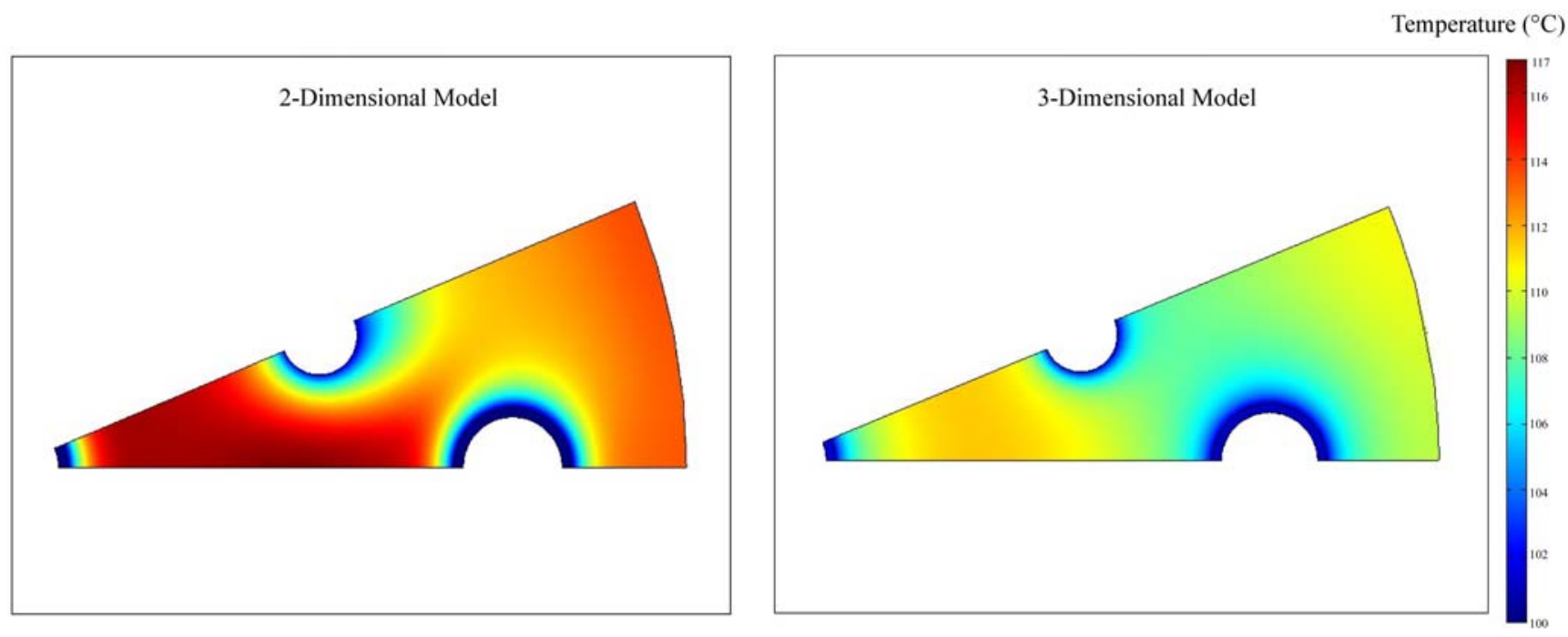

Figure 5.3-2 Comparison between 2-dimensional and 3-dimensional midplane temperature profiles at 30 seconds.
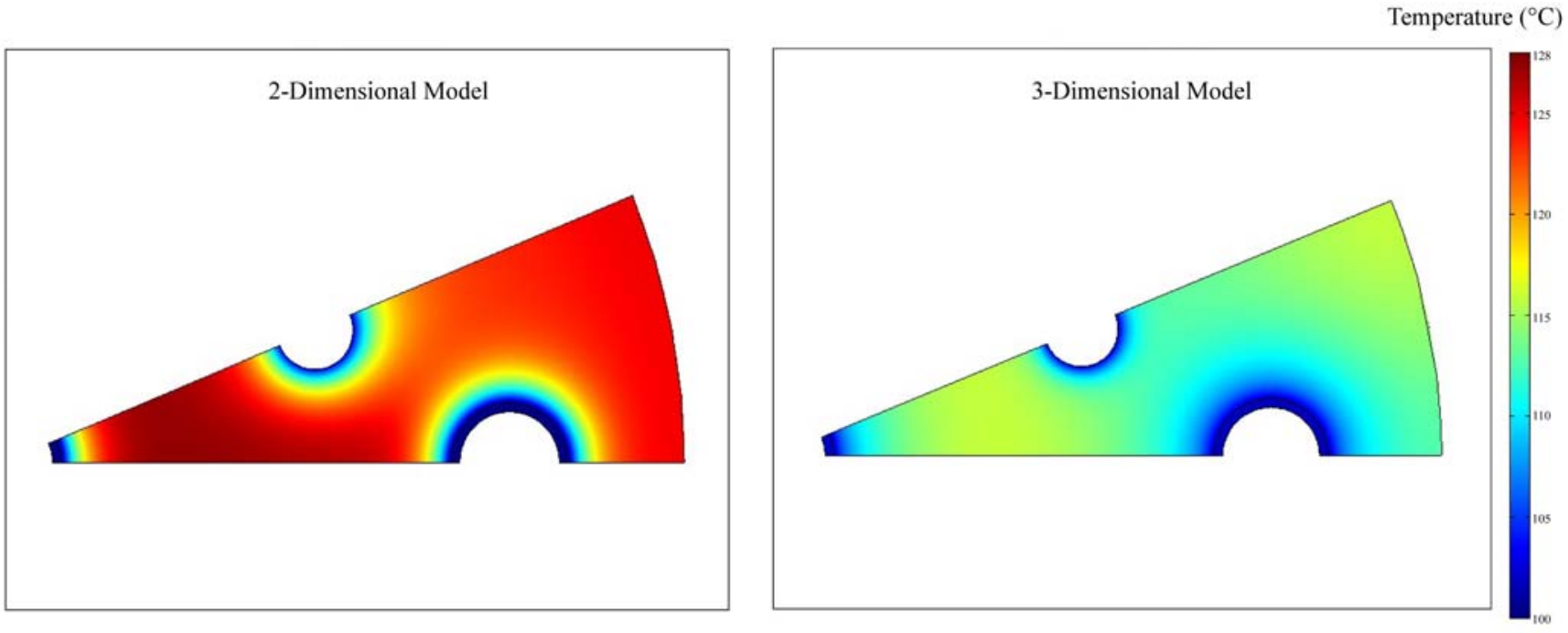

Figure 5.3-3 Comparison between 2-dimensional and 3-dimensional midplane temperature profiles at 60 seconds. 

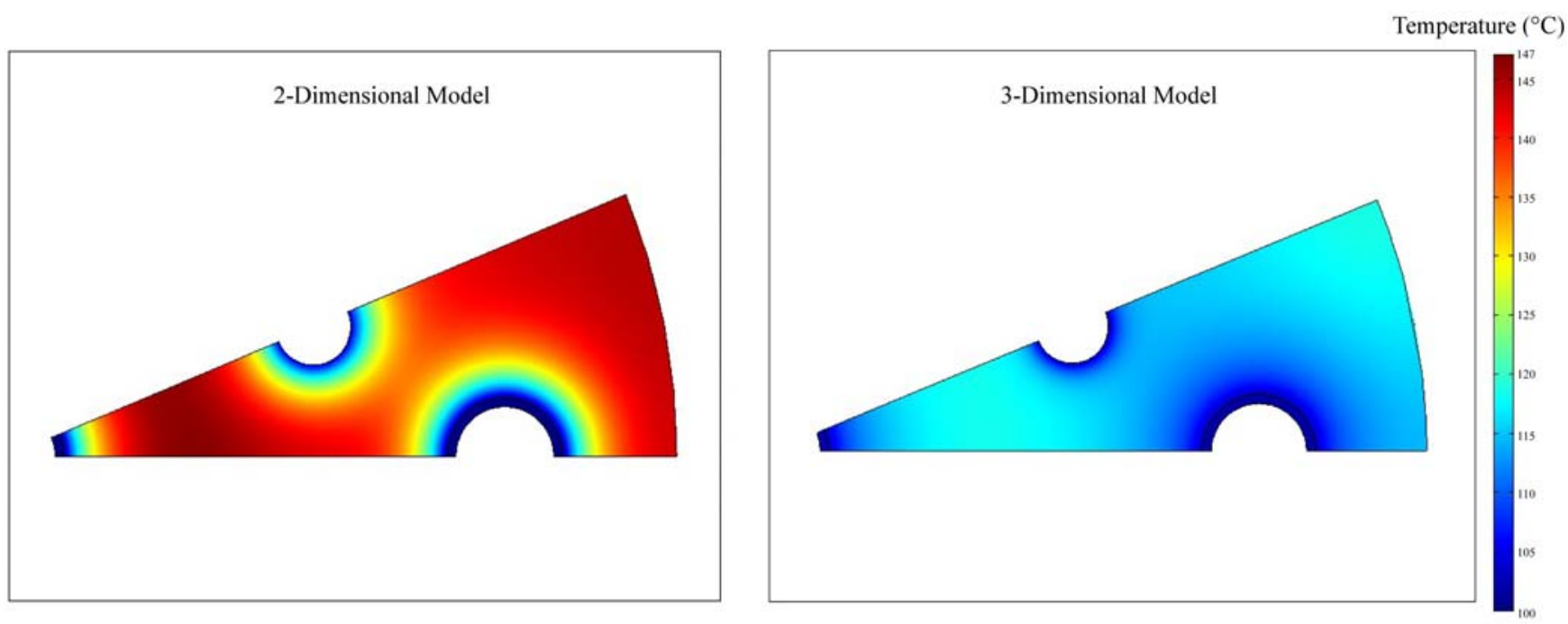

Figure 5.3-4 Comparison between 2-dimensional and 3-dimensional midplane temperature profiles at 120 seconds.
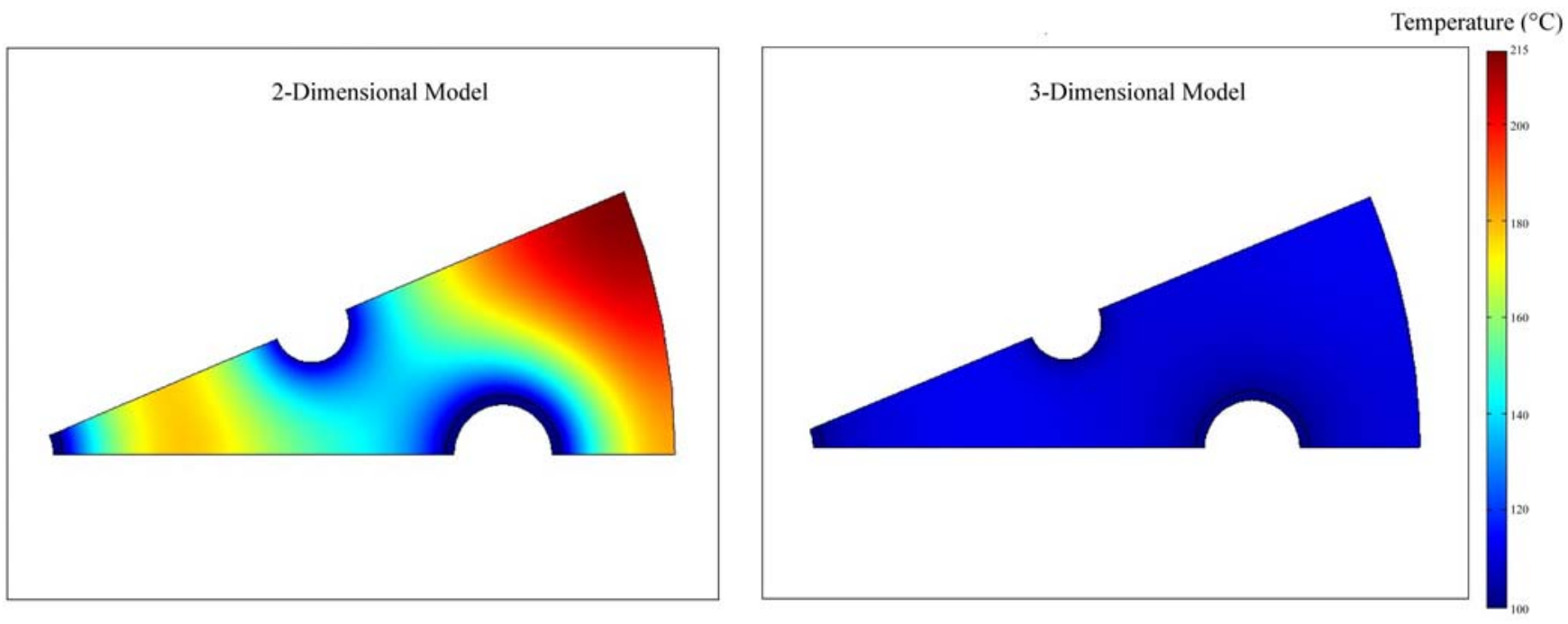

Figure 5.3-5 Comparison between 2-dimensional and 3-dimensional midplane temperature profiles at 720 seconds.

\subsection{Bed Gas Flow}

As the pressure in the hydrogen injection tube rises from its initial value of 1 bar to its final value of 50 bar, the resulting pressure gradient forces flow into the bed. For this system, the relation between the pressure gradient and the gas velocity is represented by the Blake-Kozeny equation. By this equation, the small effective diameter of the particles comprising the bed results in significant resistance to flow. As the local gas pressure in the bed increases, hydrogen is removed from the gas phase as the hydriding reactions take place, see Equation 4.4.5-1. Heating of the gas by the exothermic reactions, in turn, affects the gas pressure and the reaction rates. Expansion work performed as the gas flows in the direction of the pressure gradient also has an effect on the 
gas temperature, see Equation 4.4.3-1. These complex, coupled phenomena are considered in the energy and mass balances.

Figures 5.4-1 and 5.4-2 show the magnitude and direction of the hydrogen velocity for the 2 and 3 -dimensional finite element models at times of 10 and 40 seconds, respectively.
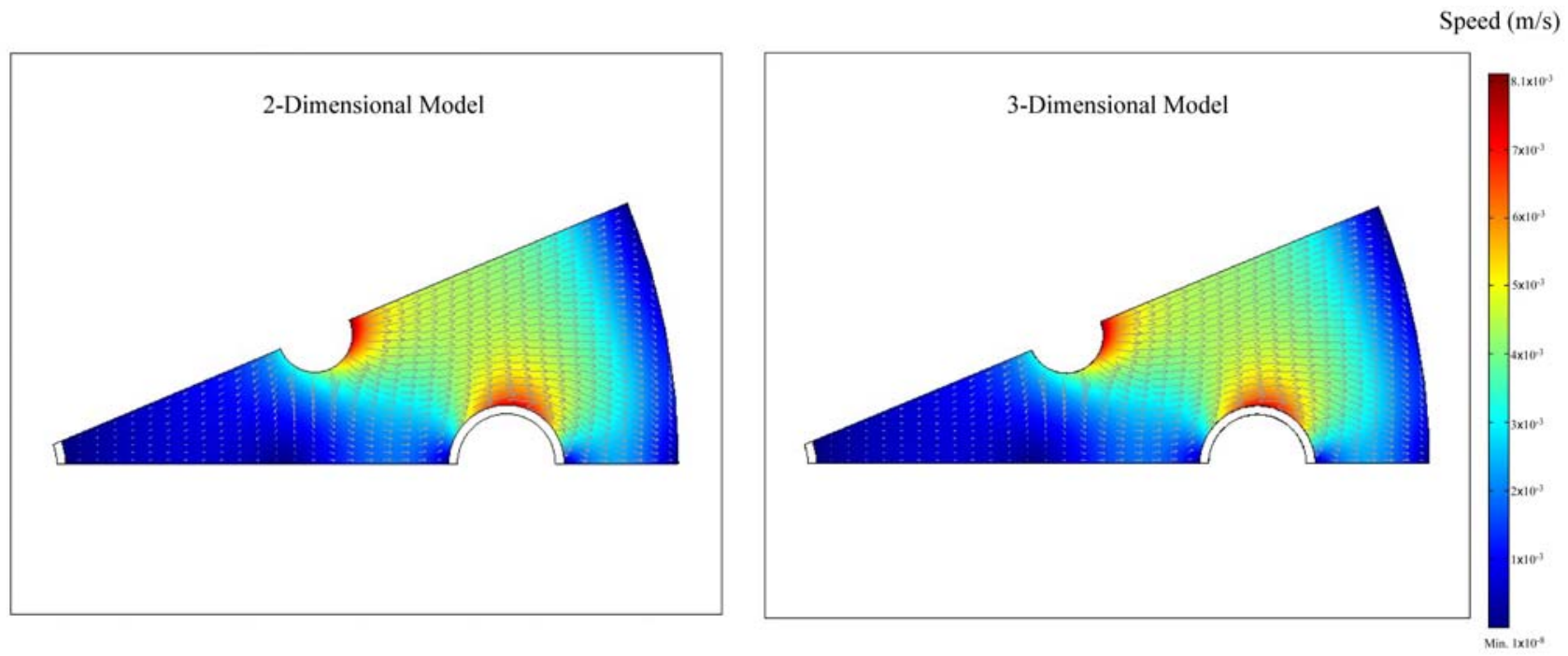

Figure 5.4-1 Hydrogen velocity profile at 10 seconds.
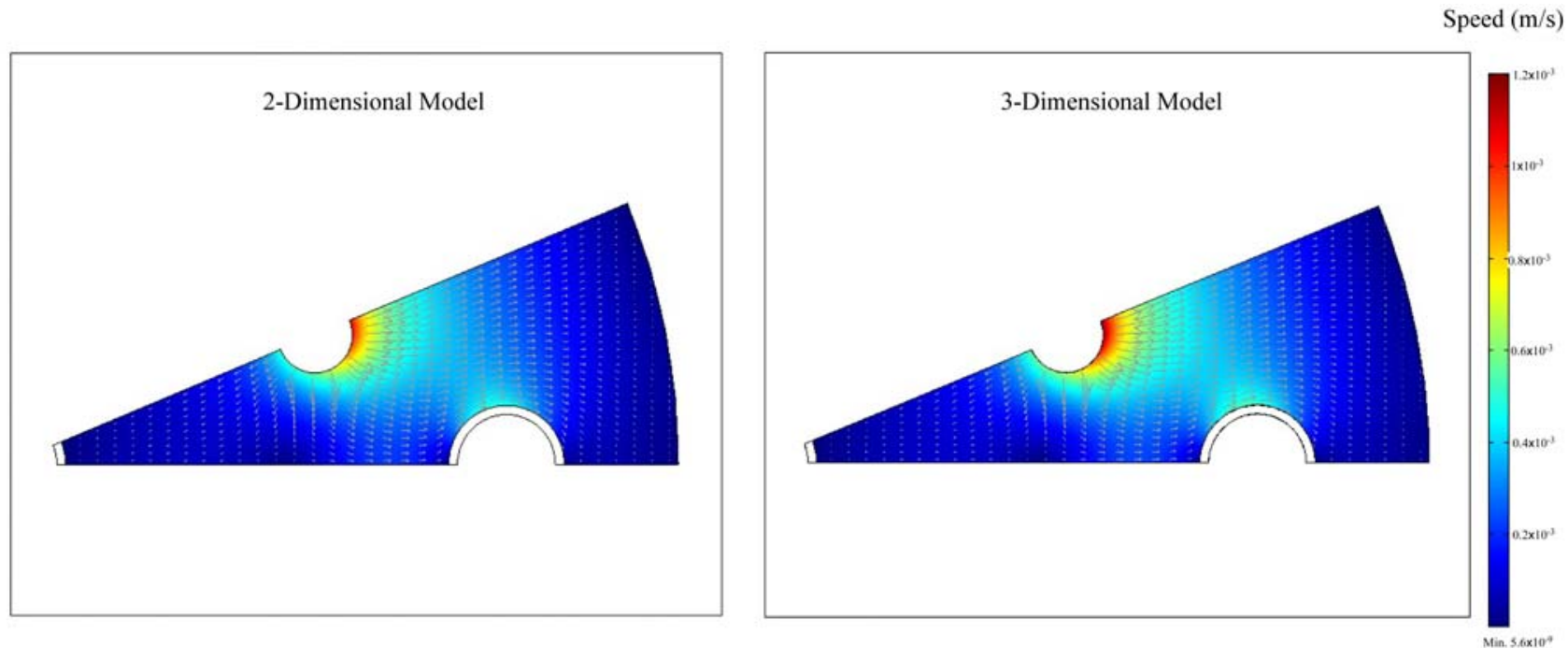

Figure 5.4-2 Hydrogen velocity profile at 40 seconds. 


\subsection{Hydride Concentration Profiles}

Conversion of $\mathrm{NaH}$ to $\mathrm{Na}_{3} \mathrm{AlH}_{6}$ and then to $\mathrm{NaAlH}_{4}$ occurrs as the bed is loaded with hydrogen. However, the hexa and tetra-hydrides first form in locations that have temperatures and pressures conducive to higher reaction rates. To use the bed efficiently, the concentration of tetra-hydride must be relatively uniform at the termination of the loading phase. Achieving full utilization of the bed requires design features that ensure proper heat transfer and flow within the bed.

Figures 5.5-1 through 5.5-4 compare the transient concentrations of $\mathrm{Na}_{3} \mathrm{AlH}_{6}$ and $\mathrm{NaAlH}_{4}$ for the 2-dimensional model and at the midplane of the hydride for the 3-dimensional model.
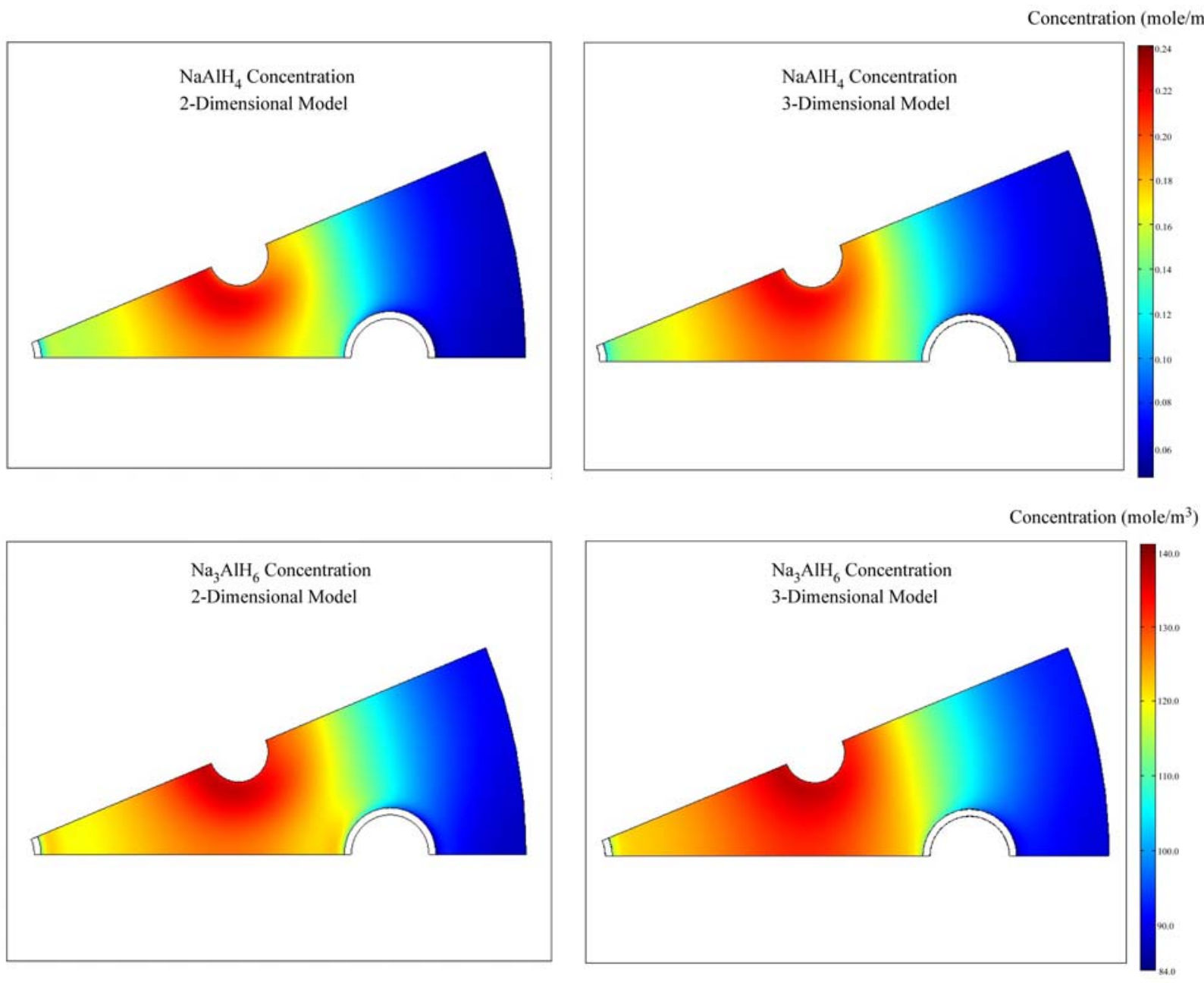

Figure 5.5-1 Comparison of 2-dimensional and 3-dimensional bed midplane hydride concentrations at 40 seconds. 
WSRC-TR-2007-00440

Revision 0
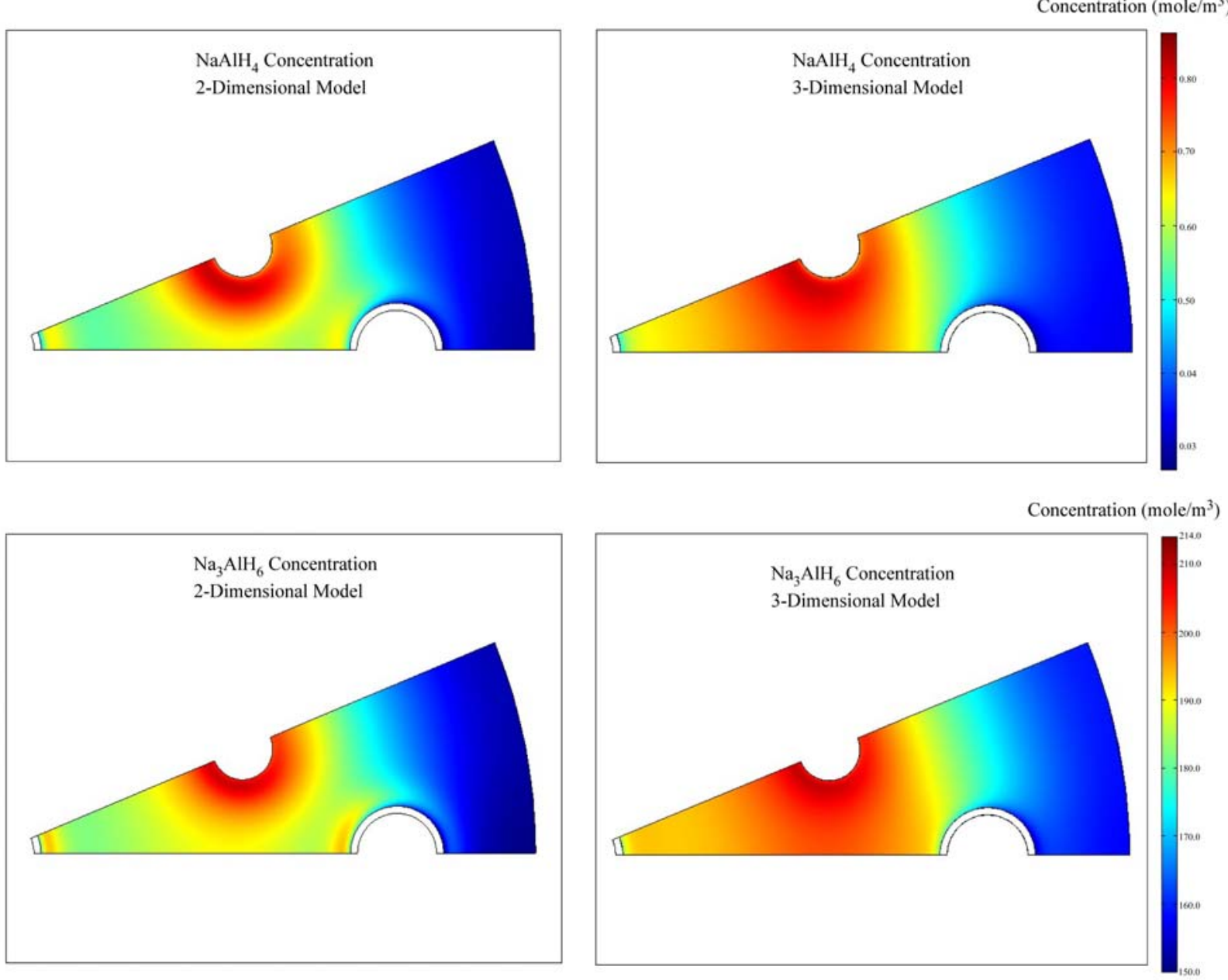

Figure 5.5-2 Comparison of 2-dimensional and 3-dimensional bed midplane hydride concentrations at 60 seconds. 

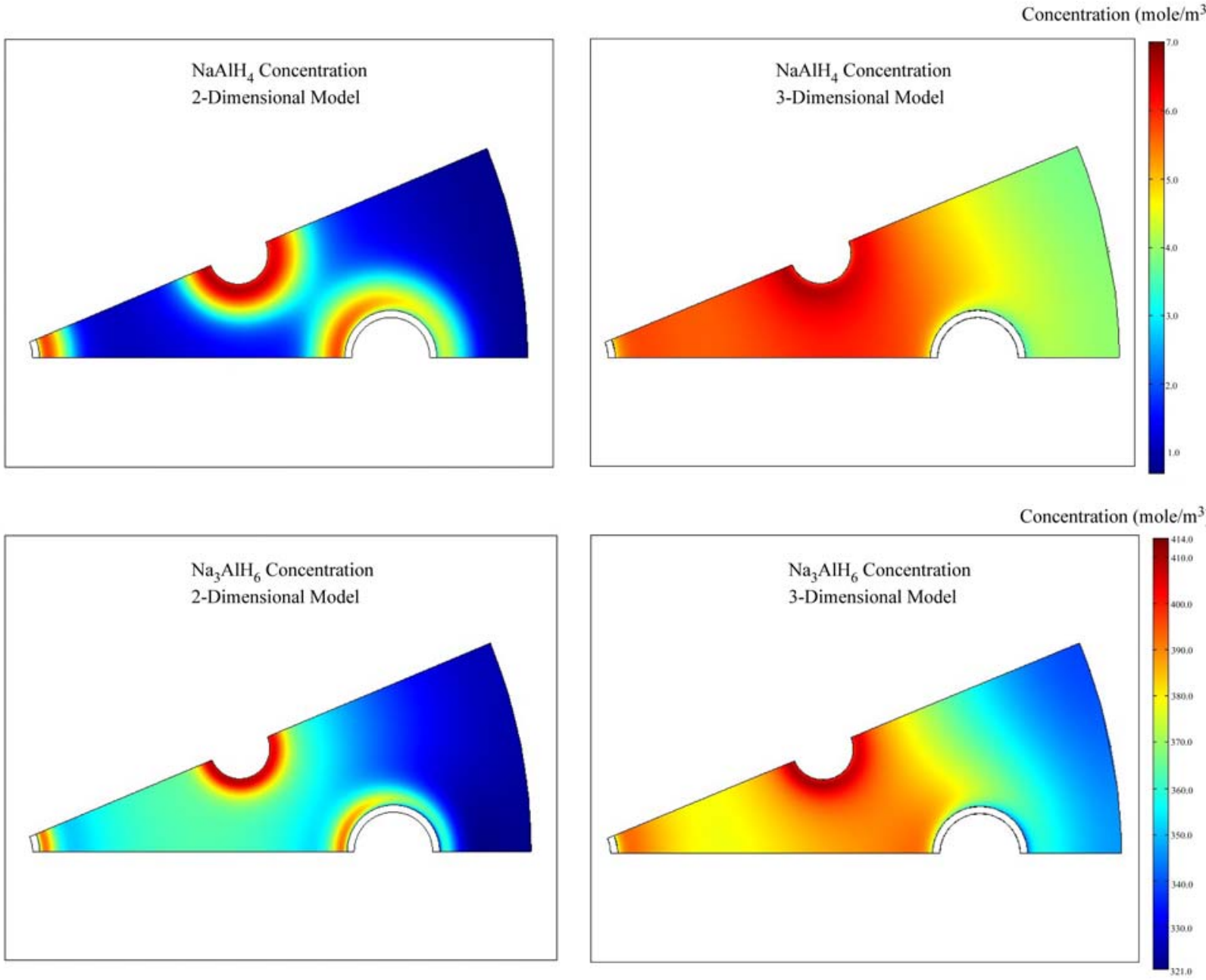

Figure 5.5-3 Comparison of 2-dimensional and 3-dimensional bed midplane hydride concentrations at 120 seconds. 

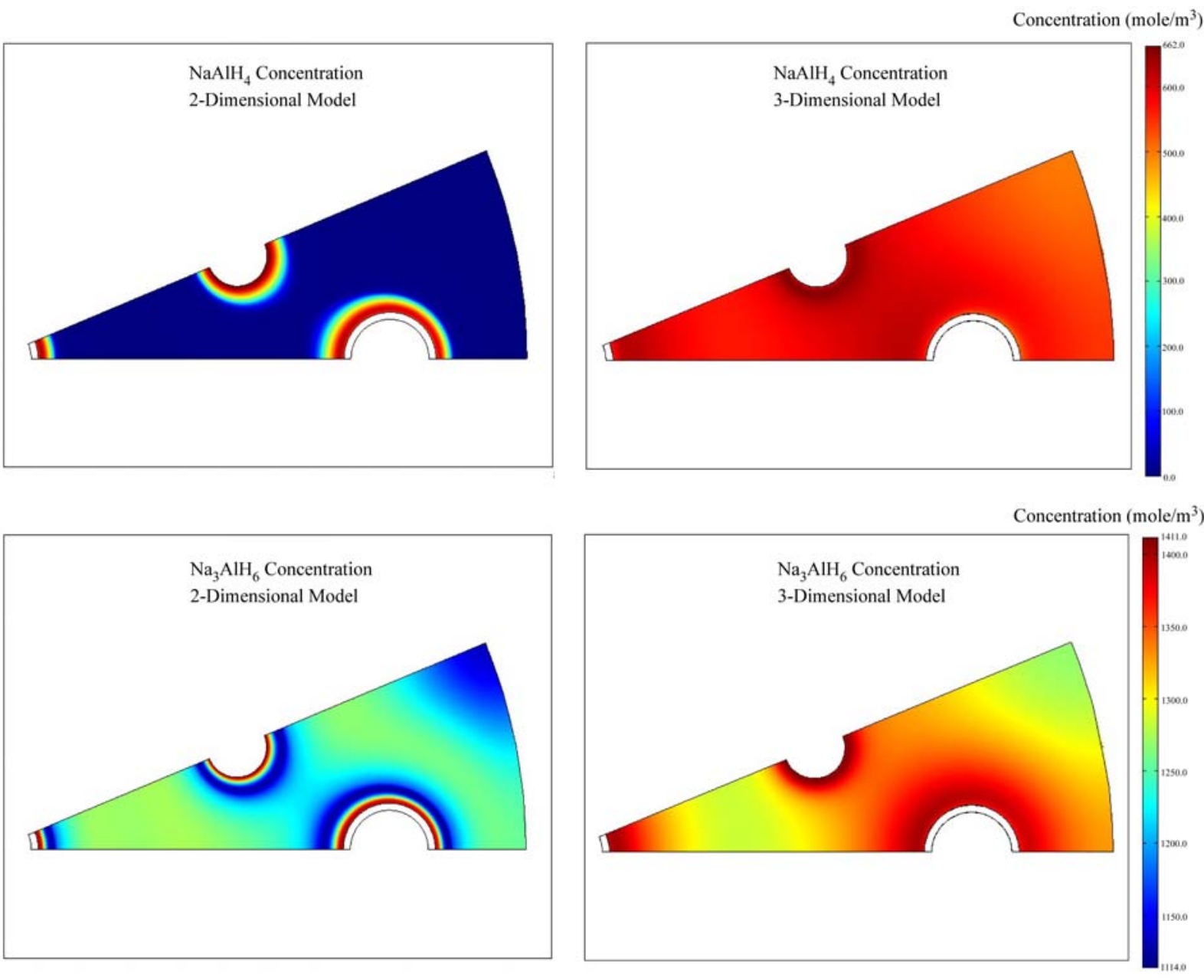

Figure 5.5-4 Comparison of 2-dimensional and 3-dimensional bed midplane hydride concentrations at 720 seconds.

\subsection{CONCLUSIONS}

The hydride bed model used in this document consists of four sub-models:

- A 0-dimensional Mathcad ${ }^{\circledR}$ based kinetics scoping model that evaluates loading and discharge kinetics, along with the maximum storage capacity, for a given hydride.

- A geometry scoping model, developed in a Microsoft Excel ${ }^{\circledR}$, that determines system dimensions (length scales) required to store a given amount of hydrogen for a particular hydride and geometric configuration. The model also calculates placement of heat transfer elements, and the gravimetric and volumetric capacities for the system.

- A scoping model that estimates coolant flowrates, temperatures, pressure drops, etc., required to remove heat generated during hydrogen uptake. This model, developed in a Microsoft Excel ${ }^{\circledR}$ workbook, can also be used to identify suitable heat transfer fluids.

- Finite element models in 2 and 3-dimensions that couple mass, momentum and heat transfer, along with temperature dependent chemical kinetics. These models, developed using COMSOL Multiphysics ${ }^{\circledR}$, are used to evaluate the detailed performance of the storage system. 
The process of modeling a particular bed configuration and storage media is as follows:

1 The hydride kinetics are evaluated with the 0 -dimensional Mathcad ${ }^{\circledR}$ kinetics scoping model. The model is used to determine the dependence of the reaction rates and hydrogen capacity on temperature and pressure. Pressures and temperatures that optimize loading and discharge rates are determined and possible errors in the kinetics model are identified. The bed gravimetric and volumetric capacities are calculated from the loading calculations and the bulk density of the storage material.

2 The hydrogen weight fraction from the kinetics scoping model, component densities, component dimensions and the required mass of hydrogen to be stored are input to the Excel $^{\circledR}$ based geometry scoping model. The model calculates the size of the system, the location of heat transfer elements, as well as the gravimetric and volumetric capacities of the system.

3 System dimensions from the geometry scoping model, heat transfer fluid properties, thermal properties of the system components, heats of reaction, total amount of hydrogen to be stored and the time required to load the system are input to the heat removal scoping model. The model calculates the coolant flowrates, convection heat transfer coefficients and other parameters required to remove heat generated by the chemical reactions governing hydrogen uptake. The model is useful for determining if the operating parameters required for the cooling system are attainable and/or practical.

4 The storage vessel dimensions, geometry, heat transfer parameters and bed configuration are input to the 2 and/or 3-dimensional finite element $\mathrm{COMSOL}^{\circledR}$ based models. A number of other input parameters including material properties, flowrates, reaction kinetics, etc. are also required.

5 Detailed system behavior predicted by the finite element models is used to assess the ability of the system to meet technical requirements.

6 System design is refined by repeating steps 1 through 5 with modified parameters.

According to the UTRC ${ }^{\mathrm{TM}}$ kinetics correlations, the kinetics scoping model showed that at 50 bar, even at a near optimal temperature of $100^{\circ} \mathrm{C}$, the weight fraction of hydrogen stored in $\mathrm{TiCl}_{3}$ catalyzed $\mathrm{NaAlH}_{4}$ over 3 minutes is 0.00238 , more that 23 times lower than the theoretical value of 0.056 . This implies a bed gravimetric capacity of $0.238 \%$ for the $2010 \mathrm{DOE}$ technical target charging time of 3 minutes. The system gravimetric capacity would be lower. Based on these results, it is apparent that a more efficacious storage material must be found.

The detailed finite element models, however, indicated that the modified shell and tube heat exchanger, with fins normal to the axis, was very effective from the perspective of heat removal and temperature control. For identical states of the coolant and feed hydrogen, the modified shell and tube system permits far better control of the bed temperature than the system without fins. This was clearly demonstrated by comparing the temperatures predicted by the 3-dimensional and 2-dimensional models, which represented storage systems with and without fins, respectively, see Figures 5.3-2 through 5.3-5. Because the bed temperatures were maintained below $120^{\circ} \mathrm{C}$, the hydrogen charging rate was significantly improved for the modified shell and tube system. The more uniform spatial temperatures in the modified storage system yielded smaller concentration gradients for the hexa and tetra-hydrides formed from NaH. This resulted in more efficient utilization of the bed. Figure 5.2-1 shows that the charging rate for the modified system is essentially the same as predicted by the 0 -dimensional kinetics scoping model. This means that 
WSRC-TR-2007-00440

Revision 0

charging in the modified system is limited by kinetics alone, which represents an upper bound to the charging rate at a given temperature and pressure.

\subsection{FUTURE WORK}

Recommended additions to the sodium alanate storage system model in this report are:

- Adjust bed dimensions to store $1000 \mathrm{~kg}$ of hydrogen during the allotted loading time.

- For the geometric configuration analyzed in this report, identify properties that the storage material must possess to meet the DOE technical targets listed in Attachment 3.

- Include pressure dependence in the thermal conductivity of hydrogen. Temperature dependence of the thermal conductivity is included in the current model.

- Apply the model to loading of partially discharged storage vessels.

- Investigate novel geometric configurations, other than shell and tube, for the storage system.

It is recommended that the systematic approach, employing the Mathcad ${ }^{\circledR}$ based kinetics model, the Microsoft Excel ${ }^{\circledR}$ based geometry model and the COMSOL Multiphysics ${ }^{\circledR}$ based finite element models be used in sensitivity studies to identify operating envelopes that hydrogen storage materials must meet to approach DOE technical targets. Since the system geometry, heat transfer characteristics, bed kinetics and heats of reaction are coupled, material operating envelopes will, of course, be related to the particular form of the bed. 
WSRC-TR-2007-00440

Revision 0

\subsection{REFERENCES}

Aldas, K. and M. Mat. "Numerical Analysis of Hydrogen Storage in Metal- Hydride Beds." Turk. J. Eng. Environ. Sci., 26, 201-207, 2002.

Aldas, K., M. Mat and Y.Kaplan. "A Three-Dimensional Model for Absorption of Hydrogen in a Metal Hydride Bed.” Int. J. Hydrogen Energy, Vol. 27, 10, 1049-1056, 2002.

Anton D. L. and D. A. Moser. "High Density Hydrogen Storage System Demonstration Using $\mathrm{NaAlH}_{4}$ Complex Compound Hydride." Proceedings of the 2005 Hydrogen Program, 2005.

Askri, F. , A. Jemni and S. B. Nasrallah. "Prediction of Transient Heat and Mass Transfer in a Closed Metal-Hydrogen Reactor.” Intl. J. Hydrogen Energy, Vol. 29, 195-208, 2004.

Avallone, E. A., T. Baumeister III. "Mark's Standard Handbook for Mechanical Engineers." $9^{\text {th }}$ Ed, McGraw-Hill, New York, NY, 1987.

Bilgili, M. and Ö. E. Ataer. "Numerical Analysis of Hydrogen Absorption in a P/M Bed." Powder Technology, 160, 141-148 2005.

Bird, R. B., W. E. Stewart, and E. N. Lightfoot. "Transport Phenomena.” John Wiley \& Sons, New York, 1960.

COMSOL Multiphysics ${ }^{\circledR}$, version 3.3.0.405. Copyright 1994-2006, COMSOL AB

El-Gammal, M. A., M. A El-Osairy, I. A. El-Osery, A. M. Metwally and M. A. Hassan. "A Study for he Major factors Affecting the Hydrogen Discharging in the Metal Hydrogen Storage Conduction Bed Model." Modelling Measurement and Control, Vol 46, 2, 35-44, 1993.

El-Osairy, M. A., I. A El-Osery, A. M. Metwally and M. M. Keshk. "Temperature and Composition Analysis of a Convective Model of Metal Hydride Hydrogen Storage Beds." Int. J. Hydrogen Energy, Vol 17, 2, 125-128, 1992a.

El-Osairy, M. A., I. A El-Osery, A. M. Metwally and M. M. Keshk. "On the Optimization of Convective Hydrogen Storage Bed Model Using $\mathrm{LaNi}_{5} \mathrm{H}_{6}$ or $\mathrm{FeTiH}_{1.6}$." Int. J. Hydrogen Energy, Vol 17, 17, 961-964, 1992b.

El-Osairy, M. A., I. A El-Osery, A. M. Metwally and M. A. Hassan. "Temperature and Composition Distributions of $\mathrm{FeTiH}_{1.6}$ and $\mathrm{MgNiH}_{4}$ for Two-Dimensional Hydrogen Energy Conduction Bed Model.” J. Alloys and Compounds, 202, 125-128, 1993.

El-Osairy, M. A., I. A El-Osery, A. M. Metwally and M. A. Hassan. "Temperature and Composition Distributions of $\mathrm{LaNi}_{5} \mathrm{H}_{6}$ metal Hydride for Different Geometries and Flow Regimes in Hydrogen Energy Conduction Bed Model." Modelling Measurement and Control, Vol 40, 1, 53-63, 1994.

El-Osery, I. A “A Comparative Study of "In-Out” and Out-In” Hydrogen Reaction Alternatives for Metal Hydride Beds Using RET1 Computer Code." Int. Assoc. Hydrogen Energy, Vol. 9, 5, 421-444, 1984a. 
WSRC-TR-2007-00440

Revision 0

El-Osery, I. A “A Comparative Study of Different Designs for Metal Hydride Hydrogen Storage Beds Using TOBA Computer Code." Hydrogen Energy Progress V, Proc. $5^{\text {th }}$ World Hydrogen Conf., Toronto, July 15-20 Vol. 3, Pergamon Press, Oxford, 1383-1392, 1984b.

El-Osery, I. A “On Computer Calculations of Temperature-Composition Relations in Metal Hydride Hydrogen Storage Beds.” Surface and Coatings Tech., 28, 397-404, 1986.

El-Osery, I. A., M. A El-Osairy, A. M. Metwally, M. M. Keshk and M. A.El-Gammal,. "Dynamic Simulation of the Convective Model for Metal Hydride Hydrogen Storage Beds." Energy Sources, Vol 15, 523-530, 1993.

Gadre, S.; A. Ebner, S. Al-Muhtaseb, J. Ritter. "Practical Modeling of Metal Hydride Hydrogen Storage Systems.” Ind. Eng. Chem. Res., Vol 42, 1713, 2003.

Gopal, M. R. and S. S, Murthy. "Prediction of Heat and Mass transfer in Annular Cylindrical Metal Hydride Beds.” Int. J. Hydrogen Energy Vol. 17, 10, 795-805, 1992.

Gopal, M. R. and S. S, Murthy. "Studies on Heat and Mass Transfer in Metal Hydride Beds." Int. J. Hydrogen Energy, Vol. 20, 11, 911-917, 1995.

Gross, K. J. "The Reversible Hydrides Solution for Hydrogen Storage.” Slide Presentation for G-CEP Hydrogen Workshop, April 14 \& 15, 2003.

Gross, K. J., E. Majzoub, G. J. Thomas, and G. Sandrock "Hydride Development for Hydrogen Storage." Proc. of the 2002 U.S. DOE Hydrogen Program Review, NREL/CP610-32405, April 14 \& 15, 2002.

Ha, M.Y.; I. K. Kim, H. D. Song; S. Sung; D. H. Lee. "A Numerical Study of Thermo-Fluid Phenomena in Metal Hydride Beds in the Hydriding Process." Int. J. Heat and Mass Transfer, Vol. 47, 2901, 2004.

Hardy, B. J. "Geometry, Heat Removal and Kinetics Scoping Models for a Hydrogen Storage Systems." Washington Savannah River Company Document, WSRC-TR-20007-00439, Rev.1, 2007.

Holman, J. P. "Heat Transfer." $4^{\text {th }}$ Edition, McGraw-Hill, New York, NY, 1976.

Jemni, A. and S.B.Nasrallah. "Study of Two-Dimensional Heat and Mass Transfer During Absorption in a Metal-Hydrogen Reactor.” Int. J. Hydrogen Energy, Vol. 20, 1, 43, 1995.

Jemni, A.; Nasrallah, B.; Lamloumi, J. "Experimental and theoretical study of a metal-hydrogen reactor.” Int. J. Hydrogen Energy, Vol. 24, 631, 1999.

Kikkinides, E.S; M.C. Georgiadis and A.K. Stubos. "Dynamic Modeling and Optimization of Hydrogen Storage in Metal Hydride Beds.” Energy, 31, 2428, 2006.

Lide, D. R., and H. V.Kehiaian. "CRC Handbook of Thermophysical and Thermochemical Data." CRC Press, Boca Raton, FL, 1994. 
WSRC-TR-2007-00440

Revision 0

Mat, M. and Y.Kaplan. "Numerical Study of Hydrogen Absorption in a $\mathrm{LaNi}_{5}$ Hydride Reactor." Int. J. Hydrogen Energy, Vol. 26, 9, 957-963, 2001.

Mathcad $^{\circledR}$, version 14.0.0.163. Copyright $(C) 2007$ Parametric Technology Corporation.

Mayer, U., M. Groll and W. Supper. "Heat and Mass Trasnfer in Metal Hydride Reaction Beds Experimental and Theoretical Results.” J. Less Common Met., 131, 235-244, 1987.

Mazumdar, S.; M. R. Gopal and S. Bhattacharyya. "Thermodynamic Analysis and Optimization of Compressor-Driven metal Hydride Cooling Systems." Int. J. Hydrogen Energy, Vol. 30, 631, 2005.

Microsoft $^{\circledR}$ Excel 2002 (10.6834.6830) SP3. Microsoft Corporation.

Mosher, D, X. Tang, S. Arsenault, B. Laube, M. Cao, R. Brown and S. Saitta. "High Density Hydrogen Storage System Demonstration Using NaAlH4 Complex Compound Hydrides." DOE Hydrogen Program Annual Peer Review, Arlington, VA, 2007.

Nasrallah, S.B. and A. Jemni. "Study of Two-Dimensional Heat and Mass Transfer During Desorption in a Metal-Hydrogen Reactor." Int. J. Hydrogen Energy, Vol. 22, 1, 67, 1997. 


\section{APPENDIX}

\section{A.1 GOVERNING EQUATIONS}

The governing equations used in the hydride bed model are derived in this appendix. For clarity, expressions input to $\mathrm{COMSOL}^{\circledR}$ are enclosed in boxes.

\section{A.1.1 Mass Balance}

The mass transfer equation for the bed is derived from the integral mass balance as

$$
\frac{\partial \mathrm{C}}{\partial \mathrm{t}}+\nabla \cdot(\overrightarrow{\mathrm{Cv}})=\frac{\mathrm{S}_{\mathrm{H}_{2}}}{\varepsilon}
$$

where: $\quad \mathrm{S}_{\mathrm{H}_{2}}=$ Rate of $\mathrm{H}_{2}$ generation per volume of bed [mole $\mathrm{H}_{2} /\left(\mathrm{m}^{3}-\mathrm{s}\right)$ ]

$\varepsilon=$ Void fraction (porosity) of particle bed

$\overrightarrow{\mathrm{v}}=$ Mean interstitial $\mathrm{H}_{2}$ velocity $[\mathrm{m} / \mathrm{s}]$

$\mathrm{C}_{\mathrm{nd}}=$ The non-dimensionalized concentration of $\mathrm{H}_{2}=\frac{\mathrm{C}}{\mathrm{C}_{\mathrm{ref}}}$

$\mathrm{C}=$ Concentration of $\mathrm{H}_{2}$ in the void space of the bed [mole $\left./ \mathrm{m}^{3}\right]$.

$\mathrm{C}_{\text {ref }}=$ The reference $\mathrm{H}_{2}$ concentration in the void space, $\mathrm{C}_{\text {ref }}\left[\mathrm{mole} / \mathrm{m}^{3}\right.$ ]

$\nabla=$ Gradient $[1 / \mathrm{m}]$.

For a sodium alanate bed the $\mathrm{H}_{2}$ uptake reaction consists of two steps following the chemical balance equation

$$
\underbrace{\mathrm{NaAlH}_{4}}_{\text {Species1 }} \underbrace{\leftrightarrow}_{\text {Re action 1 }} \underbrace{\frac{1}{3} \mathrm{Na}_{3} \mathrm{AlH}_{6}}_{\text {Species 2 }}+\frac{2}{3} \mathrm{Al}+\mathrm{H}_{2} \underbrace{\leftrightarrow}_{\text {Re action 2 }} \underbrace{\mathrm{NaH}}_{\text {Species3 }}+\mathrm{Al}+\frac{3}{2} \mathrm{H}_{2}
$$

For this case $\mathrm{S}_{\mathrm{H}_{2}}$ takes the form

$\mathrm{S}_{\mathrm{H}_{2}}=\left.\frac{v_{\mathrm{H}_{2}}}{v_{\mathrm{NaH}}}\right|_{\mathrm{Rxn} 2} \frac{\partial \mathrm{C}_{\mathrm{NaH}}}{\partial \mathrm{t}}-\left.\frac{v_{\mathrm{H}_{2}}}{v_{\mathrm{NaAlH}_{4}}}\right|_{\mathrm{Rxn} 1} \frac{\partial \mathrm{C}_{\mathrm{NaAlH}_{4}}}{\partial \mathrm{t}}$

where: $\left.\frac{v_{\mathrm{H}_{2}}}{v_{\mathrm{NaH}}}\right|_{\mathrm{Rxn} 2}=$ Ratio of the stoichiometric coefficient of $\mathrm{H}_{2}$ to $\mathrm{NaH}$ in reaction $2=0.5$

$$
\begin{aligned}
\left.\frac{v_{\mathrm{H}_{2}}}{v_{\mathrm{NaAlH}_{4}}}\right|_{\mathrm{Rxnl}} & =\text { Ratio of the stoichiometric coefficient of } \mathrm{H}_{2} \text { to } \mathrm{NaAlH}_{4} \text { in reaction } 1=1 \\
\mathrm{C}_{\mathrm{NaH}} & =\text { The bulk concentration of } \mathrm{NaH}\left[\mathrm{mole} / \mathrm{m}^{3}\right] \\
\mathrm{C}_{\mathrm{NaAlH}_{4}} & =\text { The bulk concentration of } \mathrm{NaAlH}_{4}\left[\mathrm{~mole} / \mathrm{m}^{3}\right] .
\end{aligned}
$$

Divide Eq. A.1.1-1 by the reference $\mathrm{H}_{2}$ concentration, $\mathrm{C}_{\text {ref }}\left[\mathrm{mole} / \mathrm{m}^{3}\right]$ 
$\frac{\partial \mathrm{C}_{\mathrm{nd}}}{\partial \mathrm{t}}+\nabla \cdot\left(\mathrm{C}_{\mathrm{nd}} \overrightarrow{\mathrm{v}}\right)=\frac{1}{\mathrm{C}_{\mathrm{ref}}}\left(\frac{\mathrm{S}_{\mathrm{H}_{2}}}{\varepsilon}\right)$

where: $\quad \mathrm{C}_{\mathrm{nd}}=$ The non-dimensionalized concentration of $\mathrm{H}_{2}=\frac{\mathrm{C}}{\mathrm{C}_{\mathrm{ref}}}$.

\section{A.1.2 Momentum Balance}

The momentum balance, which gives the components of the mean interstitial velocity, is simply the Blake-Kozeny equation, see Bird, Stewart and Lightfoot [1960]. Hence,

$$
\begin{aligned}
& \mathrm{u}=-\frac{\mathrm{D}_{\mathrm{p}}{ }^{2}}{150 \mu}\left(\frac{\varepsilon}{1-\varepsilon}\right)^{2} \frac{\partial \mathrm{P}}{\partial \mathrm{x}} \\
& \mathrm{v}=-\frac{\mathrm{D}_{\mathrm{p}}{ }^{2}}{150 \mu}\left(\frac{\varepsilon}{1-\varepsilon}\right)^{2} \frac{\partial \mathrm{P}}{\partial \mathrm{y}} \\
& \mathrm{w}=-\frac{\mathrm{D}_{\mathrm{p}}{ }^{2}}{150 \mu}\left(\frac{\varepsilon}{1-\varepsilon}\right)^{2} \frac{\partial \mathrm{P}}{\partial \mathrm{z}}
\end{aligned}
$$

Divide by $\mathrm{U}_{\text {ref }}$ to non-dimensionalize the components of velocity in Eqs. A.1.2-1

$$
\begin{aligned}
& \mathrm{u}_{\mathrm{nd}}=-\frac{\mathrm{D}_{\mathrm{p}}^{2}}{150 \mu}\left(\frac{\varepsilon}{1-\varepsilon}\right)^{2} \frac{\mathrm{P}_{\mathrm{ref}}}{\mathrm{U}_{\mathrm{ref}}} \frac{\partial \mathrm{P}_{\mathrm{nd}}}{\partial \mathrm{x}} \\
& \mathrm{v}_{\mathrm{nd}}=-\frac{\mathrm{D}_{\mathrm{p}}^{2}}{150 \mu}\left(\frac{\varepsilon}{1-\varepsilon}\right)^{2} \frac{\mathrm{P}_{\text {ref }}}{\mathrm{U}_{\text {ref }}} \frac{\partial \mathrm{P}_{\mathrm{nd}}}{\partial \mathrm{y}} \\
& \mathrm{w}_{\mathrm{nd}}=-\frac{\mathrm{D}_{\mathrm{p}}{ }^{2}}{150 \mu}\left(\frac{\varepsilon}{1-\varepsilon}\right)^{2} \frac{\mathrm{P}_{\mathrm{ref}}}{\mathrm{U}_{\text {ref }}} \frac{\partial \mathrm{P}_{\mathrm{nd}}}{\partial \mathrm{z}}
\end{aligned}
$$

where: $\quad U_{\text {ref }}=$ Reference velocity $[\mathrm{m} / \mathrm{s}]$

$$
\begin{aligned}
\mathrm{u}_{\mathrm{nd}} & =\frac{\mathrm{u}}{\mathrm{U}_{\mathrm{ref}}}=\text { Non-dimensional x-component of velocity } \\
\mathrm{v}_{\mathrm{nd}} & =\frac{\mathrm{v}}{\mathrm{U}_{\mathrm{ref}}}=\text { Non-dimensional y-component of velocity } \\
\mathrm{w}_{\mathrm{nd}} & =\frac{\mathrm{w}}{\mathrm{U}_{\mathrm{ref}}}=\text { Non-dimensional z-component of velocity } \\
\mathrm{P}_{\mathrm{ref}} & =\text { Reference pressure }[\mathrm{Pa}] \\
\mathrm{P}_{\mathrm{nd}} & =\frac{\mathrm{P}}{\mathrm{P}_{\mathrm{ref}}}=\text { Non-dimensional pressure }
\end{aligned}
$$




\section{A.1.3 Energy Balance}

In integral form, the energy balance for the bed is

$$
\begin{aligned}
& \frac{\partial}{\partial \mathrm{t}} \int_{\mathrm{V}}\left[\varepsilon(\rho \mathrm{l})_{\mathrm{H}_{2}}+(\rho \mathrm{l})_{\mathrm{R}}+(\rho \mathrm{l})_{\mathrm{P}}+(\rho \mathrm{l})_{\mathrm{I}}\right] \mathrm{dV}+\frac{\partial}{\partial \mathrm{t}} \int_{\mathrm{V}}\left[\varepsilon \rho_{\mathrm{H}_{2}} \frac{(\overrightarrow{\mathrm{v}} \cdot \overrightarrow{\mathrm{v}})}{2}\right] \mathrm{dV} \\
& =-\int_{\mathrm{S}}\left[\varepsilon(\rho \mathrm{l})_{\mathrm{H}_{2}} \overrightarrow{\mathrm{v}} \cdot \hat{\mathrm{n}}\right] \mathrm{dS}-\int_{\mathrm{S}}\left[\varepsilon \rho_{\mathrm{H}_{2}} \frac{(\overrightarrow{\mathrm{v}} \cdot \overrightarrow{\mathrm{v}})}{2} \overrightarrow{\mathrm{V}} \cdot \hat{\mathrm{n}}\right] \mathrm{dS}+\int_{\mathrm{S}}[\varepsilon \hat{\mathrm{n}} \cdot \underline{\underline{\tau}} \cdot \overrightarrow{\mathrm{v}}] \mathrm{dS}+\int_{\mathrm{V}} \varepsilon\left(\rho_{\mathrm{H}_{2}} \overrightarrow{\mathrm{g}} \cdot \overrightarrow{\mathrm{v}}\right) \mathrm{dV} \\
& -\int_{\mathrm{S}}[\overrightarrow{\mathrm{q}} " \hat{\mathrm{n}}] \mathrm{dS}-\int_{\mathrm{S}}[\varepsilon \mathrm{P} \overrightarrow{\mathrm{v}} \cdot \hat{\mathrm{n}}] \mathrm{dS}
\end{aligned}
$$

$$
\text { where: } \begin{aligned}
\mathbf{l} & =\text { Specific internal energy }[\mathrm{J} / \mathrm{kg}] \\
\rho & =\text { Mass density }\left[\mathrm{kg} / \mathrm{m}^{3}\right] \\
()_{\mathrm{H}_{2}} & =\text { For } \mathrm{H}_{2} \text { gas } \\
()_{\mathrm{R}} & =\text { For solid phase reactants } \\
()_{\mathrm{P}} & =\text { For solid phase products } \\
()_{\mathrm{I}} & =\text { For inert (non-reacting) material, such as metal foam } \\
\hat{\mathrm{n}} & =\text { Outward normal to surface } \\
\mathrm{S} & =\text { Surface area }\left[\mathrm{m}^{2}\right] \\
\mathrm{V} & =\text { Volume }\left[\mathrm{m}^{3}\right] \\
\tau & =\text { Stress tensor, having components } \tau_{\mathrm{ij}}\left[\mathrm{N} / \mathrm{m}^{2}\right] \\
\overrightarrow{\mathrm{g}} & =\text { Gravitational acceleration vector }\left[\mathrm{m} / \mathrm{s}^{2}\right] \\
\overrightarrow{\mathrm{q}} " & =\text { Heat flux vector }\left[\mathrm{W} / \mathrm{m}^{2}\right] \\
\mathrm{P} & =\text { Pressure }[\mathrm{Pa}]
\end{aligned}
$$

In differential form, with constant $\varepsilon$, Eq. A.1.3-1 becomes

$$
\begin{aligned}
& \varepsilon \frac{\partial(\rho \mathrm{r})_{\mathrm{H}_{2}}}{\partial \mathrm{t}}+\frac{\varepsilon}{2} \frac{\partial(\overrightarrow{\rho \mathrm{v}} \cdot \overrightarrow{\mathrm{v}})_{\mathrm{H}_{2}}}{\partial \mathrm{t}}+\frac{\partial(\rho \mathrm{l})_{\mathrm{R}}}{\partial \mathrm{t}}+\frac{\partial(\rho \mathrm{l})_{\mathrm{P}}}{\partial \mathrm{t}}+\frac{\partial(\rho \mathrm{l})_{\mathrm{I}}}{\partial \mathrm{t}} \\
& =-\varepsilon \nabla \cdot\left[(\rho \mathrm{l})_{\mathrm{H}_{2}} \overrightarrow{\mathrm{v}}\right]-\frac{\varepsilon}{2} \nabla \cdot\left[\rho_{\mathrm{H}_{2}}(\overrightarrow{\mathrm{v}} \cdot \overrightarrow{\mathrm{v}}) \overrightarrow{\mathrm{v}}\right]+\varepsilon \nabla \cdot(\underline{\tau} \cdot \overrightarrow{\mathrm{v}})+\varepsilon \rho_{\mathrm{H}_{2}} \overrightarrow{\mathrm{g}} \cdot \overrightarrow{\mathrm{v}}-\nabla \cdot \overrightarrow{\mathrm{q}} "-\varepsilon \nabla \cdot(\overrightarrow{\mathrm{Pv}})
\end{aligned}
$$

The equation for $\mathrm{H}_{2}$ continuity is

$$
\varepsilon \frac{\partial \rho_{\mathrm{H}_{2}}}{\partial \mathrm{t}}=-\varepsilon \nabla \cdot\left(\rho_{\mathrm{H}_{2}} \overrightarrow{\mathrm{v}}\right)+\mathrm{S}_{\mathrm{H}_{2}}
$$

Substitute Eq. A.1.3-3 into Eq. A.1.3-2 and rearrange terms

By definition

$\mathrm{h}=\mathrm{\imath}+\frac{\mathrm{P}}{\rho}$

where: $\quad \mathrm{S}_{\mathrm{H}_{2}}=$ Source of $\mathrm{H}_{2}$ from all chemical reactions, 


$$
\begin{array}{r}
\mathrm{S}_{\mathrm{H}_{2}}>0 \text { if } \mathrm{H}_{2} \text { is produced } \\
\mathrm{S}_{\mathrm{H}_{2}}<0 \text { if } \mathrm{H}_{2} \text { is removed } \\
\mathrm{h}=\text { Specific enthalpy }[\mathrm{J} / \mathrm{kg}]
\end{array}
$$

Substitute Eqs. A.1.3-3 and A.1.3-4 into Eq. A.1.3-2 to get

$$
\begin{aligned}
& \varepsilon \frac{\partial(\rho \mathrm{h})_{\mathrm{H}_{2}}}{\partial \mathrm{t}}+\frac{\varepsilon}{2} \frac{\partial(\rho \mathrm{v} \cdot \overrightarrow{\mathrm{v}})_{\mathrm{H}_{2}}}{\partial \mathrm{t}}+\frac{\partial(\rho \mathrm{h})_{\mathrm{R}}}{\partial \mathrm{t}}+\frac{\partial(\rho \mathrm{h})_{\mathrm{P}}}{\partial \mathrm{t}}+\frac{\partial(\rho \mathrm{h})_{\mathrm{I}}}{\partial \mathrm{t}}-\frac{\partial \mathrm{P}}{\partial \mathrm{t}} \\
& =-\varepsilon \nabla \cdot\left[(\rho \mathrm{\rho h})_{\mathrm{H}_{2}} \overrightarrow{\mathrm{v}}\right]-\frac{\varepsilon}{2} \nabla \cdot[\rho(\overrightarrow{\mathrm{v}} \cdot \overrightarrow{\mathrm{v}}) \overrightarrow{\mathrm{v}}]+\varepsilon \nabla \cdot(\underline{\tau} \cdot \overrightarrow{\mathrm{v}})+\varepsilon \rho_{\mathrm{H}_{2}} \overrightarrow{\mathrm{g}} \cdot \overrightarrow{\mathrm{v}}-\nabla \cdot \overrightarrow{\mathrm{q}} " \\
& =-\varepsilon \mathrm{h}_{\mathrm{H}_{2}} \nabla \cdot\left(\rho_{\mathrm{H}_{2}} \overrightarrow{\mathrm{v}}\right)-\varepsilon\left(\rho_{\mathrm{H}_{2}} \overrightarrow{\mathrm{v}}\right) \cdot \nabla \mathrm{h}_{\mathrm{H}_{2}}-\frac{\varepsilon}{2}(\overrightarrow{\mathrm{v}} \cdot \overrightarrow{\mathrm{v}}) \nabla \cdot\left[\rho_{\mathrm{H}_{2}} \overrightarrow{\mathrm{v}}\right]-\frac{\varepsilon}{2}\left(\rho_{\mathrm{H}_{2}} \overrightarrow{\mathrm{v}}\right) \cdot \nabla[\overrightarrow{\mathrm{v}} \cdot \overrightarrow{\mathrm{v}}] \\
& +\varepsilon \nabla \cdot(\underline{\tau} \cdot \overrightarrow{\mathrm{v}})+\varepsilon \rho_{\mathrm{H}_{2}} \overrightarrow{\mathrm{g}} \cdot \overrightarrow{\mathrm{v}}-\nabla \cdot \overrightarrow{\mathrm{q}} " \\
& =\varepsilon\left[\mathrm{h}_{\mathrm{H}_{2}}+\frac{(\overrightarrow{\mathrm{v}} \cdot \overrightarrow{\mathrm{v}})}{2}\right] \frac{\partial \rho_{\mathrm{H}_{2}}}{\partial \mathrm{t}}-\varepsilon\left(\rho_{\mathrm{H}_{2}} \overrightarrow{\mathrm{v}}\right) \cdot \nabla \mathrm{h}_{\mathrm{H}_{2}}-\frac{\varepsilon}{2}\left(\rho_{\mathrm{H}_{2}} \overrightarrow{\mathrm{v}}\right) \cdot \nabla[\overrightarrow{\mathrm{v}} \cdot \overrightarrow{\mathrm{v}}]+\varepsilon \nabla \cdot(\underline{\underline{\tau}} \cdot \overrightarrow{\mathrm{v}}) \\
& +\varepsilon \rho_{\mathrm{H}_{2}} \overrightarrow{\mathrm{g}} \cdot \overrightarrow{\mathrm{v}}-\nabla \cdot \overrightarrow{\mathrm{q}}^{\prime \prime}-\mathrm{S}_{\mathrm{H}_{2}}\left(\mathrm{~h}_{\mathrm{H}_{2}}+\frac{(\overrightarrow{\mathrm{v}} \cdot \overrightarrow{\mathrm{v}})}{2}\right)
\end{aligned}
$$

Expand the right hand side of Eq. A.1.3-5, neglect inert, ( ) $)_{\mathrm{I}}$, components and rearrange terms

$$
\begin{aligned}
& \varepsilon \rho_{\mathrm{H}_{2}}\left(\frac{\partial \mathrm{h}_{\mathrm{H}_{2}}}{\partial \mathrm{t}}+\frac{1}{2} \frac{\partial(\overrightarrow{\mathrm{v}} \cdot \overrightarrow{\mathrm{v}})}{\partial \mathrm{t}}\right)+\rho_{\mathrm{R}} \frac{\partial \mathrm{h}_{\mathrm{R}}}{\partial \mathrm{t}}+\mathrm{h}_{\mathrm{R}} \frac{\partial \rho_{\mathrm{R}}}{\partial \mathrm{t}}+\rho_{\mathrm{P}} \frac{\partial \mathrm{h}_{\mathrm{P}}}{\partial \mathrm{t}}+\mathrm{h}_{\mathrm{P}} \frac{\partial \rho_{\mathrm{P}}}{\partial \mathrm{t}}+\mathrm{S}_{\mathrm{H}_{2}}\left(\mathrm{~h}_{\mathrm{H}_{2}}+\frac{(\overrightarrow{\mathrm{v}} \cdot \overrightarrow{\mathrm{v}})}{2}\right)-\frac{\partial \mathrm{P}}{\partial \mathrm{t}} \\
& =-\varepsilon\left(\rho_{\mathrm{H}_{2}} \overrightarrow{\mathrm{v}}\right) \cdot \nabla \mathrm{h}_{\mathrm{H}_{2}}-\frac{\varepsilon}{2}\left(\rho_{\mathrm{H}_{2}} \overrightarrow{\mathrm{v}}\right) \cdot \nabla[\overrightarrow{\mathrm{v}} \cdot \overrightarrow{\mathrm{v}}]+\varepsilon \nabla \cdot(\tau \cdot \overrightarrow{\mathrm{v}})+\varepsilon \rho_{\mathrm{H}_{2}} \overrightarrow{\mathrm{g}} \cdot \overrightarrow{\mathrm{v}}-\nabla \cdot \overrightarrow{\mathrm{q}} "
\end{aligned}
$$

Now the reaction mass balance

[Rate of change in mass of reactants] $=$ [Rate of change in mass of products]

is

$$
\frac{\partial \rho_{\mathrm{R}}}{\partial \mathrm{t}}=-\left[\frac{\partial \rho_{\mathrm{P}}}{\partial \mathrm{t}}+\mathrm{S}_{\mathrm{H}_{2}}\right]
$$

So that

$\mathrm{h}_{\mathrm{R}} \frac{\partial \rho_{\mathrm{R}}}{\partial \mathrm{t}}+\mathrm{h}_{\mathrm{P}} \frac{\partial \rho_{\mathrm{P}}}{\partial \mathrm{t}}+\mathrm{S}_{\mathrm{H}_{2}} \mathrm{~h}_{\mathrm{H}_{2}}=\sum_{\mathrm{i}}\left[\frac{1}{\mathrm{M}_{\mathrm{i}}} \frac{\partial \rho_{\mathrm{i}}}{\partial \mathrm{t}} \Delta \mathrm{H}_{\mathrm{i}}\right]$

where: $\quad \mathrm{M}_{\mathrm{i}}=$ Molecular weight of species i per mole $[\mathrm{kg} / \mathrm{g}$-mole $]$

$\rho_{\mathrm{i}}=$ Mass density of species $\mathrm{i}\left[\mathrm{kg} / \mathrm{m}^{3}\right]$

$\Delta \mathrm{H}_{\mathrm{i}}=$ Enthalpy of reaction on a molar basis of species $\mathrm{i}[\mathrm{J} /(\mathrm{mol}$ of $\mathrm{i})]$

Substitute Eq. A.1.3-8 into Eq. A.1.3-6 to obtain the total energy balance as 


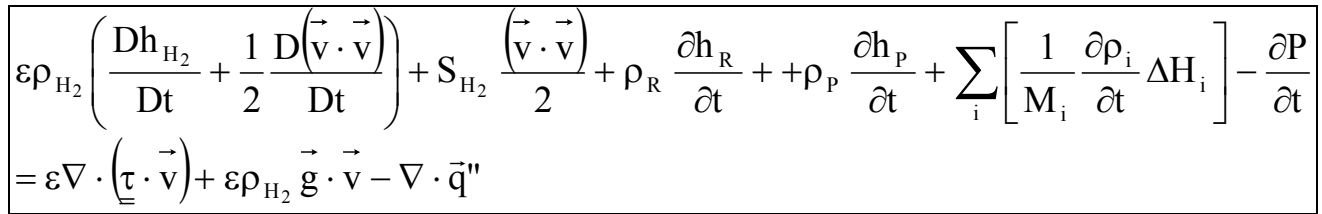

Where $\frac{D()}{D t}$ is the substantial or material derivative, having the operator form $\frac{\partial()}{\partial t}+\vec{v} \cdot \nabla()$.

The momentum balance for the packed bed is

$$
\begin{aligned}
\varepsilon \frac{\partial\left(\rho_{\mathrm{H}_{2}} \overrightarrow{\mathrm{v}}\right)}{\partial \mathrm{t}} & =-\varepsilon \nabla \mathrm{P}-\varepsilon \nabla \cdot\left[\overrightarrow{\mathrm{v}}\left(\rho_{\mathrm{H}_{2}} \overrightarrow{\mathrm{v}}\right)\right]+\varepsilon \nabla \cdot \underline{=}+\varepsilon \rho \overrightarrow{\mathrm{g}} \\
& =-\varepsilon \nabla \mathrm{P}-\varepsilon \overrightarrow{\mathrm{v}} \nabla \cdot\left(\rho_{\mathrm{H}_{2}} \overrightarrow{\mathrm{v}}\right)-\varepsilon\left(\rho_{\mathrm{H}_{2}} \overrightarrow{\mathrm{v}}\right) \cdot \nabla \overrightarrow{\mathrm{v}}+\varepsilon \nabla \cdot \underline{\underline{\tau}}+\varepsilon \rho \overrightarrow{\mathrm{g}}
\end{aligned}
$$

Apply the continuity equation, Eq. A.1.3-3, to Eq. A.1.3-10, and the momentum balance is

$$
\varepsilon \rho_{\mathrm{H}_{2}} \frac{\mathrm{D} \overrightarrow{\mathrm{v}}}{\mathrm{Dt}}+\overrightarrow{\mathrm{v}} \mathrm{S}_{\mathrm{H}_{2}}=-\varepsilon \nabla \mathrm{P}+\varepsilon \nabla \cdot \underline{\underline{\tau}}+\varepsilon \rho \overrightarrow{\mathrm{g}}
$$

Apply $\overrightarrow{\mathrm{V}} \cdot \|$ to Eq. A.1.3-11 to obtain the mechanical energy balance as

$$
\frac{\varepsilon \rho_{\mathrm{H}_{2}}}{2} \frac{\mathrm{D}(\overrightarrow{\mathrm{v}} \cdot \overrightarrow{\mathrm{v}})}{\mathrm{Dt}}+(\overrightarrow{\mathrm{v}} \cdot \overrightarrow{\mathrm{v}}) \mathrm{S}_{\mathrm{H}_{2}}=-\varepsilon \overrightarrow{\mathrm{v}} \cdot \nabla \mathrm{P}+\varepsilon \overrightarrow{\mathrm{v}} \cdot(\nabla \cdot \underline{\underline{\tau}})+\varepsilon \rho \overrightarrow{\mathrm{g}} \cdot \overrightarrow{\mathrm{v}}
$$

Where

$$
\overrightarrow{\mathrm{v}} \cdot(\nabla \cdot \underset{=}{\tau})=\mathrm{v}_{\mathrm{j}} \frac{\partial \tau_{\mathrm{ij}}}{\partial \mathrm{x}_{\mathrm{i}}} \quad \text { (summation convention) }
$$

Subtract the mechanical energy balance, Eq. A.1.3-12, from the energy balance, Eq. A.1.3-9, using Eq. A.1.3-13, to get the thermal energy balance

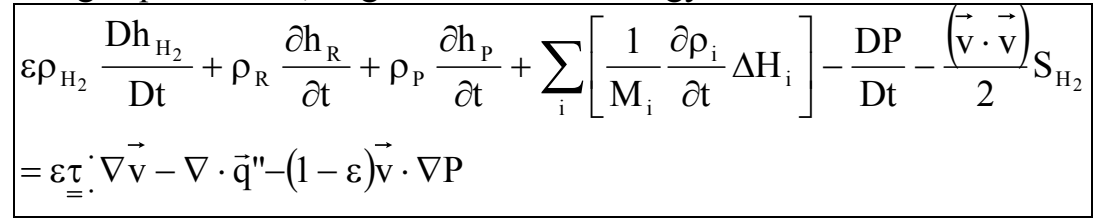

From

$\mathrm{dh}=\left.\frac{\partial \mathrm{h}}{\partial \mathrm{T}}\right|_{\mathrm{P}} \mathrm{dT}+\left.\frac{\partial \mathrm{h}}{\partial \mathrm{P}}\right|_{\mathrm{T}} \mathrm{dP}$

The substantial derivative is

$\frac{\mathrm{Dh}}{\mathrm{Dt}}=\left.\frac{\partial \mathrm{h}}{\partial \mathrm{T}}\right|_{\mathrm{P}} \frac{\mathrm{DT}}{\mathrm{Dt}}+\left.\frac{\partial \mathrm{h}}{\partial \mathrm{P}}\right|_{\mathrm{T}} \frac{\mathrm{DP}}{\mathrm{Dt}}$

For $\mathrm{H}_{2}$ as an ideal gas $\mathrm{h}_{\mathrm{H}_{2}}=\mathrm{h}_{\mathrm{H}_{2}}(\mathrm{~T})$ 
$\frac{\mathrm{Dh}_{\mathrm{H}_{2}}}{\mathrm{Dt}}=\left.\frac{\partial \mathrm{h}_{\mathrm{H}_{2}}}{\partial \mathrm{T}}\right|_{\mathrm{P}} \frac{\mathrm{DT}}{\mathrm{Dt}}=\mathrm{Cp}_{\mathrm{H}_{2}} \frac{\mathrm{DT}}{\mathrm{Dt}}$

For solids assume that $\mathrm{h}_{\mathrm{H}_{2}} \approx \mathrm{h}_{\mathrm{H}_{2}}(\mathrm{~T})$, so that

$\frac{\mathrm{Dh}}{\mathrm{Dt}}=\left.\frac{\partial \mathrm{h}}{\partial \mathrm{T}}\right|_{\mathrm{P}} \frac{\mathrm{DT}}{\mathrm{Dt}}=\mathrm{Cp} \frac{\mathrm{DT}}{\mathrm{Dt}}=\mathrm{Cp}\left(\frac{\partial \mathrm{T}}{\partial \mathrm{t}}+\overrightarrow{\mathrm{v}}_{\text {solid }} \cdot \nabla \mathrm{T}\right)=\mathrm{Cp} \frac{\partial \mathrm{T}}{\partial \mathrm{t}}=\frac{\partial \mathrm{h}}{\partial \mathrm{t}}$

Substitute Eqs. A.1.3-16 and A.1.3-17 into Eq. A.1.3-14 and neglect stress work, work done by gravitational forces and the contribution of kinetic energy terms. The thermal energy balance is then

$$
\begin{aligned}
\left(\varepsilon \rho_{\mathrm{H}_{2}} \mathrm{Cp}_{\mathrm{H}_{2}}+\rho_{\mathrm{R}} \mathrm{Cp}_{\mathrm{R}}+\rho_{\mathrm{P}} \mathrm{Cp} \mathrm{p}_{\mathrm{P}}\right) \frac{\partial \mathrm{T}}{\partial \mathrm{t}} & =\frac{\partial \mathrm{P}}{\partial \mathrm{t}}+\varepsilon \overrightarrow{\mathrm{v}} \cdot \nabla \mathrm{P}+\nabla \cdot \mathrm{k} \nabla \mathrm{T} \\
& -\sum_{\mathrm{i}}\left[\frac{1}{\mathrm{M}_{\mathrm{i}}} \frac{\partial \rho_{\mathrm{i}}}{\partial \mathrm{t}} \Delta \mathrm{H}_{\mathrm{i}}\right]-\varepsilon \rho_{\mathrm{H}_{2}} \mathrm{Cp}_{\mathrm{H}_{2}} \overrightarrow{\mathrm{v}} \cdot \nabla \mathrm{T}
\end{aligned}
$$

where: $\quad \mathrm{k}=$ Bed thermal conductivity.

Non-dimensionalize Eq. A.1.3-18 by dividing by the product o the reference temperature and the reference speed, $\mathrm{T}_{\text {ref. }}$ Also, rearrange terms to put the equation into the form used by $\mathrm{COMSOL}^{\circledR}$. $\rho_{\text {bed }} \mathrm{Cp}_{\text {bed }} \frac{\partial \mathrm{T}_{\text {nd }}}{\partial \mathrm{t}}-\nabla \cdot \mathrm{k} \nabla \mathrm{T}_{\text {nd }}=-\varepsilon \rho_{\mathrm{H}_{2}} \mathrm{Cp}_{\mathrm{H}_{2}}\left(\frac{\partial \mathrm{T}_{\text {nd }}}{\partial \mathrm{t}}+\overrightarrow{\mathrm{v}} \cdot \nabla \mathrm{T}_{\mathrm{nd}}\right)+\frac{1}{\mathrm{~T}_{\mathrm{ref}}}\left(\frac{\partial \mathrm{P}}{\partial \mathrm{t}}+\varepsilon \overrightarrow{\mathrm{v}} \cdot \nabla \mathrm{P}\right)$

$$
-\frac{1}{\mathrm{~T}_{\text {ref }}}\left(\sum_{\mathrm{i}}\left[\frac{1}{\mathrm{M}_{\mathrm{i}}} \frac{\partial \rho_{\mathrm{i}}}{\partial \mathrm{t}} \Delta \mathrm{H}_{\mathrm{i}}\right]\right)
$$

where: $\quad \rho_{\text {bed }} C p_{\text {bed }}=\rho_{\mathrm{R}} C p_{\mathrm{R}}+\rho_{\mathrm{P}} \mathrm{Cp} \mathrm{p}_{\mathrm{P}}$

$$
\begin{aligned}
\mathrm{T}_{\text {ref }} & =\text { Reference temperature }[\mathrm{K}] \\
\mathrm{T}_{\mathrm{nd}} & =\frac{\mathrm{T}}{\mathrm{T}_{\text {ref }}}=\text { Non-dimensional temperature }
\end{aligned}
$$

Rewrite the heat of reaction term as

Source $=-\left(\sum_{\mathrm{i}}\left[\frac{1}{\mathrm{M}_{\mathrm{i}}} \frac{\partial \rho_{\mathrm{i}}}{\partial \mathrm{t}} \Delta \mathrm{H}_{\mathrm{i}}\right]\right)$

Substitute Eq. A.1.3-20 into Eq. A.1.3-19

$$
\begin{gathered}
\rho_{\text {bed }} \mathrm{Cp}_{\text {bed }} \frac{\partial \mathrm{T}_{\text {nd }}}{\partial \mathrm{t}}-\nabla \cdot k \nabla \mathrm{T}_{\text {nd }}=-\varepsilon \rho_{\mathrm{H}_{2}} \mathrm{Cp}_{\mathrm{H}_{2}}\left(\frac{\partial \mathrm{T}_{\text {nd }}}{\partial \mathrm{t}}+\overrightarrow{\mathrm{v}} \cdot \nabla \mathrm{T}_{\text {nd }}\right)+\frac{1}{\mathrm{~T}_{\text {ref }}}\left(\frac{\partial \mathrm{P}}{\partial \mathrm{t}}+\varepsilon \overrightarrow{\mathrm{V}} \cdot \nabla \mathrm{P}\right) \\
+\frac{1}{\mathrm{~T}_{\text {ref }}} \text { Source }
\end{gathered}
$$


WSRC-TR-2007-00440

Revision 0

\section{A.1.4 Reaction Kinetics}

\section{A.1.4.1 United Technologies Sodium Alanate Model}

The United Technologies Research Center ${ }^{\mathrm{TM}}$ (UTRC) developed an empirical kinetics model for $\mathrm{TiCl}_{3}$ catalyzed $\mathrm{NaAlH}_{4}$. For this material, the chemical reaction is

$\underbrace{\mathrm{NaAlH}_{4}}_{\text {Species1 }} \underbrace{\leftrightarrow}_{\text {Re action 1 }} \underbrace{\frac{1}{3} \mathrm{Na}_{3} \mathrm{AlH}_{6}}_{\text {Species 2 }}+\frac{2}{3} \mathrm{Al}+\mathrm{H}_{2} \underbrace{\leftrightarrow}_{\text {Re action 2 }} \underbrace{\mathrm{NaH}}_{\text {Species3 }}+\mathrm{Al}+\frac{3}{2} \mathrm{H}_{2}$

Define the expressions:

$\mathrm{r}_{1 \mathrm{~F}} \equiv \mathrm{C}_{\text {eqv }} \mathrm{A}_{1 \mathrm{~F}} \exp \left[-\frac{\mathrm{E}_{1 \mathrm{~F}}}{\mathrm{RT}}\right]\left[\frac{\mathrm{P}(\mathrm{C}, \mathrm{T})-\mathrm{P}_{\text {eq } 1}(\mathrm{~T})}{\mathrm{P}_{\text {eq } 1}(\mathrm{~T})}\right]$
$\mathrm{r}_{1 \mathrm{~B}} \equiv-\mathrm{C}_{\text {eqv }} \mathrm{A}_{1 \mathrm{~B}} \exp \left[-\frac{\mathrm{E}_{1 \mathrm{~B}}}{\mathrm{RT}}\right]\left[\frac{\mathrm{P}_{\text {eq } 1}(\mathrm{~T})-\mathrm{P}(\mathrm{C}, \mathrm{T})}{\mathrm{P}_{\text {eq } 1}(\mathrm{~T})}\right]$
$\mathrm{r}_{2 \mathrm{~F}} \equiv-\mathrm{C}_{\text {eqv }} \mathrm{A}_{2 \mathrm{~F}} \exp \left[-\frac{\mathrm{E}_{2 \mathrm{~F}}}{\mathrm{RT}}\right]\left[\frac{\mathrm{P}(\mathrm{C}, \mathrm{T})-\mathrm{P}_{\text {eq } 2}(\mathrm{~T})}{\mathrm{P}_{\text {eq } 2}(\mathrm{~T})}\right]$
$\mathrm{r}_{2 \mathrm{~B}} \equiv \mathrm{C}_{\text {eqv }} \mathrm{A}_{2 \mathrm{~B}} \exp \left[-\frac{\mathrm{E}_{2 \mathrm{~B}}}{\mathrm{RT}}\right]\left[\frac{\mathrm{P}_{\text {eq } 2}(\mathrm{~T})-\mathrm{P}(\mathrm{C}, \mathrm{T})}{\mathrm{P}_{\text {eq } 2}(\mathrm{~T})}\right]$

A.1.4.1-2a-d

where: $\quad \mathrm{C}=$ Concentration of $\mathrm{H}_{2}\left[\right.$ moles $\left./ \mathrm{m}^{3}\right]$

$\mathrm{C}_{\text {eqv }}=$ Equivalent concentration of $\mathrm{NaAlH}_{4}\left[\right.$ moles $\left./ \mathrm{m}^{3}\right]$ based on the initial concentrations of all metal species

$=\mathrm{C}_{10}+3 \mathrm{C}_{20}+\mathrm{C}_{30}$

$\mathrm{C}_{10}=$ Initial concentration of $\mathrm{NaAlH}_{4}\left[\mathrm{moles} / \mathrm{m}^{3}\right]$

$\mathrm{C}_{20}=$ Initial concentration of $\mathrm{Na}_{3} \mathrm{AlH}_{6}\left[\mathrm{moles} / \mathrm{m}^{3}\right]$

$\mathrm{C}_{30}=$ Initial concentration of $\mathrm{NaH}\left[\mathrm{moles} / \mathrm{m}^{3}\right]$

$\mathrm{P}_{\text {eq1 }}(\mathrm{T})$ and $\mathrm{P}_{\mathrm{eq} 2}(\mathrm{~T})$ are the $\mathrm{H}_{2}$ pressures, in $\mathrm{Pa}$, in equilibrium with the $\mathrm{NaAlH}_{4}$ and the $\mathrm{Na}_{3} \mathrm{AlH}_{6}$ metal hydrides, respectively, at temperature $\mathrm{T}$, in $[\mathrm{K}]$. These relations are given by the van't Hoff equations:

$\mathrm{P}_{\text {eq } 1}(\mathrm{~T})=10^{5} \exp \left[\frac{\Delta \mathrm{H}_{1}}{\mathrm{RT}}-\frac{\Delta \mathrm{S}_{1}}{\mathrm{R}}\right]$
$\mathrm{P}_{\text {eq } 2}(\mathrm{~T})=10^{5} \exp \left[\frac{\Delta \mathrm{H}_{2}}{\mathrm{RT}}-\frac{\Delta \mathrm{S}_{2}}{\mathrm{R}}\right]$

Values for the constants used in Eqs. A.1.4.1-2a-d, and A.1.4.1-3a-b are listed in Table A.1.4.1-1 
Table A.1.4.1-1

Constants for the Rate and Equilibrium Expressions

\begin{tabular}{|c|c|}
\hline Constant & Value \\
\hline \hline $\mathrm{A}_{1 \mathrm{~F}}$ & $10^{8}$ \\
\hline $\mathrm{A}_{1 \mathrm{~B}}$ & $4 \times 10^{5}$ \\
\hline $\mathrm{A}_{2 \mathrm{~F}}$ & $1.5 \times 10^{5}$ \\
\hline $\mathrm{A}_{2 \mathrm{~B}}$ & $6 \times 10^{12}$ \\
\hline $\mathrm{E}_{1 \mathrm{~F}}$ & $80.0 \mathrm{~kJ} / \mathrm{mol}$ \\
\hline $\mathrm{E}_{1 \mathrm{~B}}$ & $110.0 \mathrm{~kJ} / \mathrm{mol}$ \\
\hline $\mathrm{E}_{2 \mathrm{~F}}$ & $70.0 \mathrm{~kJ} / \mathrm{mol}$ \\
\hline $\mathrm{E}_{2 \mathrm{~B}}$ & $110.0 \mathrm{~kJ} / \mathrm{mol}$ \\
\hline$\chi_{1 \mathrm{~F}}$ & 2.0 \\
\hline$\chi_{1 \mathrm{~B}}$ & 2.0 \\
\hline$\chi_{2 \mathrm{~F}}$ & 1.0 \\
\hline$\chi_{2 \mathrm{~B}}$ & 1.0 \\
\hline$\frac{\Delta \mathrm{H}_{1}}{\mathrm{R}}$ & -4475 \\
\hline$\frac{\Delta \mathrm{S}_{1}}{\mathrm{R}}$ & -14.83 \\
\hline$\frac{\Delta \mathrm{H}_{2}}{\mathrm{R}}$ & -6150 \\
\hline$\frac{\Delta \mathrm{S}_{2}}{\mathrm{R}}$ & -16.22 \\
\hline
\end{tabular}

The reference for this model, contained in Attachment A.2, proposes the kinetics equations

$\frac{\mathrm{dC}_{1}}{\mathrm{dt}}= \begin{cases}\mathrm{r}_{1 \mathrm{~F}}\left[\frac{3 \mathrm{C}_{2}(\mathrm{t})}{\mathrm{C}_{\text {eqv }}}-\mathrm{C}_{2 \text { sat }}(\mathrm{T})\right]^{\chi_{1 \mathrm{~F}}} & \text { if } \mathrm{P} \geq \mathrm{P}_{\text {eq } 1}(\mathrm{~T}) \\ \mathrm{r}_{1 \mathrm{~B}}\left[\frac{\mathrm{C}_{1}(\mathrm{t})}{\mathrm{C}_{\text {eqv }}}\right]^{\chi_{1 \mathrm{~B}}} & \text { if } \mathrm{P}<\mathrm{P}_{\text {eq1 }}(\mathrm{T}) \text { and } \mathrm{C}_{1}(\mathrm{t}) \geq 0\end{cases}$

and

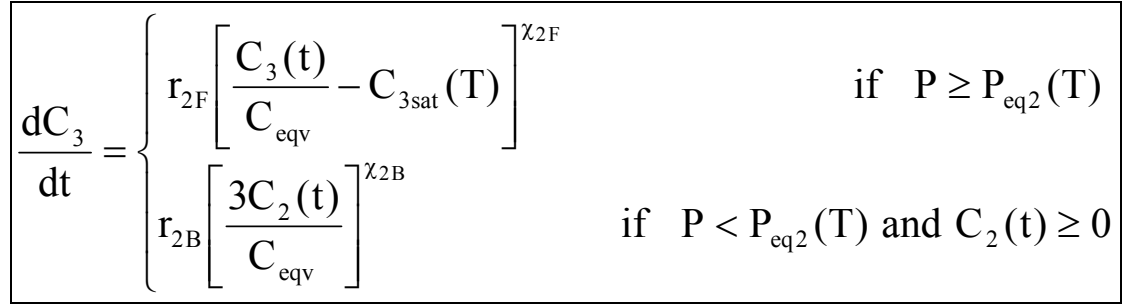

By Eq. A.1.4.1-1

$\frac{\mathrm{dC}_{2}}{\mathrm{dt}}=-\frac{1}{3}\left(\frac{\mathrm{dC}_{1}}{\mathrm{dt}}+\frac{\mathrm{dC}_{3}}{\mathrm{dt}}\right)$ or $\mathrm{C}_{2}=\mathrm{C}_{20}-\frac{1}{3}\left[\left(\mathrm{C}_{1}-\mathrm{C}_{10}\right)+\left(\mathrm{C}_{3}-\mathrm{C}_{30}\right)\right]$

A.1.4.1-4c 
where: $\quad \mathrm{C}_{1}=$ Concentration of $\mathrm{NaAlH}_{4}\left[\mathrm{moles} / \mathrm{m}^{3}\right]$

$\mathrm{C}_{2}=$ Concentration of $\mathrm{Na}_{3} \mathrm{AlH}_{6}\left[\mathrm{moles} / \mathrm{m}^{3}\right]$

$\mathrm{C}_{3}=$ Concentration of $\mathrm{NaH}\left[\right.$ moles $\left./ \mathrm{m}^{3}\right]$

Based on data for the loading of $\mathrm{NaH}$, expressions for $\mathrm{C}_{2 \text { sat }}(\mathrm{T})$ and $\mathrm{C}_{3 \text { sat }}(\mathrm{T})$, in $\left[\mathrm{moles} / \mathrm{m}^{3}\right]$, were estimated by UTRC in Attachment 1 as

$\mathrm{C}_{2 \text { sat }}(\mathrm{T})=0$

$\mathrm{C}_{3 \text { sat }}(\mathrm{T})=\mathrm{r}_{\mathrm{sat}}\left(1-\frac{\mathrm{wf}_{\text {iso }}^{\mathrm{sat}}(\mathrm{T})}{0.056}\right)$

where: $\quad \mathrm{r}_{\mathrm{sat}}=\operatorname{Max}\left[1,\left(1-\frac{0.0373}{0.056-\mathrm{wf}_{\mathrm{iso}}^{\mathrm{sat}}(\mathrm{T})}\right)\right]$

The values for $\mathrm{wf}_{\text {iso }}^{\text {sat }}(\mathrm{T})$, the saturation hydrogen weight fraction for loading at a fixed temperature T, are listed in Table A.1.4.1-2. Both the Mathcad ${ }^{\circledR}$ kinetics model, and the $\mathrm{COMSOL}^{\circledR}$ two and three-dimensional system models, use a spline fit to this data with extrapolated values fixed at the endpoints.

Table A.1.4.1-2

Values for $\mathrm{wf}_{\text {iso }}^{\text {sat }}(\mathrm{T})$

\begin{tabular}{|c|c|}
\hline $\mathbf{T}(\mathbf{K})$ & wf $_{\text {iso }}^{\text {sat }}(\mathrm{T})$ \\
\hline \hline 353.15 & 0.021 \\
\hline 363.15 & 0.023 \\
\hline 373.15 & 0.029 \\
\hline 393.15 & 0.022 \\
\hline 413.15 & 0.018 \\
\hline
\end{tabular}

The weight fraction of $\mathrm{H}_{2}$ contained in the sodium alanate metal, based on Eq. 1.4.1-1, is defined as

$$
\begin{aligned}
\text { wf } & =\frac{\text { Mass of } \mathrm{H}_{2} \text { in Metal }}{\text { Equivalent Mass of } \mathrm{NaAlH}_{4}} \\
& =\frac{\left(1.5 \mathrm{n}_{\mathrm{NaAlH}_{4}}+0.5 \mathrm{n}_{\left.\mathrm{Na}_{3} \mathrm{AlH}_{6}\right) \mathrm{M}_{\mathrm{H}_{2}}}\right.}{\left(\mathrm{n}_{\mathrm{NaAlH}_{4}}+3 \mathrm{n}_{\mathrm{Na}_{3} \mathrm{AlH}_{6}}+\mathrm{n}_{\mathrm{NaH}}\right) \mathrm{M}_{\mathrm{NaALH}_{4}}} \\
& =\frac{1.5 \mathrm{C}_{1}+0.5 \mathrm{C}_{2}}{\mathrm{C}_{\text {eqv }}} \frac{\mathrm{M}_{\mathrm{H}_{2}}}{\mathrm{M}_{\mathrm{NaALH}_{4}}}
\end{aligned}
$$

where: $\quad n_{\mathrm{NaAlH}_{4}}=$ Number of moles of $\mathrm{NaAlH}_{4}$

$$
\mathrm{n}_{\mathrm{Na}_{3} \mathrm{AlH}_{6}}=\text { Number of moles of } \mathrm{Na}_{3} \mathrm{AlH}_{6}
$$




$$
\begin{aligned}
\mathrm{n}_{\mathrm{NaH}} & =\text { Number of moles of } \mathrm{NaH} \\
\mathrm{M}_{\mathrm{NaALH}_{4}} & =\text { Gram molecular weight of } \mathrm{NaAlH}_{4}[\mathrm{~kg} / \mathrm{g}-\mathrm{mol}] \\
\mathrm{M}_{\mathrm{Na}_{3} \mathrm{AlH}_{6}} & =\text { Gram molecular weight of } \mathrm{Na}_{3} \mathrm{AlH}_{6}[\mathrm{~kg} / \mathrm{g}-\mathrm{mol}] \\
\mathrm{M}_{\mathrm{NaH}} & =\text { Gram molecular weight of } \mathrm{NaH}[\mathrm{kg} / \mathrm{g}-\mathrm{mol}] \\
\mathrm{M}_{\mathrm{H}_{2}} & =\text { Gram molecular weight of } \mathrm{H}_{2}[\mathrm{~kg} / \mathrm{g}-\mathrm{mol}]
\end{aligned}
$$

For sodium alanate, the reaction heat term for the energy balance in Eq. A.1.3-19 is Source $=\frac{\mathrm{dC}_{1}}{\mathrm{dt}} \Delta \mathrm{H}_{\mathrm{rxn} 1}-0.5 \frac{\mathrm{dC}_{3}}{\mathrm{dt}} \Delta \mathrm{H}_{\mathrm{rxn} 2}$

where by Gross [2003]:

$\Delta \mathrm{H}_{\mathrm{rxn} 1}=$ Heat of per mole of $\mathrm{H}_{2}$ consumed going to left for reaction 1 $=-37 \mathrm{~kJ} /\left(\mathrm{mol} \mathrm{H}_{2}\right)$

$\Delta \mathrm{H}_{\mathrm{rxn} 2}=$ Heat of per mole of $\mathrm{H}_{2}$ consumed going to left for reaction 2 $=-47 \mathrm{~kJ} /\left(\mathrm{mol} \mathrm{H}_{2}\right)$ 


\section{A.2 SYSTEM SCALING AND KINETICS}

\section{A.2.1 System Dimensions}

The dimensions for the $\mathrm{NaAlH}_{4}$ system modeled in this document were based on the parameters input to the Microsoft Excel ${ }^{\circledR}$ scaling tool shown in Figure A.2.1, see Hardy [2007].

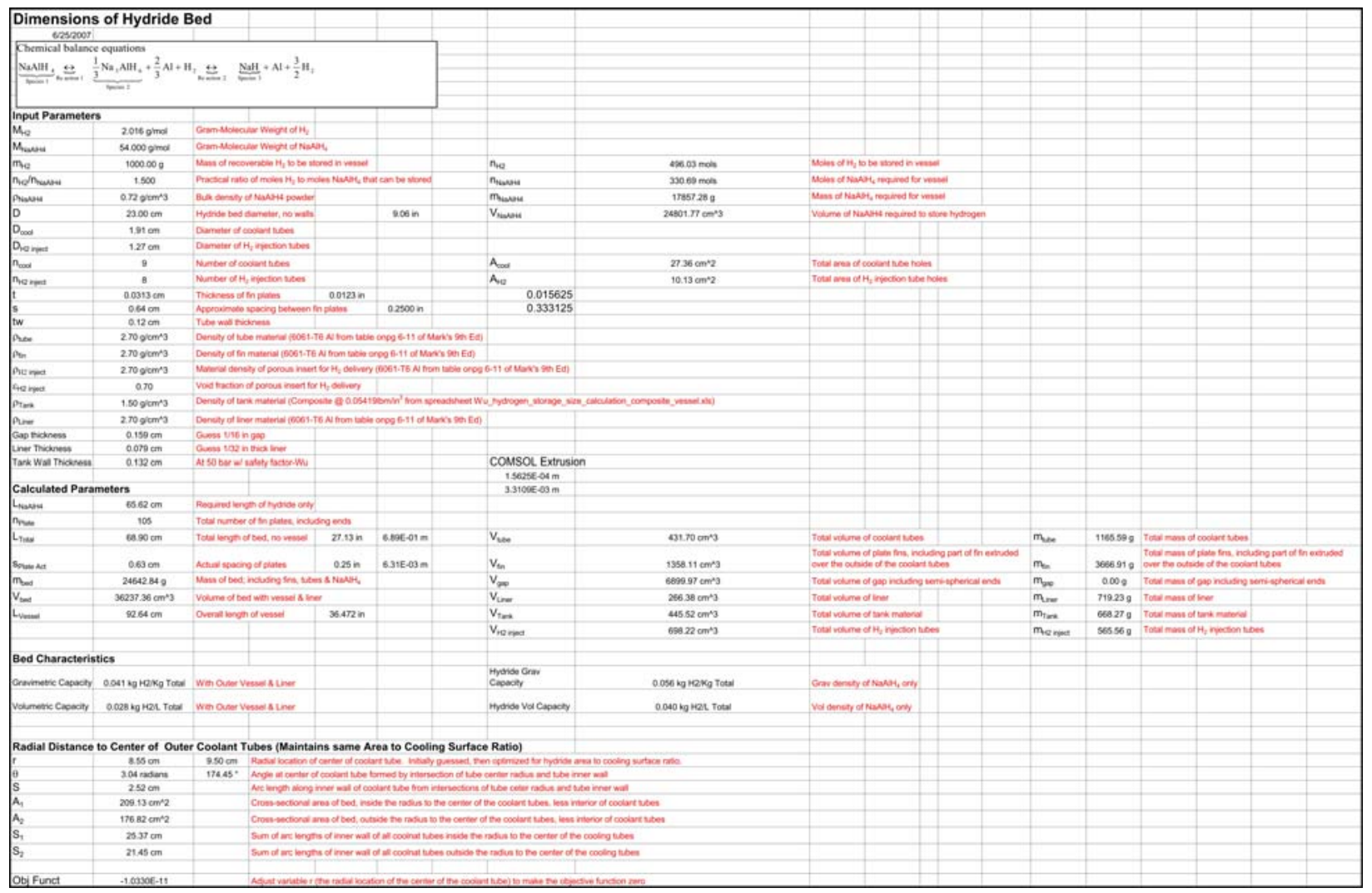

Figure A.2.1 System dimensions calculated with the scaling tool. 


\section{A.2.2 Heat Transfer Requirements For the $\mathrm{NaAlH}_{4}$ System}

Heat transfer requirements for the $\mathrm{NaAlH}_{4}$ system modeled in this document were based on calculations with the Microsoft Excel ${ }^{\circledR}$ scaling tool shown in Figure A.2.2, see Hardy [2007].

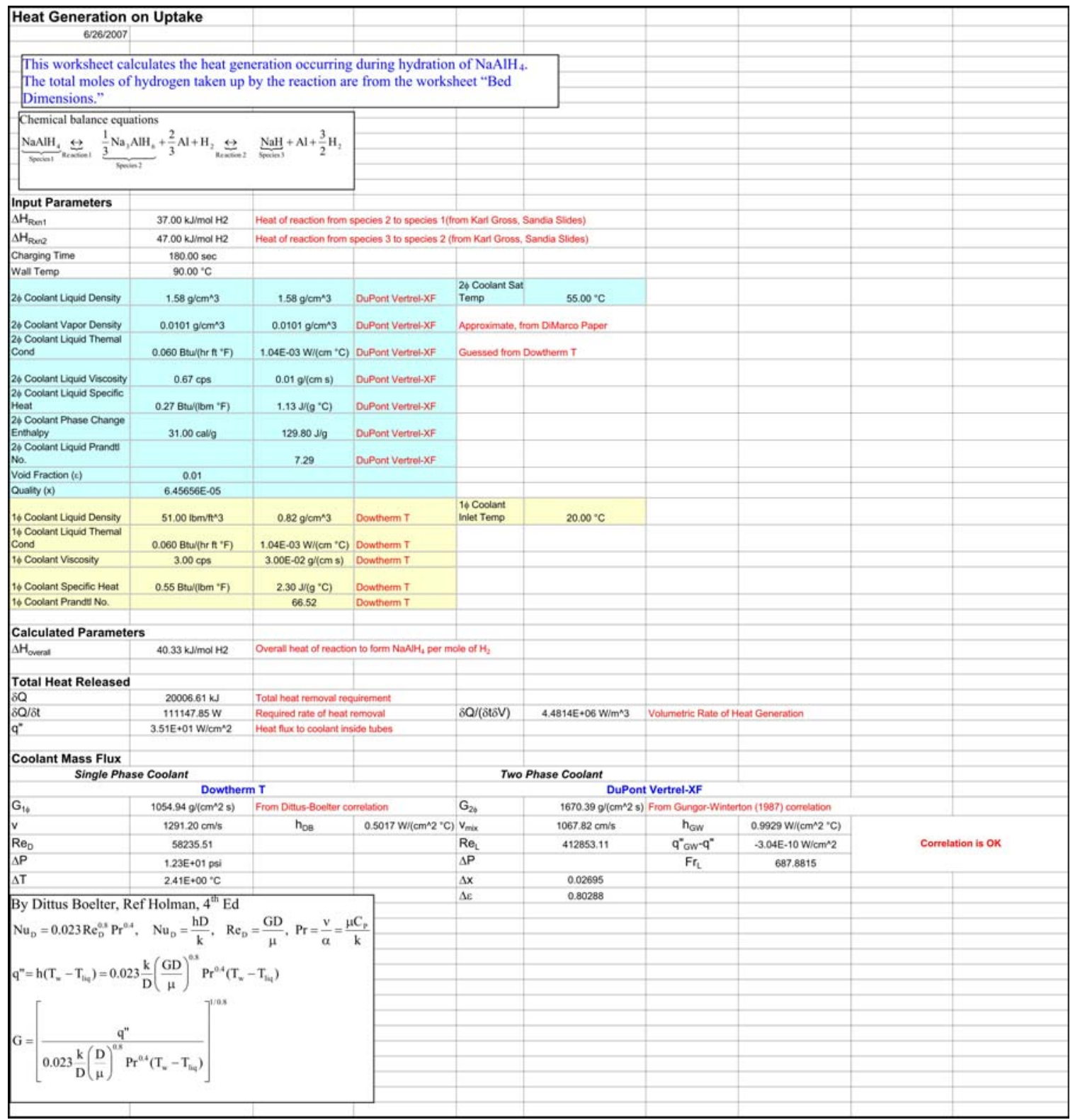

Figure A.2.2 System heat transfer parameters estimated with the scaling tool. 


\section{A.2.3 $\mathrm{NaAlH}_{4}$ Reaction Kinetics}

Chemical kinetics and bed utilization for $\mathrm{NaAlH}_{4}$ were evaluated with the model developed in Mathcad $^{\circledR}$, shown below, see Hardy [2007].

\section{Evaluation of Kinetics Model for $\mathrm{NaH}$}

\begin{tabular}{|c|}
\hline \multicolumn{1}{c|}{ Reaction } \\
$\mathrm{NaAlH}_{4} \leftrightarrow \quad 1 / 3 \mathrm{Na}_{3} \mathrm{AlH}_{6}+2 / 3 \mathrm{Al}+\mathrm{H}_{2} \leftrightarrow \quad \mathrm{NaH}+\mathrm{Al}+3 / 2 \mathrm{H}_{2}$ \\
Species 1 Rxn $1 \quad$ Species 2
\end{tabular}

Nomenclature

$\mathrm{C}_{1}=$ Concentration of $\mathrm{NaAlH}_{4}\left(\mathrm{~mol} / \mathrm{m}^{3}\right)$

$\mathrm{C}_{2}=$ Concentration of $\mathrm{Na}_{3} \mathrm{AlH}_{6}\left(\mathrm{~mol} / \mathrm{m}^{3}\right)$

$\mathrm{C}_{3}=$ Concentration of $\mathrm{NaH}\left(\mathrm{mol} / \mathrm{m}^{3}\right)$

$\mathrm{n}_{\mathrm{H} 2}=$ Moles of $\mathrm{H} 2$ taken in to the metal hydride $\left(\mathrm{mol} / \mathrm{m}^{3}\right)$

$r_{1 F}=$ Rate of formation of $\mathrm{NaAlH}_{4}$ from $\mathrm{Na}_{3} \mathrm{AlH}_{6}$ (mol/m ${ }^{3}$-sec)

$r_{1 B}=$ Rate of dissociation of $\mathrm{NaAlH}_{4}$ to $\mathrm{Na}_{3} \mathrm{AlH}_{6}\left(\mathrm{~mol} / \mathrm{m}^{3}-\mathrm{sec}\right)$

$r_{2 F}=$ Rate of formation of $\mathrm{Na}_{3} \mathrm{AlH}_{6}$ from $\mathrm{NaH}\left(\mathrm{mol} / \mathrm{m}^{3}-\mathrm{sec}\right)$

$r_{2 B}=$ Rate of dissociation of $\mathrm{Na}_{3} \mathrm{AlH}_{6}$ to $\mathrm{NaH}\left(\mathrm{mol} / \mathrm{m}^{3}-\mathrm{sec}\right)$

Tchg $:=100$

Tdisch $:=120$

Pchg $:=50 \quad$ Pressure (bar)

Pdisch $:=1 \quad$ Pressure (bar)

General Parameter Values

$\mathrm{RR}:=8.314$ Ideal gas constant $(\mathrm{J} / \mathrm{mol}-\mathrm{K})$

\section{Note that}

$\partial C_{2} / \partial t=-1 / 3\left(\partial C_{1} / \partial t+\partial C_{3} / \partial t\right)$

$\partial \mathrm{n}_{\mathrm{H} 2} / \partial \mathrm{t}=\partial \mathrm{C}_{1} / \partial \mathrm{t}-1 / 2 \partial \mathrm{C}_{3} / \partial \mathrm{t}$

and

$\partial \mathrm{C}_{1} / \partial \mathrm{t}=\mathrm{r}_{1 \mathrm{~F}}$ If $\mathrm{P}>\mathrm{Peq} 1(\mathrm{~T})$

$\partial \mathrm{C}_{1} / \partial \mathrm{t}=-\mathrm{r}_{1 \mathrm{~B}}$ If $\mathrm{P}<\mathrm{Peq} 1(\mathrm{~T})$

$\partial \mathrm{C}_{3} / \partial t=r_{2 B}$ If $\mathrm{P}<\mathrm{Peq} 1(\mathrm{~T})$

$\partial C_{3} / \partial t=-r_{2 F}$ If $P>P e q 1(T)$

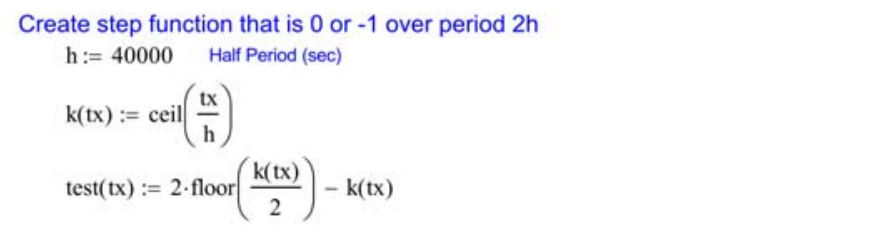


WSRC-TR-2007-00440

Revision 0

$\mathrm{P}(\mathrm{tx}):=$ if(test $(\mathrm{tx})<0$, Pchg, Pdisch) Pressure (bar)

Parameter Values (From Fit to Data)

\section{Reaction 1}

A1F $:=10^{8} \quad$ A1B $:=4 \cdot 10^{12} \quad \chi_{1 \mathrm{~F}}:=2.0 \quad \chi_{\mathrm{IB}}:=2.0$

E1F $:=8000$ activation Energy $(\mathrm{KJ} / \mathrm{mol}) \quad$ E1B $:=11000$ Activation Energy $(\mathrm{KJ} / \mathrm{mol})$

$\Delta \mathrm{H} \_\mathrm{R} 1:=-4475 \quad \Delta \mathrm{S} \_\mathrm{R} 1:=-14.83$

\section{Reaction 2}

$\mathrm{A} 2 \mathrm{~F}:=1.5 \cdot 10^{5} \quad$ A2B $:=6 \times 10^{12} \quad \chi_{2} \mathrm{~F}:=1.0 \quad \chi_{2 \mathrm{~B}}:=1.0$

E2F $:=70000 \quad$ Activation Energy $(\mathrm{J} / \mathrm{mol}) \quad$ E2B $:=110000$ Activation Energy $(\mathrm{J} / \mathrm{mol})$

$\Delta H \_R 2:=-6150 \quad \Delta S \_R 2:=-16.22$

Equilibrium Pressure (in bar?)

Reaction 1

P_eq1(TT) $:=\exp \left(\frac{\Delta H_{-} R 1}{T T+273}-\Delta S_{-} R 1\right) \quad \pi$ is Temperature in (C)

Reaction 2

P_eq2(TT) $:=\exp \left(\frac{\Delta H \_R 2}{T T+273}-\Delta S_{-} R 2\right) \quad \pi$ is Temperature in (C)
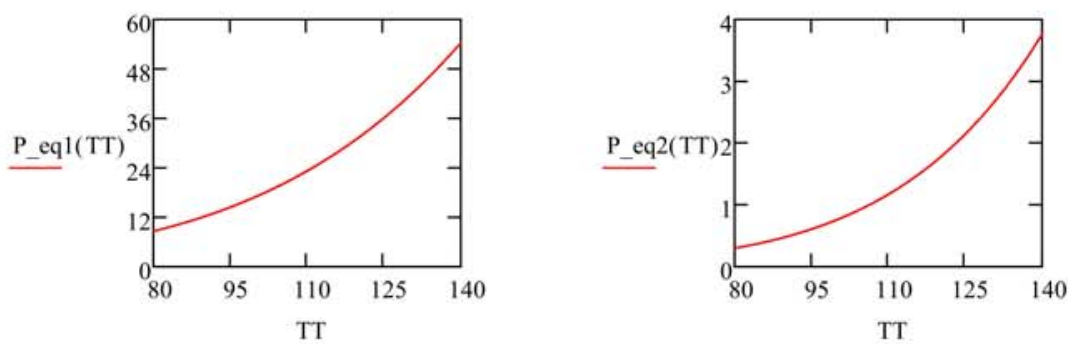

Initial Conditions

$\mathrm{C} 10:=0 \quad \mathrm{C} 20:=0 \quad \mathrm{C} 30:=330.69 \quad \mathrm{nH} 20:=0$

$\operatorname{Temp}(\mathrm{tx}):=\mathrm{if}(\operatorname{test}(\mathrm{tx})<0$, Tchg, Tdisch) $\quad$ Temperature $(\mathrm{C})$

\section{Saturation Concentrations} $\mathrm{Ceqv}:=\mathrm{C} 10+3 \cdot \mathrm{C} 20+\mathrm{C} 30 \begin{aligned} & \text { Equivalent Concentration, Needed to relate species concentrations }\left(\mathrm{mol} / \mathrm{m}^{3}\right) \text { to the } \\ & \text { non-dimensional concenrations used in calculations }\end{aligned}$

Fit the saturation weight fraction to temperature

$T \mathrm{~T}$ is in $\mathrm{C}$ 


wfdata :
\begin{tabular}{r|r|r|}
\hline & \multicolumn{1}{|c|}{0} & 1 \\
\cline { 2 - 4 } 0 & 300 & 0.021 \\
\hline 1 & 353 & 0.021 \\
\hline 2 & 353.15 & 0.021 \\
\hline 3 & 359 & 0.022 \\
\hline 4 & 363.15 & 0.023 \\
\hline 5 & 373.15 & 0.029 \\
\hline 6 & 393.15 & 0.022 \\
\hline 7 & 405 & 0.019 \\
\hline 8 & 413.15 & 0.018 \\
\hline 9 & 413.5 & 0.018 \\
\hline 10 & 600 & 0.018 \\
\hline
\end{tabular}

$\underset{\text { wfdata }}{\text { waman }}:=\operatorname{csort}($ wfdata, 0$)$

vTT $:=$ wfdata $^{\langle 0\rangle}-273.15$

TT is in C

vy $:=$ wfdata $\langle 1\rangle$

vs $:=1$ spline(vTT, vy)

wf_sat(TT) $:=$ interp(vs, vTT, vy, TT)

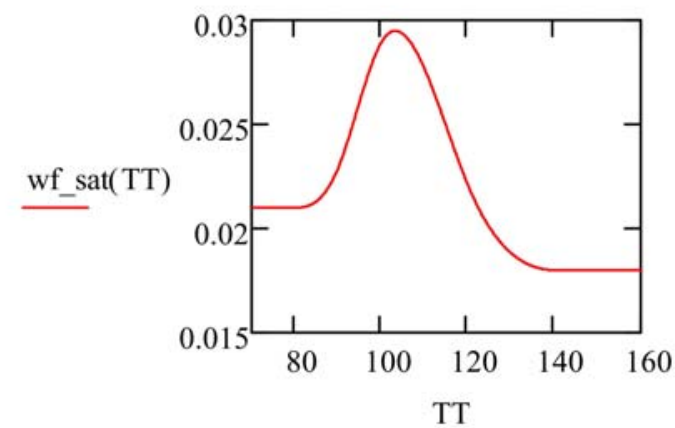

Compute the non-dimensional "saturation" concentrations from fit

$$
\begin{array}{ll}
\operatorname{rsat}(\mathrm{TT}):=\max \left(1,1-\frac{0.056-0.0187}{0.056-\mathrm{wf} \text { sat(TT) }}\right) & \text { TT is in C } \\
\text { C3sat(TT) }:=\left(1-\frac{\mathrm{wf} \text { _sat(TT) }}{0.056}\right) \cdot \operatorname{rsat}(\mathrm{TT}) & \text { TT is in C } \\
\text { C2sat(TT) }:=\frac{(1-\operatorname{rsat}(\mathrm{TT})) \cdot(0.056-\text { wf_sat(TT)) }}{(0.056-0.0187)} & \text { TT is in C }
\end{array}
$$




\section{Forward and Backward Reaction Rates}

$$
\begin{aligned}
& \mathrm{r} 1 \mathrm{~F}(\mathrm{TT}, \mathrm{tx}):=\mathrm{if}\left[\left(\mathrm{P}(\mathrm{tx}) \geq \mathrm{P} \_ \text {eq1 }(\mathrm{TT})\right), \mathrm{Ceqv} \cdot \mathrm{A} 1 \mathrm{~F} \cdot \exp \left[\frac{-\mathrm{E} 1 \mathrm{~F}}{\mathrm{RR} \cdot(\mathrm{TT}+273.15)}\right] \cdot \frac{\mathrm{P}(\mathrm{tx})-\mathrm{P} \_ \text {eq1 }(\mathrm{TT})}{\mathrm{P} \text { eq1(TT)}}, 0\right] \quad T \mathrm{~T} \text { is in C } \\
& \operatorname{r1B}(T T, t x):=\operatorname{if}\left[\left(P(t x)<P \_e q 1(T T)\right), \text { Ceqv } \cdot A 1 B \cdot \exp \left[\frac{-E 1 B}{R R \cdot(T T+273.15)}\right] \cdot\left[\frac{\left.\left(P \_ \text {eq1(TT }\right)-P(t x)\right)}{P \_ \text {_eq1(TT) }}\right], 0\right] \\
& \mathrm{r} 2 \mathrm{~F}(\mathrm{TT}, \mathrm{tx}):=\operatorname{if}\left[\left(\mathrm{P}(\mathrm{tx}) \geq \mathrm{P} \_\mathrm{eq} 2(\mathrm{TT})\right), \mathrm{Ceqv} \cdot \mathrm{A} 2 \mathrm{~F} \cdot \exp \left[\frac{-\mathrm{E} 2 \mathrm{~F}}{\mathrm{RR} \cdot(\mathrm{TT}+273.15)}\right] \cdot\left[\frac{\left(\mathrm{P}(\mathrm{tx})-\mathrm{P} \_ \text {eq2(TT) }\right)}{\left.\mathrm{P} \_ \text {eq2(TT }\right)}\right], 0\right] \\
& \mathrm{r} 2 \mathrm{~B}(\mathrm{TT}, \mathrm{tx}):=\mathrm{if}\left[\left(\mathrm{P}(\mathrm{tx})<\mathrm{P} \_\mathrm{eq} 2(\mathrm{TT})\right), \mathrm{Ceqv} \cdot \mathrm{A} 2 \mathrm{~B} \cdot \exp \left[\frac{-\mathrm{E} 2 \mathrm{~B}}{\mathrm{RR} \cdot(\mathrm{TT}+273.15)}\right] \cdot\left(\frac{\left.\mathrm{P} \_ \text {eq2(TT }\right)-\mathrm{P}(\mathrm{tx})}{\mathrm{P} \_ \text {eq2 }(\mathrm{TT})}\right), 0\right]
\end{aligned}
$$

\section{Hydrogen Concentration From Kinetics Equations}

Given

$$
\begin{aligned}
& \frac{\mathrm{d}}{\mathrm{dt}} \mathrm{C} 1(\mathrm{t})=\operatorname{r1F}(\operatorname{Temp}(\mathrm{t}), \mathrm{t}) \cdot\left(\left(\frac{3 \mathrm{C} 2(\mathrm{t})}{\operatorname{Ceqv}}-\mathrm{C} 2 \operatorname{sat}(\operatorname{Temp}(\mathrm{t}))\right)\right)^{\chi_{1 \mathrm{~F}}}-\mathrm{r} 1 \mathrm{~B}(\operatorname{Temp}(\mathrm{t}), \mathrm{t}) \cdot\left(\frac{\mathrm{C} 1(\mathrm{t})}{\mathrm{Ceqv}}\right)^{\chi_{1 B}} \\
& \frac{\mathrm{d}}{\mathrm{dt}} \mathrm{C} 2(\mathrm{t})=-\left[\frac{1}{3} \cdot\left(\frac{\mathrm{d}}{\mathrm{dt}} \mathrm{Cl}(\mathrm{t})+\frac{\mathrm{d}}{\mathrm{dt}} \mathrm{C} 3(\mathrm{t})\right)\right] \\
& \frac{\mathrm{d}}{\mathrm{dt}} \mathrm{C} 3(\mathrm{t})=-\mathrm{r} 2 \mathrm{~F}(\operatorname{Temp}(\mathrm{t}), \mathrm{t}) \cdot\left(\frac{\mathrm{C} 3(\mathrm{t})}{\mathrm{Ceqv}}-\mathrm{C} 3 \operatorname{sat}(\operatorname{Temp}(\mathrm{t}))\right)^{\chi_{2 \mathrm{~F}}}+\mathrm{r} 2 \mathrm{~B}(\operatorname{Temp}(\mathrm{t}), \mathrm{t}) \cdot\left(\frac{3 \mathrm{C} 2(\mathrm{t})}{\operatorname{Ceqv}}\right)^{\chi_{2 \mathrm{~B}}} \\
& \frac{\mathrm{d}}{\mathrm{dt}} \mathrm{nH} 2(\mathrm{t})=\frac{\mathrm{d}}{\mathrm{dt}} \mathrm{C} 1(\mathrm{t})-\frac{1}{2} \cdot\left(\frac{\mathrm{d}}{\mathrm{dt}} \mathrm{C} 3(\mathrm{t})\right) \quad \begin{array}{l}
\mathrm{nH} 2 \\
\text { are contained for release in the metal hydride }
\end{array} \\
& \mathrm{C} 1(0)=\mathrm{C} 10 \quad \mathrm{C} 2(0)=\mathrm{C} 20 \quad \mathrm{C} 3(0)=\mathrm{C} 30 \quad \mathrm{nH} 2(0)=\mathrm{nH} 20 \\
& \left(\begin{array}{c}
\mathrm{C} 1 \\
\mathrm{C} 2 \\
\mathrm{C} 3 \\
\mathrm{nH} 2
\end{array}\right):=\text { Odesolve }\left[\left(\begin{array}{c}
\mathrm{C} 1 \\
\mathrm{C} 2 \\
\mathrm{C} 3 \\
\mathrm{nH} 2
\end{array}\right), \mathrm{t}, 240000,20000\right] \quad \text { tis time in seconds }
\end{aligned}
$$


WSRC-TR-2007-00440

Revision 0

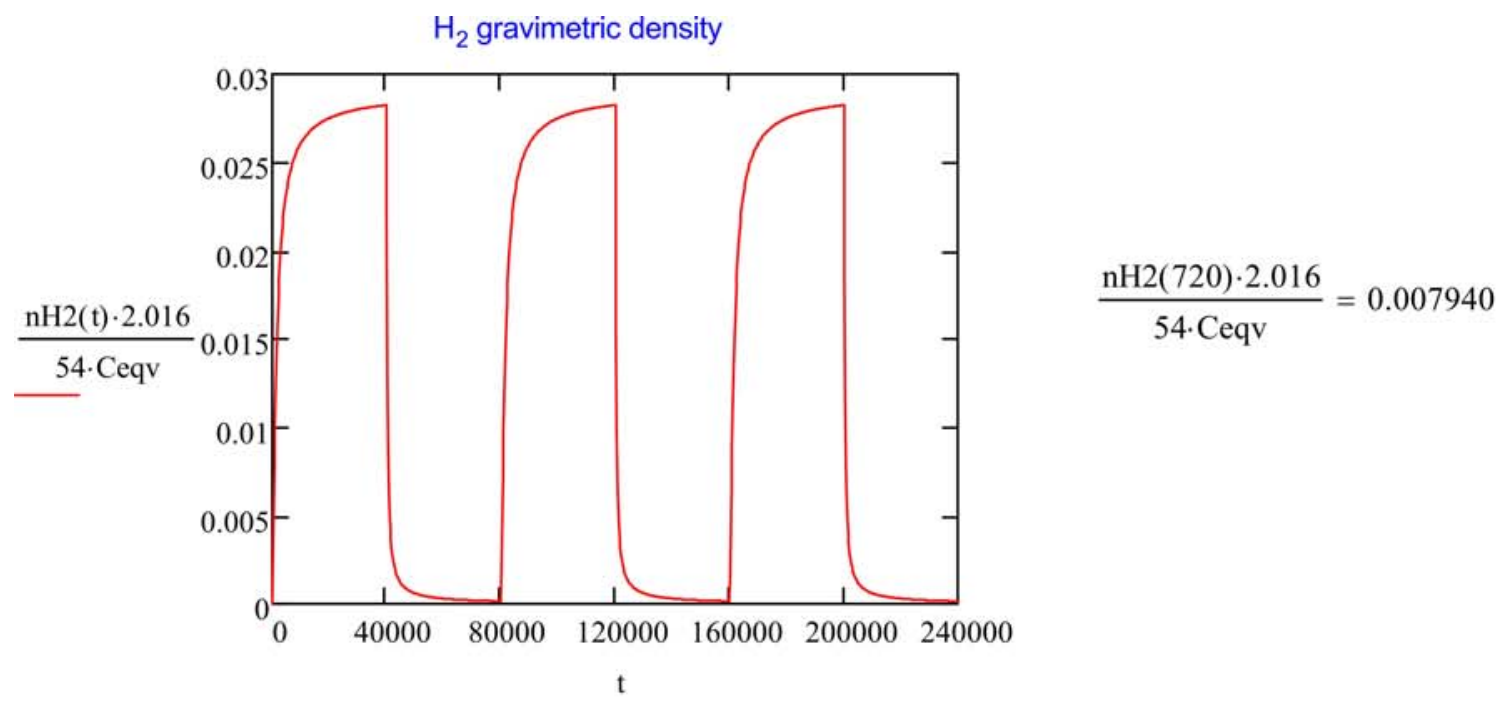

Time (s)

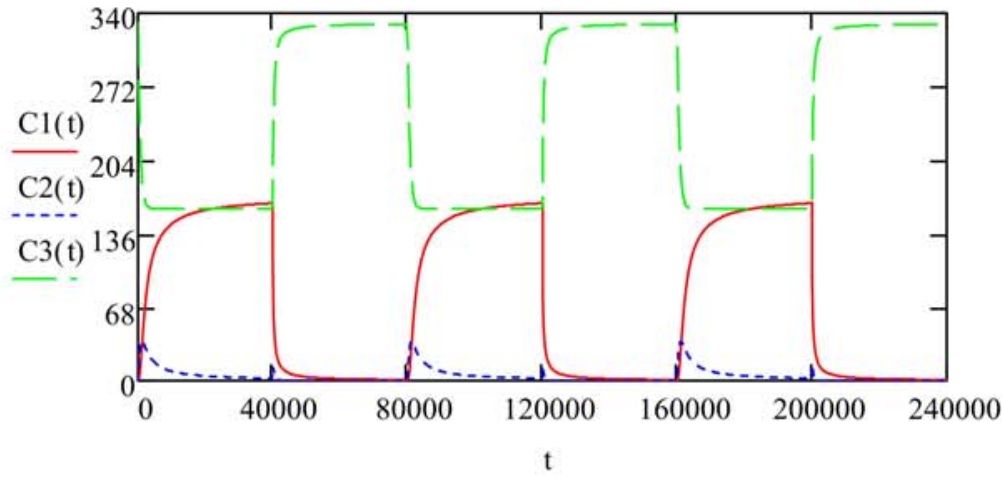

Time (s)

Fractional Utilization of Bed

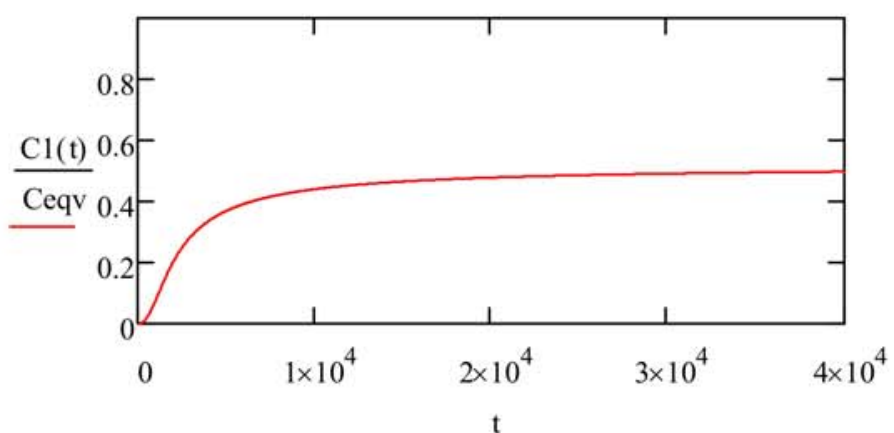

Time (s) 
WSRC-TR-2007-00440

Revision 0

\title{
ATTACHMENTS
}

\section{Attachment 1}

\author{
Practical Sorption Kinetics of $\mathrm{TiCl}_{3}$ Catalyzed $\mathrm{NaAlH}_{4}$ \\ Xia Tang, Daniel A Mosher and Donald L Anton \\ United Technologies Research Center
}

411 Silver Lane

East Hartford, CT 06108

\begin{abstract}
Sodium alanate has been studied as a promising candidate material for reversible hydrogen storage due to its intermediate temperature range and relatively high storage capacity. Its rates of desorption and absorption of hydrogen have been shown to be enhanced by the addition of $\mathrm{Ti}$ in various compounds. To date, the sorption kinetics, especially absorption kinetics, is not well understood. In this study, a practical sorption kinetics model for $\mathrm{TiCl}_{3}$ catalyzed $\mathrm{NaAlH}_{4}$ has been developed to assist in the engineering design and evaluation of a prototype hydrogen storage system.
\end{abstract}

\section{Introduction}

The design of a hydrogen storage system using any exothermic hydriding compound, such as $\mathrm{NaAlH}_{4}$, requires detailed consideration of local heat management. This is especially important in the critical hydrogen absorption stage, where high kinetics are required and heat flow is at its maximum. Thermal transport architectures such as cooling tubes and metal foam structures need to be designed to meet the optimum operational characteristics of the hydrogen storage media. In order to design and model these architectures and obtain a gravimetrically and volumetrically optimized storage system, absorption and desorption kinetic models need to be identified and validated. Many current models, such as the wellknown Arrhenius model, are insufficient to characterize materials behavior under transient or partially discharged conditions. Previous kinetics studies of $\mathrm{NaAlH}_{4}$ mainly focused on the desorption reaction [14]. Aborption and desorption kinetics models were developed by Luo and Cross [5] to simulate $\mathrm{NaH}+\mathrm{Al}$ $\leftrightarrow \mathrm{NaAlH}_{4}$ reactions using $\mathrm{NaH}$ and $\mathrm{Al}$ as starting materials. No kinetics model was reported to simulate transient hydriding rate and hydrogen absorption capacity of $\mathrm{NaH}+\mathrm{Al}$ derived from $\mathrm{NaAlH}_{4}$. In this study, a solid/gas chemical kinetics model originally developed by El-Osery [6-9] to design conventional metal hydride systems was utilized. This model was adapted for use in the multi-step hydrogen absorption mechanisms of $\mathrm{NaH}+\mathrm{Al} \rightarrow \mathrm{NaAlH}_{4}$.

\section{Basic Kinetics Model}

The dehydrogenation and hydrogenation of sodium alanate involve the following well-known reactions: $\mathrm{NaAlH}_{4} \leftrightarrow 1 / 3 \mathrm{Na}_{3} \mathrm{AlH}_{6}+2 / 3 \mathrm{Al}+\mathrm{H}_{2} \leftrightarrow \mathrm{NaH}+\mathrm{Al}+3 / 2 \mathrm{H}_{2}$

For compactness, the compositional state can be tracked by a single variable for each product/reactant, $\mathrm{C}_{1}, \mathrm{C}_{2}$ and $\mathrm{C}_{3}$ as:

$\mathrm{C}_{1}: \mathrm{NaH}+\mathrm{Al}+3 / 2 \mathrm{H}_{2}$

$\mathrm{C}_{2}: 1 / 3 \mathrm{Na}_{3} \mathrm{AlH}_{6}+2 / 3 \mathrm{Al}+\mathrm{H}_{2}$ 
$\mathrm{C}_{3}: \mathrm{NaAlH}_{4}$

The nomenclatures for all reactions are listed in Table 1.

Table 1 Nomenclature for All Reactions

\begin{tabular}{|c|c|c|c|}
\hline Label & Action & Reactant & Product \\
\hline $\mathrm{r}_{1}$ & Dehydriding of $\mathrm{Na}_{3} \mathrm{AlH}_{6}$ & $\mathrm{C}_{2}$ & $\mathrm{C}_{1}$ \\
\hline $\mathrm{r}_{2}$ & Hydriding of $\mathrm{NaH}$ & $\mathrm{C}_{1}$ & $\mathrm{C}_{2}$ \\
\hline $\mathrm{r}_{3}$ & Dehydriding of $\mathrm{NaAlH}_{4}$ & $\mathrm{C}_{3}$ & $\mathrm{C}_{2}$ \\
\hline $\mathrm{r}_{4}$ & Hydriding of $\mathrm{Na}_{3} \mathrm{AlH}_{6}$ & $\mathrm{C}_{2}$ & $\mathrm{C}_{3}$ \\
\hline
\end{tabular}

Reaction rates can be represented by equation (1) based on the metal hydride model developed by ElOsery [6-7]:

$\left(\frac{d C_{j}}{d t}\right)_{r_{i}}=f_{T}(T) * f_{P}(P) * f_{C}\left(C_{k}\right)$

$i$ for reaction $r_{i}$

$j$ for composition product $C_{j}$

$k$ for composition reactant $C_{k}$

The temperature dependant term is that of the typical Arrhenius equation given as:

$f_{T}=A_{i} \exp \left(-\frac{E_{i}}{R T}\right)$

The pressure dependant term can be expressed simply as a first order expression:

$f_{P}=(-1)^{i} *\left(\frac{P-P_{e, i}}{P_{e, i}}\right)$

where $\mathrm{P}_{\mathrm{e}, \mathrm{i}}$ is the equilibrium pressure for the reaction and is valid for both hydriding and dehydriding. Equilibrium pressure $P_{e, i}$ is temperature dependant and obeys the van't Hoff equation:

$\ln \left(P_{e, i}\right)=\frac{\Delta H}{R T}-\frac{\Delta S}{R}$

In El-Osery's description, a first order function of hydrogen/metal atomic ratio was used in a concentration factor for hydriding. In hydriding reactions of the $\mathrm{NaH}+\mathrm{Al}$ system, however, two solid reactants are involved in each reaction respectively. They may have higher reaction orders. The concentration factor is thus represented as being proportional to the reactant concentration to some power, $\chi_{\mathrm{i}}$ as:

$f_{C}=\left(C_{k}\right)^{\chi_{i}}$

Combining these factors results in the rate equation:

$\frac{d C_{j}}{d t}=A_{i} \exp \left(-\frac{E_{i}}{R T}\right) *(-1)^{i} *\left(\frac{P-P_{e, i}}{P_{e, i}}\right) *\left(C_{k}\right)^{\chi_{i}}$

Applying equation (2) to $r_{2}$ and $r_{4}$, one obtains the following equations for high pressure hydriding $\left(r_{2}\right.$ and $\mathrm{r}_{4}$ are active).

$\left(\frac{d C_{2}}{d t}\right)_{r 2}=A_{2} \exp \left(-\frac{E_{2}}{R T}\right) *\left(\frac{P-P_{e, 2}}{P_{e, 2}}\right) *\left(C_{1}\right)^{\chi_{2}}$ and $\left(\frac{d C_{1}}{d t}\right)_{r 2}=-\left(\frac{d C_{2}}{d t}\right)_{r 2}$ 


$$
\left(\frac{d C_{3}}{d t}\right)_{r 4}=A_{4} \exp \left(-\frac{E_{4}}{R T}\right) *\left(\frac{P-P_{e, 4}}{P_{e, 4}}\right) *\left(C_{2}\right)^{\chi_{4}} \text { and }\left(\frac{d C_{2}}{d t}\right)_{r 4}=-\left(\frac{d C_{3}}{d t}\right)_{r 4}
$$

The reaction rate of each composition can be represented as:

$$
\begin{aligned}
\frac{d C_{1}}{d t} & =-A_{2} \exp \left(-\frac{E_{2}}{R T}\right) *\left(\frac{P-P_{e, 2}}{P_{e, 2}}\right) *\left(C_{1}\right)^{\chi_{2}} \\
\frac{d C_{2}}{d t} & =A_{2} \exp \left(-\frac{E_{2}}{R T}\right) *\left(\frac{P-P_{e, 2}}{P_{e, 2}}\right) *\left(C_{1}\right)^{\chi_{2}}-A_{4} \exp \left(-\frac{E_{4}}{R T}\right) *\left(\frac{P-P_{e, 4}}{P_{e, 4}}\right) *\left(C_{2}\right)^{\chi_{4}} \\
\frac{d C_{3}}{d t} & =A_{4} \exp \left(-\frac{E_{4}}{R T}\right) *\left(\frac{P-P_{e, 4}}{P_{e, 4}}\right) *\left(C_{2}\right)^{\chi_{4}}
\end{aligned}
$$

$0 \leq C_{i} \leq 1$

with the initial reaction conditions: $C_{1}^{t=0}=1, C_{2}^{t=0}=0, C_{3}^{t=0}=0$,

\section{Experimental Procedure}

To validate the applicability of this kinetic model, a well-known alanate composition was chosen for empirical assessment. Commercial grade $\mathrm{NaAlH}_{4}$ was purchased from Albemarle Co. (Baton Rouge, LA) with a chemical certification analysis of $86.3 \% \mathrm{NaAlH}_{4}, 4.7 \% \mathrm{Na}_{3} \mathrm{AlH}_{6}, 7.5 \%$ free $\mathrm{Al}$ and $10.1 \%$ insoluble $\mathrm{Al}$ (with all analyses given in wt\%). The catalyst, $\mathrm{TiCl}_{3}$ (99.99\%), was obtained from Aldrich Corp. All materials were used in the as-received condition.

The $\mathrm{NaAlH}_{4}$ was catalyzed with $4 \mathrm{~mol} \% \mathrm{TiCl}_{3}$ by high energy SPEX ball milling for three hours under nitrogen. Immediately after ball milling, approximately $1 \mathrm{~g}$ of the sample was transferred into the sample holder of a modified Sievert's apparatus. All the storage and transferring of $\mathrm{NaAlH}_{4}$ and $\mathrm{TiCl}_{3}$ were performed under a high purity nitrogen environment inside a glove box with an oxygen concentration $<10^{-}$ ${ }^{5} \mathrm{ppm}$.

$\mathrm{TiCl}_{3}$ catalyzed $\mathrm{NaAlH}_{4}$ was first desorbed at $150^{\circ} \mathrm{C}$ in vacuum for more than 7 hours to ensure maximum desorption. Absorption was conducted with the hydrogen pressure ranging from 6.8-6.0 MPa. Extent of reaction versus time was measured by monitoring hydrogen pressure change using a gas reaction controller made by Advanced Materials Co. (Pittsburg, PA).

\section{Results and Discussion}

Rate equations (5) to (7) represent an ideal kinetics model, where the total charging capacity over long periods approaches the ideal capacity of $5.6 \mathrm{wt} \%$. However, in reality, the total capacity is usually less than the theoretical value. Saturation compositions, $C_{k}^{\text {Sat }}(T)$, are introduced into the rate equations to reflect this non-ideal capacity. They represent the residual reactant compositions at the hydriding saturation point fordifferent temperature values.

The concentration factors in equation (1d) are thus changed to:

$$
\begin{aligned}
& f_{C}=\left(C_{k}-C_{k}^{s a t}(t)\right)^{\chi_{i}} \text { if } C_{k}-C_{k}^{s a t}(T) \geq 0 \\
& f_{C}=0 \text { if } C_{k}-C_{k}^{s a t}(T)<0
\end{aligned}
$$

The rate equations are represented accordingly by: 


$$
\begin{aligned}
\frac{d C_{1}}{d t} & =-A_{2} \exp \left(-\frac{E_{2}}{R T}\right) *\left(\frac{P-P_{e, 2}}{P_{e, 2}}\right) *\left[C_{1}-C_{1}^{s a t}(T)\right]^{\chi_{2}} \\
\frac{d C_{2}}{d t} & =A_{2} \exp \left(-\frac{E_{2}}{R T}\right) *\left(\frac{P-P_{e, 2}}{P_{e, 2}}\right) *\left[C_{1}-C_{1}^{s a t}(T)\right]^{\chi_{2}}-A_{4} \exp \left(-\frac{E_{4}}{R T}\right) *\left(\frac{P-P_{e, 4}}{P_{e, 4}}\right) *\left[C_{2}-C_{2}^{s a t}(T)\right]^{\chi_{4}}(9) \\
\frac{d C_{3}}{d t} & =A_{4} \exp \left(-\frac{E_{4}}{R T}\right) *\left(\frac{P-P_{e, 4}}{P_{e, 4}}\right) *\left[C_{2}-C_{2}^{s a t}(T)\right]^{\chi_{4}}
\end{aligned}
$$

The modified compositions and total hydriding capacity at saturation are:

$C_{1}=C_{1}^{s a t}(T), \quad C_{2}=C_{2}^{s a t}(T), \quad C_{3}=1-C_{1}^{s a t}(T)-C_{2}^{s a t}(T)$

The total $\mathrm{H}_{2}$ absorption capacity $w_{\text {iso }}^{\text {sat }}(T)$ :

$w_{\text {iso }}^{\text {sat }}(T)=0.0187 * C_{2}^{\text {sat }}(T)+0.056 *\left(1-C_{1}^{\text {sat }}(T)-C_{2}^{\text {sat }}(T)\right)$

Curve fitting with experimental data using equations (8) to (13) is shown in Figure 1. The parameters used for fitting are listed in Table 2. The slope and intercept in the van't Hoff plot were derived from data

\begin{tabular}{|c|c|c|}
\hline$(\Delta \mathrm{H} / \mathrm{R}) \mathrm{r}_{2}$ & -6150 & Slope in van't Hoff plot \\
\hline$-(\Delta \mathrm{S} / \mathrm{R}) \mathrm{r}_{2}$ & 16.22 & Intercept in van't Hoff plot \\
\hline $\mathrm{A}_{2}$ & $1.50 \mathrm{E}+05$ & Pre-exponent coefficient for $r_{2}$ \\
\hline $\mathrm{E}_{2}$ & 70 & Activation energy for $\mathrm{r}_{2}, \mathrm{KJ} / \mathrm{mol}$ of $\mathrm{H}_{2}$ for $\mathrm{r}_{2}$ \\
\hline$\chi_{2}$ & 1 & Reaction order for $r_{2}$ \\
\hline$(\Delta \mathrm{H} / \mathrm{R}) \mathrm{r}_{4}$ & -4475 & Slope in van't Hoff plot, $r_{4}$ \\
\hline$-(\Delta \mathrm{S} / \mathrm{R}) \mathrm{r}_{4}$ & 14.83 & Intercept in van't Hoff plot, $\mathrm{r}_{4}$ \\
\hline $\mathrm{A}_{4}$ & $1.00 \mathrm{E}+08$ & Pre-exponent coefficient for $\mathrm{r}_{4}$ \\
\hline$\overline{\mathrm{E}_{4}}$ & 80 & Activation energy for $\mathrm{r}_{2}, \mathrm{~kJ} / \mathrm{mol}$ of $\mathrm{H}_{2}$ for $\mathrm{r}_{4}$ \\
\hline$\chi_{4}$ & 2 & Reaction order for $r_{4}$ \\
\hline
\end{tabular}
published by Cross et al. [10].

Table 2 Fitting Parameters in Figure 1

The activation energies, $E_{i}$, for $r_{2}$ and $r_{4}$ are 70 and $80 \mathrm{KJ} / \mathrm{mol}$ of $\mathrm{H}_{2}$ and the pre-exponent coefficients, $\mathrm{A}_{\mathrm{i}}, 1.50 \mathrm{E}+05$ and $1.00 \mathrm{E}+08$ respectively. The hydriding reaction, $\mathrm{r}_{4}\left(\mathrm{Na}_{3} \mathrm{AlH}_{6}\right.$ to $\left.\mathrm{NaAlH}_{4}\right)$ has a higher activation energy than the reaction, $\mathrm{r}_{2}, \mathrm{NaH}$ to $\mathrm{Na}_{3} \mathrm{AlH}_{6}$. However, the pre-exponential coefficient of $\mathrm{r}_{4}$ is much higher than $r_{2}$. This could be due to catalyst placement preferentially at positions favorable to $r_{4}$ reaction. The reaction orders of the two hydriding steps appear to be different, with $r_{2}$ being nominally a first order reaction, and $\mathrm{r}_{4}$ a second order reaction. The reaction orders are consistent with those reported by Luo and Gross [5]. During the formation of $\mathrm{Na}_{3} \mathrm{AlH}_{6}, \mathrm{NaH}$ is the limiting reactant and $\mathrm{Al}$ is in access. Al concentration can be considered as constant and the reaction becomes a pseudo first order. In $\mathrm{r}_{4}$, the reactants, $\mathrm{Na}_{3} \mathrm{AlH}_{6}$ and $\mathrm{Al}$, are in stichometric ratio. Both concentrations can affect reaction rate. The formation of $\mathrm{NaAlH}_{4}$, therefore, is a second order reaction. 


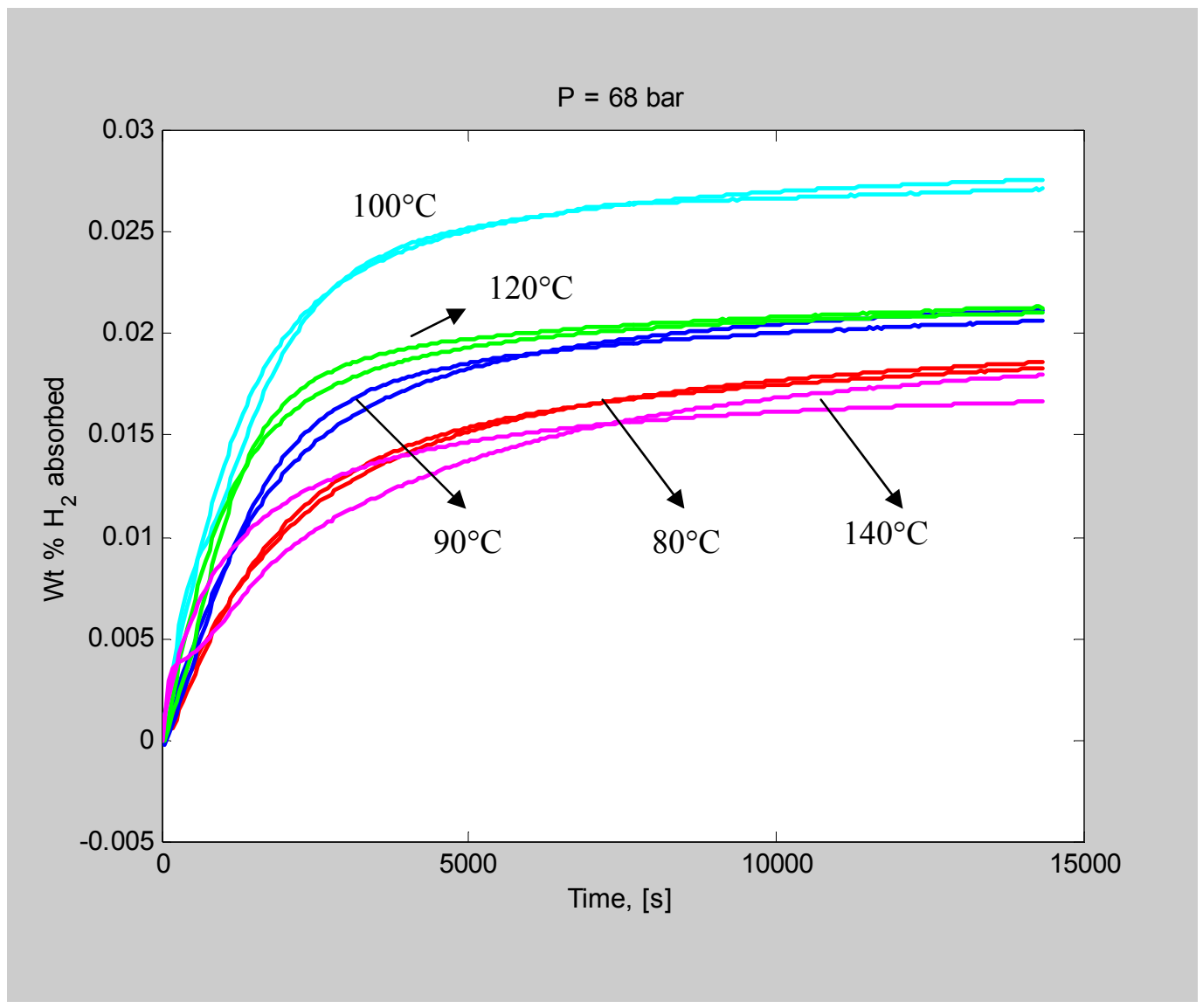

Figure $1 \quad \mathrm{H}_{2}$ absorption curves at $80-140^{\circ} \mathrm{C}$ with $\mathrm{H}_{2}$ pressure ranging from $6.0-6.8 \mathrm{MPa}$. The dashed lines are model results, with red $=80^{\circ} \mathrm{C}$; blue $=90^{\circ} \mathrm{C}$; cyan $=100^{\circ} \mathrm{C}$; green $=120^{\circ} \mathrm{C}$; and magenta $=140^{\circ} \mathrm{C}$.

As shown in Figure 1, the model fits experimental data well in absorption temperature range of $80^{\circ} \mathrm{C}$ $120^{\circ} \mathrm{C}$. However, the fit is not as accurate for absorption at $140^{\circ} \mathrm{C}$. As the temperature increases, the hydriding reaction of $\mathrm{Na}_{3} \mathrm{AlH}_{6}$ to $\mathrm{NaAlH}_{4}$ approaches its thermodynamic equilibrium at 6.0-6.8 $\mathrm{MPa}$ hydrogen pressure. The $P_{e}$ for $2 \mathrm{~mol} \% \mathrm{Ti}\left(\mathrm{OBu}^{\mathrm{n}}\right)_{4}$ catalyzed materials is $5.4 \mathrm{MPa}$ [9]. Although the reaction rate increases with temperature, the capacity decreases as a result of decreasing thermodynamic driving force. Absorption at this temperature is not recommended at this hydriding pressure.

By close inspection. it can be seen in Figure 1 that inflection regions are present during the initial rapid hydriding. Similar inflections were also observed in previous absorption data published by Sandrock et al. [11]. There are two possibilities for this observation; (i) a temperature rise in the sample upon exothermic hydriding of $\mathrm{NaH}$ to form $\mathrm{Na}_{3} \mathrm{AlH}_{6}$ or (ii) the combination of slowing down of the first hydriding reaction, $\mathrm{r}_{2}$, and starting of the second reaction, $\mathrm{r}_{4}$. To resolve this question, accurate sample temperature measurement is required. This non-isothermal factor can be included in future models when accurate in-situ measurement of the sample temperature becomes available. In addition, the current model is fit to isothermal hydriding data, with the assumption that the hydriding rate is not affected by thermal histories except that captured by the variables $C_{k}$. Reactions involving solid reactants and products usually involve product nucleation and growth periods, and reaction rates are closely related to the characteristics of these periods. Previous thermal histories could affect particle sizes, packing and reactant/catalyst distribution. These changes will have an effect on the characteristics of nucleation and growth, therefore altering reaction rates. Future kinetics models should take these factors into consideration. 


\section{Conclusion}

A practical kinetics model has been developed to simulate hydrogen absorption of $\mathrm{NaH}+\mathrm{Al}$ obtained from $\mathrm{TiCl}_{3}$ catalyzed $\mathrm{NaAlH}_{4}$. Physical meaning of the basic model is discussed. Modification of the model has been made with additional parameters for non-stoichiometric saturation compositions. The modified model fits well with experimental data at temperatures ranging from $80^{\circ} \mathrm{C}$ to $120^{\circ} \mathrm{C}$ in the pressures range 6.0-6.8 MPa. This model has provided kinetic information needed in the design of $1 \mathrm{~kg}$ hydrogen storage system using $\mathrm{NaAlH}_{4}$ as storage media. Although this model needs further refinement to include nonisothermal factors and solid state reaction mechanisms, it has given valuable insights in optimizing thermal management and operational conditions for the $1 \mathrm{~kg}$ prototype system.

\section{Acknowledgements}

The funding for this study is provided by U.S. Department of Energy, under the contract DE-FC3602AL67610 and the input of Dr. C. Read. The authors also acknowledge Mr. R. Brown for his valuable contribution in performing experimental work.

\section{References}

1. T. Kiyobayashi, S.S. Srinivasan, D. Sun and C.M. Jensen, J. Phys. Chem.A 107, 7671-7674 (2003).

2. G. Sandrock, K. Gross and G. Thomas, J. Alloys Comp. 339 299-308 (2002).

3. K.J. Gross, E.H. Majzoub and S.W. Spangler, J. Alloys Comp. 356-357, 423-428 (2003).

4. D.L. Anton, J. Alloys Comp. 356-357, 400-404 (2003).

5. W. Luo and K.J. Gross, J. Alloys Comp. 385 224-231 (2002).

6. I.A. El-Osery, Int. J. Hydrogen Energy, 8, 191-198 (1983).

7. M.A. El-Osairy, I.A. El-Osery, A.M. Metwally and M.A. Hassan, J. Alloys Comp. 202, 125128(1993)

8. M.A. El-Gammal, I.A. El-Osery, A.M. Metwally and M.A. Hassan, Modeling, Measurement and Control, 46, 35-44 (1994).

9. M.A. El-Osairy, I.A. El-Osery, A.M. Metwally and M.A. Hassan, Int. J. Hydrogen Energy, 18, 517-524 (1993)

10. K.J. Gross, G.J. Thomas and C.M. Jensen, J. Alloys Comp. 330-332 683-690 (2002).

11. G. Sandrock, K. Gross and G. Thomas, J. Alloys Comp. 339 299-308 (2002). 
WSRC-TR-2007-00440

Revision 0

\section{Attachment 2}

\section{Kinetics Model Refinements \\ Dan Mosher \\ 6/26/03

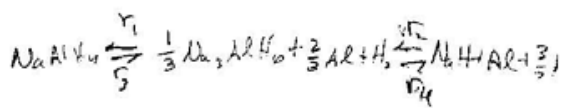

A number of refinements have been added to the kinetics model framework:

1. Check to make sure the composition variables are not outside the bounds of

$$
0 \leq C_{i} \leq \mathrm{I}
$$

2. Modify the reaction rate forms to allow different saturation hydrogen weight percentages at different temperatures.

1 Maintaining consistent values of the compositions, $C_{i} \longleftarrow$ Mole fiection ${ }^{2}$ ?

1.1 Comment on Model Aspect which Keeps Consistent values of $C_{i}$

What is it in the modeling framework that maintains consistent values for the compositions? The consistency requirements are

and

$$
0 \leq C_{i} \leq 1 \quad C_{1} \rightarrow N_{a H}+\mathrm{T}_{2}+3 / 2+
$$

Equation 1 $\quad \sum_{i=1}^{3} C_{i}=1$

$$
\begin{aligned}
& C_{2} \rightarrow 1 / 3 \alpha_{a_{3}} \mathrm{AlH}_{6}+2 / 3 \mathrm{Al}+H^{\prime} \\
& C_{3} \rightarrow \mathrm{N}_{4} \mathrm{AlH}_{4}
\end{aligned}
$$

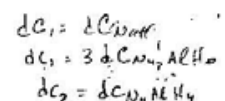

For reaction 2 involving the hydriding of $\mathrm{NaH}$ (in the original model form with no saturation levels), we have

Equation 2

$$
\left(\frac{d C_{2}}{d t}\right)_{r 2} \propto\left(C_{1}\right)^{\chi_{2}}
$$

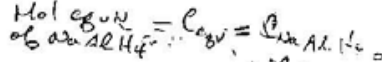

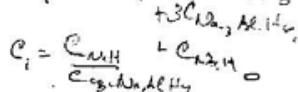

This produces a $C_{2}$ that will reach a limit as $C_{1} \rightarrow 0$, but it does not ensure that $0 \leq C_{2} \leq 1$. However, the relationship which balances the product formation rate with the reactant consumption rate,

\section{Equation 3}

$$
\left(\frac{d C_{1}}{d t}\right)_{r 2}=-\left(\frac{d C_{2}}{d t}\right)_{r 2}
$$

when integrated over a small time step, will produce

In this case,

$$
\left(\Delta C_{1}\right)_{r 2}=-\left(\Delta C_{2}\right)_{r 2}
$$

$$
\left(\Delta C_{1}+\Delta \dot{C}_{2}\right)_{r 2}=\left(-\Delta C_{2}+\Delta C_{2}\right)_{r 2}=0
$$

If we consider pressure regime three where both reactions 2 and 4 are active, we will also have

If we add these two equations,

$$
\left(\Delta C_{2}+\Delta C_{3}\right)_{r 4}=0
$$

Equation $4 \quad\left(\Delta C_{1}+\Delta C_{2}\right)_{r 2}+\left(\Delta C_{2}+\Delta C_{3}\right)_{r 4}=0$

Since the model framework specifies that for pressure regime 3 ,

$$
\begin{gathered}
\left(\Delta C_{1}\right)_{\text {total }}=\left(\Delta C_{1}\right)_{r 2} \\
\left(\Delta C_{2}\right)_{\text {total }}=\left(\Delta C_{2}\right)_{r 2}+\left(\dot{\Delta} C_{2}\right)_{r 4} \\
\left(\Delta C_{3}\right)_{\text {total }}=\left(\Delta C_{3}\right)_{r 4}
\end{gathered}
$$


WSRC-TR-2007-00440

Revision 0

Equation 4 becomes

$$
\left(\Delta C_{1}+\Delta C_{2}+\Delta C_{3}\right)_{\text {total }}=0
$$

or

$$
C_{1}+C_{2}+C_{3}=\text { constant }
$$

If we start with values which sum to 1 , then Equation 1 will be satisfied for all time.

Figure 1 demonstrates that this indeed does occur during the simultations even with the potential errors associated with numerical integration. The sum of C's is $1.000000+/-8 \mathrm{e}-7$.

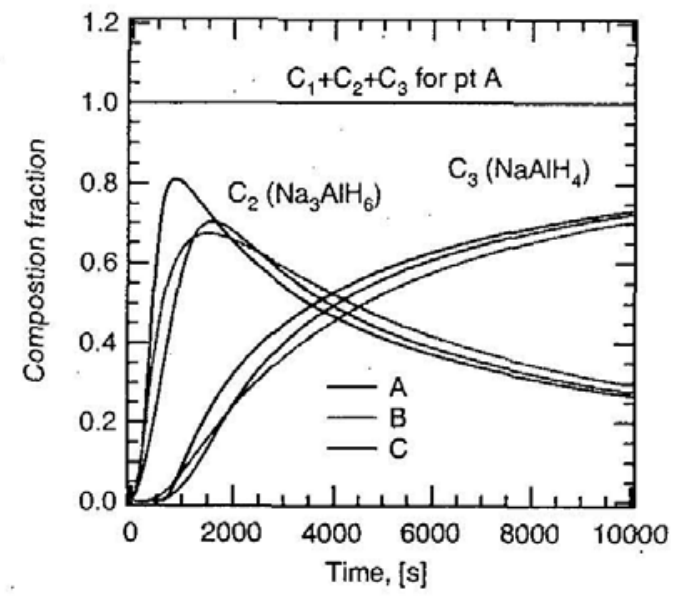

Figure 1: Composition results for four hole configuration.

\subsection{Potential Issue with Numerical Integration which Should Be Corrected}

With numerical integration, finite time steps are used. In this case, it is conceivable that the value of a reactant would not hit exactly 0 but could overshoot and become negative. An important influence of this is the value of the exponent $\chi$ on the composition variable. For the specific reaction of Equation 2 with $\chi_{2}=1$, if $C_{1}<0$ then $d C_{2} / d t<0$ and by Equation 3, $d C_{1} / d t>0$ which will self correct the value of $C_{1}$ toward 0 . However, if $\chi_{2}=2$, the square of a negative number is a positive number, so that $C_{1}$ will become more negative in a run away numerical effect where $C_{1}$ becomes substantially less than 0 and $C_{2}$ becomes substantially greater than 1 . As discussed above,

$$
\left(\Delta C_{1}+\Delta C_{2}\right)_{r 2}=0
$$

would still apply but the individual values of $C_{1}$ and $C_{2}$ will diverge and be meaningless. Even though a value of $\chi=2$ has been used in ABAQUS simulations, this problem has not been observed probably because the reaction rates slow down adequately as $C_{1} \rightarrow 0$ so that the finite time steps do not produce an overshoot.

Nevertheless, modifications should be added to the coding to make sure that all of the compositions stay within the physical bounds of 0 and 1 . One approach is to simply check the values of the compositions and if they are starting to deviate, to set them equal to 0 or 1 as appropriate. For the particular reaction, it also might be necessary to adjust the conjugate variable in the reaction to avoid any drifting of the composition sum. Another approach is to modify the coding used to represent Equation 2 as 
WSRC-TR-2007-00440

Revision 0

$$
\left(\frac{d C_{2}}{d t}\right)_{r 2} \propto \operatorname{sign}\left(C_{1}\right) *\left[a b s\left(C_{1}\right)\right]^{\chi_{2}}
$$

This has two advantages. First, the self correcting nature is preserved even if $\chi=2$. Second, there will not be computation errors if $C_{1}$ is negative and the exponent is non-integer. Another, perhaps perferrable approach is to have

$$
\begin{gathered}
\left(\frac{d C_{2}}{d t}\right)_{r 2} \propto\left[C_{1}\right]^{\chi_{2}} \text { if } C_{1} \geq 0 \\
\left(\frac{d C_{2}}{d t}\right)_{r 2}=0 \text { if } C_{1}<0
\end{gathered}
$$

This essentially stops the hydriding reaction when the reactant concentration become slightly negative.

\section{Modeling of Saturation Weight Percentages Which Vary with Temperature}

\subsection{Introduction}

$$
\frac{\text { wt } H_{2} \text { in Hetal }}{\text { wo Hrided Hetal }}
$$

As shown in Figure 2, the saturation weight fraction absorbed can vary significantly with temperature. The value of $90 \mathrm{C}$ is 0.02 and that for $100 \mathrm{C}$ is 0.027 . In the present modeling structure, the hydrogen weight fraction stored in the material is calculated from the composition variables as

Equation 5

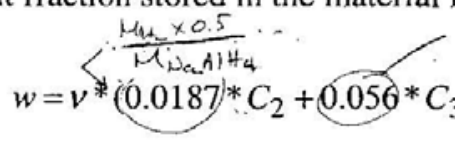

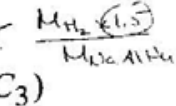

$$
\begin{aligned}
& \text { - } \mu_{H_{2}}=20.6 \mathrm{~g} / \mathrm{ml} \\
& \text { MaAl thy }=54,004 \mathrm{~g} / \mathrm{mul} \\
& M_{N_{a t}}=24,00 \text { sinal } \\
& M_{\mathrm{N}_{\mathrm{A}} A \mathrm{AH}_{6}}=1.05 .02 \mathrm{~g} / \mathrm{mal}
\end{aligned}
$$

The variable $v$ represents the nonideal capacity. As a first attempt to fit the data in Figure 2, this variable was made temperature dependent,

\section{Equation 6}

$$
w=v(T) *\left(0.0187 * C_{2}+0.056 * C_{3}\right)
$$

and the comparison with data in Figure 2 is reasonably good at longer times. The complexities of the incubation period where not modeled and therefore the short time comparison is not good.

This approach is adequate to match the constant temperature data, but it will have unrealistic behavior when temperature is changing. As an example, if at $10,000 \mathrm{~s}$, the temperature is changed from 90 to $100 \mathrm{C}$, the weight fraction will jump instantaneously from 0.02 to 0.027 which would not occur physically. Additional experiments in which the temperature is changed will be conducted to examine this effect. 
WSRC-TR-2007-00440

Revision 0

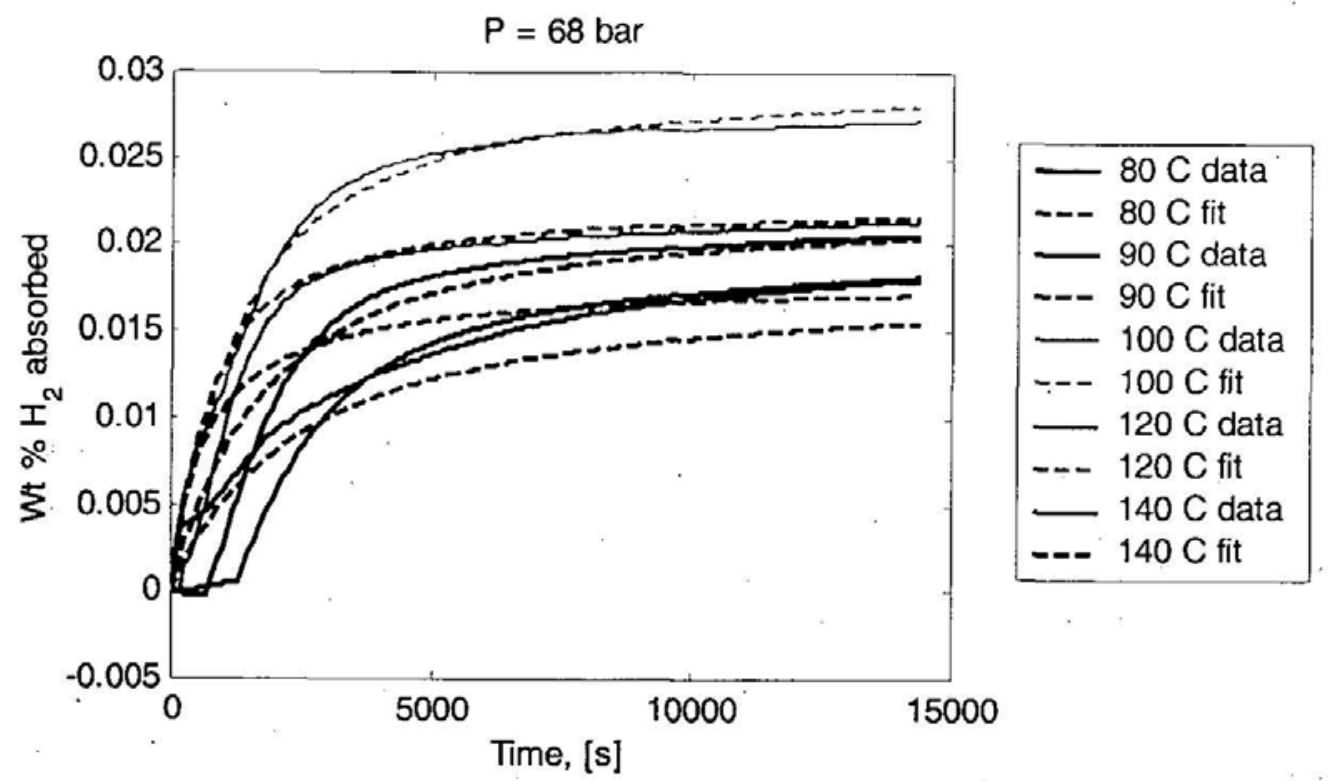

Figure 2: Absorption data for $6 \% \mathrm{TiCl} 3$ with fit to constant temperature model.

\subsection{Saturation Form for Single Composition, $C_{I}$}

The framework modifications to allow for saturation weight fraction differences for arbitrary temperature histories are discussed next. One modeling approach is to have

$$
\left(\frac{d C_{2}}{d t}\right)_{r 2} \propto\left(C_{1}-C_{1}^{s a t}(T)\right)^{x_{2}}
$$

which should be represented in the coding as

Equation 7

$$
\left(\frac{d C_{2}}{d t}\right)_{r 2} \propto\left[C_{1}-C_{1}^{s a t}(T)\right]^{\chi_{2}} \text { if } C_{1}-C_{1}^{s a t}(T) \geq 0
$$

Equation $8 \quad\left(\frac{d C_{2}}{d t}\right)_{r 2}=0$ if $C_{1}-C_{1}^{s a t}(T)<0$

The value of this saturation $C_{1}$ is calcuated by considering the resulting long-time composition,

$$
C_{1}=C_{1}^{\text {sat }}, C_{2}=0, C_{3}=1-C_{1}^{\text {sat }} \text {. }
$$

and substituting these values into a modified version of Equation 5 where the obsolete factor of $v$ has been removed,

$$
\text { Equation } 9 \quad w=0.0187 * C_{2}+0.056 * C_{3}
$$

This results in a saturation value for the weight fraction under an isothermal temperature history of

or

$$
w_{i s o}^{\text {sat }}=0.056 *\left(1-C_{1}^{\text {sat }}\right)
$$


WSRC-TR-2007-00440

Revision 0

Equation 10

$$
C_{1}^{s a t}(T)=1-\frac{w_{i s o}^{s a t}(T)}{\cdot 0: 056}
$$

$C_{c t}(\tau)=\frac{C_{0}^{a t} t(I)}{C_{\text {cot } x}}$

The parameter $w_{i s o}^{\text {sat }}(T)$ represents the saturation level at long times for the absorbed weight fraction of hydrogen under an isothermal temperature history.

Because reaction 2 is a hydriding reaction, it can only proceed in the direction where $C_{2}$ is being produced and therefore we must have $C_{1}>C_{1}^{\text {sat }}$. If not, then Equation 8 applies.

The equation for the second hydriding reaction would not necessarily need to be altered with a saturation level for the reactant,

$$
\left(\frac{d C_{3}}{d t}\right)_{r 4} \propto\left(C_{2}\right)^{\chi_{4}}
$$

To illustrate this with an example, consider if $w_{i s o}^{\text {sat }}=0.020$ and so $C_{1}^{\text {sat }}=0.643$. If we start off with $C_{1}=1, C_{2}=0, C_{3}=0$, then after a long amount of hydriding, we would obtain $C_{1}=0.643, \quad C_{2}=0, \quad C_{3}=0.357$.

then we will obtain the desired value of

$$
w=0.0187 * 0+0.056 * 0.357=0.020
$$

This approach appears to give reasonble physical behavior when changing temperatures for $C_{1}^{\text {sat }}$. increasing with time. If for example, we hydride at $90 \mathrm{C}$ for $10,000 \mathrm{~s}$ and then increase the temperature to $100 \mathrm{C}$, the value of $C_{1}^{\text {sat }}$ will decrease and reaction 2 will become active again.

This will produce a gradual change in $w$ rather than the step change of Equation 6 . Whether this rate of change matches experiment is another question which needs to be addressed with additional experiments.

\subsection{Saturation Form for Two Compositions, $C_{1}$ and $C_{2}$}

If we are not able to match experiments (or if we just prefer the approach below with more adjustabie parameters), a possible modification is to have a saturation level of $C_{2}^{\text {sat }}$ for reaction 4

Equation $11 \quad\left(\frac{d C_{3}}{d t}\right)_{r 4} \propto\left[C_{2}-C_{2}^{s a t}(T)\right]^{\chi_{4}}$ if $C_{2}-C_{2}^{s a t}(T) \geq 0$

$$
\text { Equation } 12 \quad\left(\frac{d C_{3}}{d t}\right)_{r 4}=0 \text { if } C_{2}-C_{2}^{s a t}(T)<0
$$

and to choose values of $C_{1}^{\text {sat }}$ and $C_{2}^{\text {sat }}$ from $w_{\text {iso }}^{\text {sat }}$ so that they are consistent with the final capacity. For this, after long times of hydriding in pressure regime 3 at a certain temperature $T$,

Applying Equation 9,

$$
C_{1}=C_{1}^{\text {sat }}(T), \quad C_{2}=C_{2}^{\text {sat }}(T), \quad C_{3}=1-C_{1}^{\text {sat }}(T)-C_{2}^{\text {sat }}(T)
$$

Equation $13 \quad w_{i s o}^{\text {sat }}(T)=0.0187 * C_{2}^{\text {sat }}(T)+0.056 *\left(1-C_{1}^{\text {sat }}(T)-C_{2}^{\text {sat }}(T)\right)$ 
There are two unknowns and one equation, so we cannot uniquely determine $C_{1}^{\text {sat }}$ and $C_{2}^{\text {sat }}$. An assumption on their relationship to each other or additional data is required to proceed. If we relate the two saturation values by (an alternate relation given in Equation 17 below was used ultimately in the coding implementation)

$$
R^{s a t}=\frac{C_{2}^{s a t}(T)}{C_{1}^{s a t}(T)},
$$

assuming that $R^{\text {sat }}$ does not depend on temperature, then

$$
\text { Equation } 14 \quad C_{2}^{\text {sat }}(T)=R^{s a t} * C_{1}^{\text {sat }}(T)
$$

and from Equation 13,

$$
w_{\text {iso }}^{\text {sat }}(T)=0.0187 * R^{\text {sat }} * C_{1}^{\text {sat }}(T)+0.056 *\left(1-C_{1}^{\text {sat }}(T)-R^{\text {sat }} * C_{1}^{\text {sat }}(T)\right)
$$

Solving for $C_{1}^{\text {sat }}$,

$$
\begin{gathered}
w_{\text {iso }}^{\text {sat }}=C_{1}^{\text {sat }} *\left(0.0187 * R^{\text {sat }}+0.056 *\left(-1-R^{\text {sat }}\right)\right)+0.056 \\
w_{\text {iso }}^{\text {sat }}-0.056=C_{1}^{\text {sat }} *\left(R^{\text {sat }} *(0.0187-0.056)-0.056\right) \\
C_{1}^{\text {sat }}=\frac{w_{i s o}^{\text {sat }}-0.056}{R^{\text {sat }} *(0.0187-0.056)-0.056}
\end{gathered}
$$

and multiplying numerator and denominator by -1 ,

$$
\text { Equation } 15 \quad C_{1}^{\text {sat }}=\frac{0.056-w_{\text {iso }}^{\text {sat }}}{0.056+R^{\text {sat }} *(0.056-0.0187)}
$$

And putting the temperature dependencies back in,

Equation 16

$$
C_{1}^{\text {sat }}(T)=\frac{0.056-w_{\text {iso }}^{\text {sat }}(T)}{0.056+R^{\text {sat }} *(0.056-0.0187)}
$$

As a check, if we only have $C_{1}^{\text {sat }}$, so that $R^{\text {sat }}=0$, then

which agrees with Equation 10.

$$
C_{1}^{\text {sat }}=\frac{0.056-w_{\text {iso }}^{\text {sat }}}{0.056}=1-\frac{w_{\text {iso }}^{\text {sat }}}{0.056}
$$

The parameter $R^{\text {sat }}$ is an additional model parameter that can be adjusted to give the best match of all the data. In particular, it is expected that the data from temperature change tests will be the most useful in determining a representative value of $R^{\text {sat }}$. Also, it was noted in parameter fits that the value of $R^{\text {sat }}$ produced an inflection of the curve in some circumstances.

Returning to Equation 13 and solving for $C_{2}^{\text {sat }}(T)$,

$$
\begin{aligned}
& w_{\text {iso }}^{\text {sat }}(T)=(0.0187-0.056) * C_{2}^{\text {sat }}(T)+0.056 *\left(1-C_{1}^{\text {sat }}(T)\right) \\
& (0.0187-0.056) * C_{2}^{\text {sat }}(T)=w_{\text {iso }}^{\text {sat }}(T)-0.056 *\left(1-C_{1}^{\text {sat }}(T)\right)
\end{aligned}
$$


WSRC-TR-2007-00440

Revision 0

$$
\begin{aligned}
& C_{2}^{\text {sat }}(T)=\frac{w_{\text {iso }}^{\text {sat }}(T)-0.056 *\left(1-C_{1}^{\text {sat }}(T)\right)}{(0.0187-0.056)}
\end{aligned}
$$

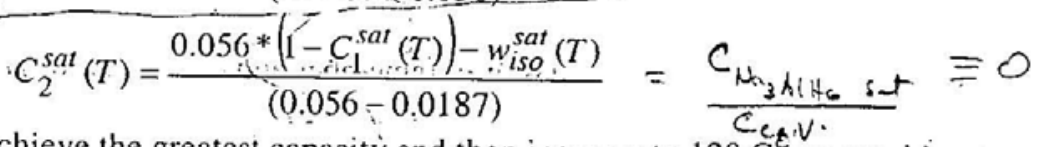

If we hydride at $100 \mathrm{C}$ to achieve the greatest capacity and then increase to $120 \mathrm{C}$, we would not expect the saturation weight fraction to drop to the lower level of a constant $120 \mathrm{C}$ history. Experiments need to examine this. If experiments do find that the saturation weight fraction does not change after the temperature change from 100 to $120 \mathrm{C}$, then this will be consistent with the model described above. To step through examination of the model, when the temperature is increased from 100 to $120 \mathrm{C}$, the value of $w_{i s o}^{\text {sat }}(T)$ will drop. The values of $C_{1}^{\text {sat }}(T)$ and $C_{2}^{\text {sat }}(T)$ determined from Equation 16 and Equation 14 will increase so that the arguments $\left(C_{1}-C_{1}^{\text {sat }}\right)$ and $\left(C_{2}-C_{2}^{\text {sat }}\right)$ will be less than zero and according to Equation 8 and Equation 12, the reaction rates will be zero as desired.

Physically, if $C_{1}^{\text {sat }}(T)=1$, then both reactions $\mathrm{r} 2$ and $\mathrm{r} 4$ will be eliminated and the saturated weight fraction can be set as low as 0 . However, setting $C_{2}^{\text {sat }}(T)=1$ by itself will only restrict reaction r4. If $C_{1}^{s a t}(T) \approx 0$ associated with large values of $R^{\text {sat }}$, then the minimum weight fraction stored will be 0.0187 and this will all occur during reaction $r 2$ giving little opportunity for an inflected curve. Because of this, restrictions on valid values of $R^{\text {sat }}$ and $w_{\text {iso }}^{\text {sat }}(T)$ would be needed.

Rather than attempt such restrictions, afid alternate form relating $C_{1}^{\text {sat }}(T)$ and $C_{2}^{\text {sat }}(T)$. was developed. In order for $C_{1}^{\text {sat }}(T) \geq 0$,

$$
\begin{gathered}
0.056 *\left(1-C_{1}^{\text {sat }}(T)\right) \geq w_{\text {iso }}^{\text {sat }}(T) \\
C_{1}^{\text {sat }}(T) \leq 1-\frac{w_{\text {iso }}^{\text {sat }}(T)}{0.056}
\end{gathered}
$$

A convenient way to impose this restriction is to define

Then define a new independent parameter, $r^{\text {sat }}$,

$$
C_{1}^{\text {sat }, \max }(T)=1-\frac{w_{i s o}^{\text {sat }}(T)}{0.056}
$$

\section{Equation 17}

$$
r^{s a t}=\frac{C_{1}^{s a t}(T)}{C_{1}^{s a t, \max }(T)}
$$

such that

or

$$
C_{1}^{\text {sat }}(T)=r^{\text {sat }} * C_{1}^{\text {sat, } \max }(T)
$$


WSRC-TR-2007-00440

Revision 0

\section{Equation 18}

$$
C_{1}^{s a t}(T)=r^{s a t} *\left(1-\frac{w_{i s o}^{s a t}(T)}{0.056}\right)
$$

In this way, the restriction is easier to remember and enforce as $0 \leq r^{\text {sat }} \leq 1$. Note that the right hand factor in Equation 18 will also be between 0 and 1 for reasonable values of $w_{i s o}^{\text {sat }}(T)$ so that after multiplying these two factors, we will have $0 \leq C_{1}^{\text {sat }}(T) \leq 1$. Once $r^{\text {sat }}$ is chosen, compute $C_{1}^{\text {sat }}(T)$ from Equation 18 and compute $C_{2}^{\text {sat }}(T)$ from

$$
\begin{aligned}
C_{2}^{\text {sat }}(T) & =\frac{0.056 *\left(1-r^{\text {sat }} *\left(1-\frac{w_{\text {iso }}^{\text {sat }}(T)}{0.056}\right)\right)-w_{\text {iso }}^{\text {sat }}(T)}{(0.056-0.0187)} \\
& =\frac{\left(0.056-r^{\text {sat }} *\left(0.056-w_{\text {iso }}^{\text {sat }}(T)\right)\right)-w_{\text {iso }}^{\text {sat }}(T)}{(0.056-0.0187)} \\
& =\frac{\left(1-r^{\text {sat }}\right) *\left(0.056-w_{\text {iso }}^{\text {sat }}(T)\right)}{(0.056-0.0187)}
\end{aligned}
$$

or

Equation 19

$$
C_{2^{\prime \prime}}^{\text {sat }}(T)=\frac{\left(1-r^{s a t}\right) *\left(0.056-w_{i s o}^{s a t}(T)\right)}{(0.056-0.0187)}
$$

The form of Equation 19 shows that $C_{2}^{\text {sat }}(T)$ must go to zero as $r^{\text {sat }}$ approaches 1 or $w_{i s o}^{\text {sat }}(T)$ approaches 0.056 . This is intuitive since the first condition is if all of the nonideal capacity is accounted for in $C_{1}^{s a t}(T)$ and the latter is that the actual capacity equals the ideal level, i.e. no need for saturation compositions. An additional restriction is needed however, because it is possible for $C_{2}^{\text {sat }}(T)$ to become greater than 1 if $w_{i s o}^{\text {sat }}(T)$ is less than 0.0187 and $r^{\text {sat }}$ is 0 or nearly 0 . To examine this second restriction,

$$
\begin{gathered}
C_{2}^{\text {sat }}(T) \leq 1 \\
\frac{\left(1-r^{\text {sat }}\right) *\left(0.056-w_{i s o}^{\text {sat }}(T)\right)}{(0.056-0.0187)} \leq 1 \\
\left(1-r^{\text {sat }}\right) *\left(0.056-w_{i s o}^{\text {sat }}(T)\right) \leq(0.056-0.0187) \\
1-r^{\text {sat }} \leq \frac{(0.056-0.0187)}{\left(0.056-w_{i s o}^{\text {sat }}(T)\right)} \\
r^{\text {sat }} \geq 1-\frac{0.056-0.0187}{0.056-w_{i s o}^{\text {sat }}(T)}
\end{gathered}
$$

One characteristic of the model with both $C_{1}^{\text {sat }}(T)$ and $C_{2}^{\text {sat }}(T)$ is if we start out with an initial composition of $C_{2}=0$, the first hydriding reaction will need to proceed to the point were $C_{2}>C_{2}^{\text {sat }}$ before reaction 4 will begin. Thus there will be a time lag between when some $C_{2}$ reactant is available and when reaction 4 becomes active. This may produce an inflection in the curve. 
WSRC-TR-2007-00440

Revision 0

\subsection{Modified Form for All Pressure Regimes}

The previous examination has focused just on pressure regime 3 for which both reactions are proceeding in the hydriding direction. For reversible reactions, we would anticipate that the amount stored would need to equal the amount released, at lcast after steady state has been reached. Because the amount stored was limited by introducing saturation levels for $C_{1}$ and $C_{2}$, the amount released will already be limited and we do not need to change the form for the dehydriding reactions (although the parameters will need to be modified from previous estimates). Another way to consider whether to have saturation levels on the dehydriding reactions is to think that in the dehydriding direction, we want all of the reactants to be consumed so the compositions can return to the initial state of $C_{1}=1, C_{2}=0, C_{3}=0$. If we have saturation levels for $C_{2}$ or $C_{3}$, then the dehydriding rate will go to zero before the compositions drop to zero. Therefore, we do not want saturation values on the reactants for the dehydriding reactions.

In the current model framework, the composition at the start of hydriding test after complete dehydriding would be

$$
C_{1}=1, \quad C_{2}=0, \quad C_{3}=0
$$

and the composition at the start of dehydriding after complete hydriding at temperature $T$ would be

$$
C_{1}=C_{1}^{\text {sat }}(T), \quad C_{2}=C_{2}^{s a t}(T), \quad C_{3}=1-C_{1}^{s a t}(T)-C_{2}^{s a t}(T)
$$

A sketch of the three pressure regimes is shown in Figure 3.

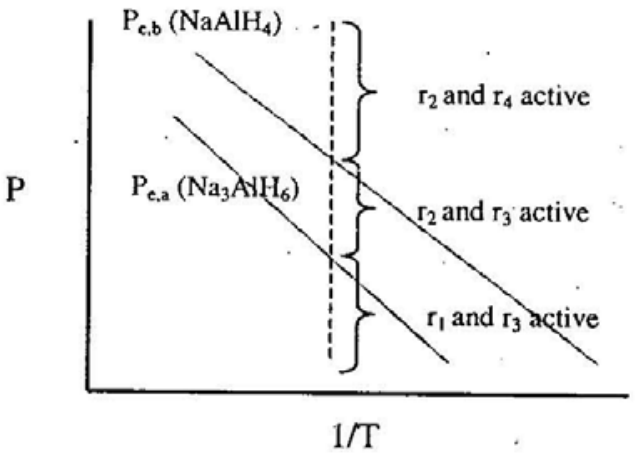

Figure 3: Reaction pressure regimes. 
The complete model for all three pressure regimes will be,

Table 1: Complete listing of reaction rate equations.

\begin{tabular}{|c|c|}
\hline $\mathrm{r} 1$ and $\mathrm{r} 3$ active & $\begin{array}{l}\text { If } C_{2} \geq 0,\left(\frac{d C_{1}}{d t}\right)_{r 1}=A_{1} \exp \left(-\frac{E_{1}}{R T}\right) *\left(\frac{P_{e, 1}-P}{P_{e, 1}}\right) *\left(C_{2}\right)^{\chi_{1}} \\
\left(\frac{d C_{2}}{d t}\right)_{r 1}=-\left(\frac{d C_{1}}{d t}\right)_{r 1} \\
\text { If } C_{3} \geq 0, \quad\left(\frac{d C_{2}}{d t}\right)_{r 3}=A_{3} \exp \left(-\frac{E_{3}}{R T}\right) *\left(\frac{P_{e, 3}-P}{P_{e, 3}}\right) *\left(C_{3}\right)^{\chi_{3}} \\
\left(\frac{d C_{3}}{d t}\right)_{r 3}=-\left(\frac{d C_{2}}{d t}\right)_{r 3}\end{array}$ \\
\hline $\begin{array}{l}\text { Pressure regime } 2 \\
\mathrm{r} 2 \text { and } \mathrm{r} 3 \text { active }\end{array}$ & $\begin{array}{l}\text { If } C_{1}-C_{1}^{s a t}(T) \geq 0,\left(\frac{d C_{2}}{d t}\right)_{r 2}=A_{2} \exp \left(-\frac{E_{2}}{R T}\right) *\left(\frac{P-P_{e, 2}}{P_{e, 2}}\right) *\left(C_{1}-C_{1}^{s a t}(T)\right)^{\chi_{2}} \\
\left(\frac{d C_{1}}{d t}\right)_{r 2}=-\left(\frac{d C_{2}}{d t}\right)_{r 2} \\
\text { If } C_{3} \geq 0, \quad\left(\frac{d C_{2}}{d t}\right)_{r 3}=A_{3} \exp \left(-\frac{E_{3}}{R T}\right) *\left(\frac{P_{e, 3}-P}{P_{e, 3}}\right) *\left(C_{3}\right)^{\chi_{3}} \\
\left(\frac{d C_{3}}{d t}\right)_{r 3}=-\left(\frac{d C_{2}}{d t}\right)_{r 3} .\end{array}$ \\
\hline $\begin{array}{l}\text { Pressure regime } 3 \\
\text { r2 and r4 active }\end{array}$ & $\begin{array}{l}\text { If } C_{1}-C_{1}^{s a t}(T) \geq 0,\left(\frac{d C_{2}}{d t}\right)_{r 2}=A_{2} \exp \left(-\frac{E_{2}}{R T}\right) *\left(\frac{P-P_{e, 2}}{P_{e, 2}}\right) *\left(C_{1}-C_{1}^{s a t}(T)\right)^{\chi_{2}} \\
\left(\frac{d C_{1}}{d t}\right)_{r 2}=-\left(\frac{d C_{2}}{d t}\right)_{r 2} \\
\text { If } C_{2}-C_{2}^{s a t}(T) \geq 0,\left(\frac{d C_{3}}{d t}\right)_{r 4}=A_{4} \exp \left(-\frac{E_{4}}{R T}\right) *\left(\frac{P-P_{e, 4}}{P_{e, 4}}\right) *\left(C_{2}-C_{2}^{s a t}(T)\right)^{\chi_{4}} \\
\left(\frac{d C_{2}}{d t}\right)_{r 4}=-\left(\frac{d C_{3}}{d t}\right)_{r 4}\end{array}$ \\
\hline
\end{tabular}

If the quantities stated in Table 1 which need to be $\geq 0$ are actually $<0$, then the associated reaction rate is set to 0 .

For all three pressure regimes, the total rate of change for $C_{2}$ will be the sum for each of the two active reactions,

$$
\left(\frac{d C_{2}}{d t}\right)_{\text {total }}=\left(\frac{d C_{2}}{d t}\right)_{\mathrm{r} 1 \text { or } \mathrm{r} 2}+\left(\frac{d C_{2}}{d t}\right)_{\mathrm{r} 3 \text { or } \mathrm{r} 4}
$$


WSRC-TR-2007-00440

Revision 0

As present previously, the equilibrium pressure is

$$
\ln \left(P_{e}\right)=\frac{\Delta H}{R T}-\frac{\Delta S}{R}
$$

or

Equation 20

$$
P_{e}(T)=\exp \left(\frac{\Delta H}{R T}-\frac{\Delta S}{R}\right)
$$

\section{Effect of Parameters on Curve Characteristics}

Some parameter fitting and sensitivity studies were conducted with the initial relation of

Equation 14 using $R^{\text {sat }}$ for the saturation compositions. The value of $R^{\text {sat }}$ influences the weight fraction level at which the inflection point occurs for the transition between the reactions. This is shown in Figure 4 through Figure 7 for the $100 \mathrm{C}$ data. A slightly different set of parameters was used to fit the $120 \mathrm{C}$ data shown in Figure 8 through Figure 11.

Using Equation 17 to choose different values of the saturation compositions, it seemed more difficult to produce the inflection point in the curves during parameter estimatation trials using MATLAB. There is no restriction in the new form that should make this happen, and it is likely that this was caused by having different values of the other model parameters that affect the relative rates etc. of the two hydriding reactions. A small amount of thought was invested into what conditions would lead to a more prominent inflection region, but this was shelved in the interest of completing the model and its application. For an inflection region to occur, one needs reaction 2 to slow down, to have reaction 4 become active, to have reaction 2 still proceed to produce more reactant for reaction 4 but to have reaction 4 accelerate in hydrogen production. It is still unclear what values of the parameters (or dependencies between them) will produce a pronounced inflection region.

The fit to experimental data using Equation 17 is shown in Figure 12 using the parameter values of Table 2. The value of $r^{\text {sat }}$ was set equal to 1 for all temperatures, which in effect sets $C_{2}^{\text {sat }}=0$ and would appear to eliminate the possibility of an inflection region. Other parameter combination are still possible to give a better match. Neviertheless, the results are reasonably good. The fit at $140 \mathrm{C}$ is the poorest due to the large inflection region. The model was also fit to the desorption data shown in Figure 13. A different value for $C_{1}^{\text {sat }}=0.5$ was used to best match * the resulting capacities. We could argue that such flexibility in choosing $C_{1}^{\text {sat }}$ is acceptable since we do not known the actual composition of the as received / milled material. 

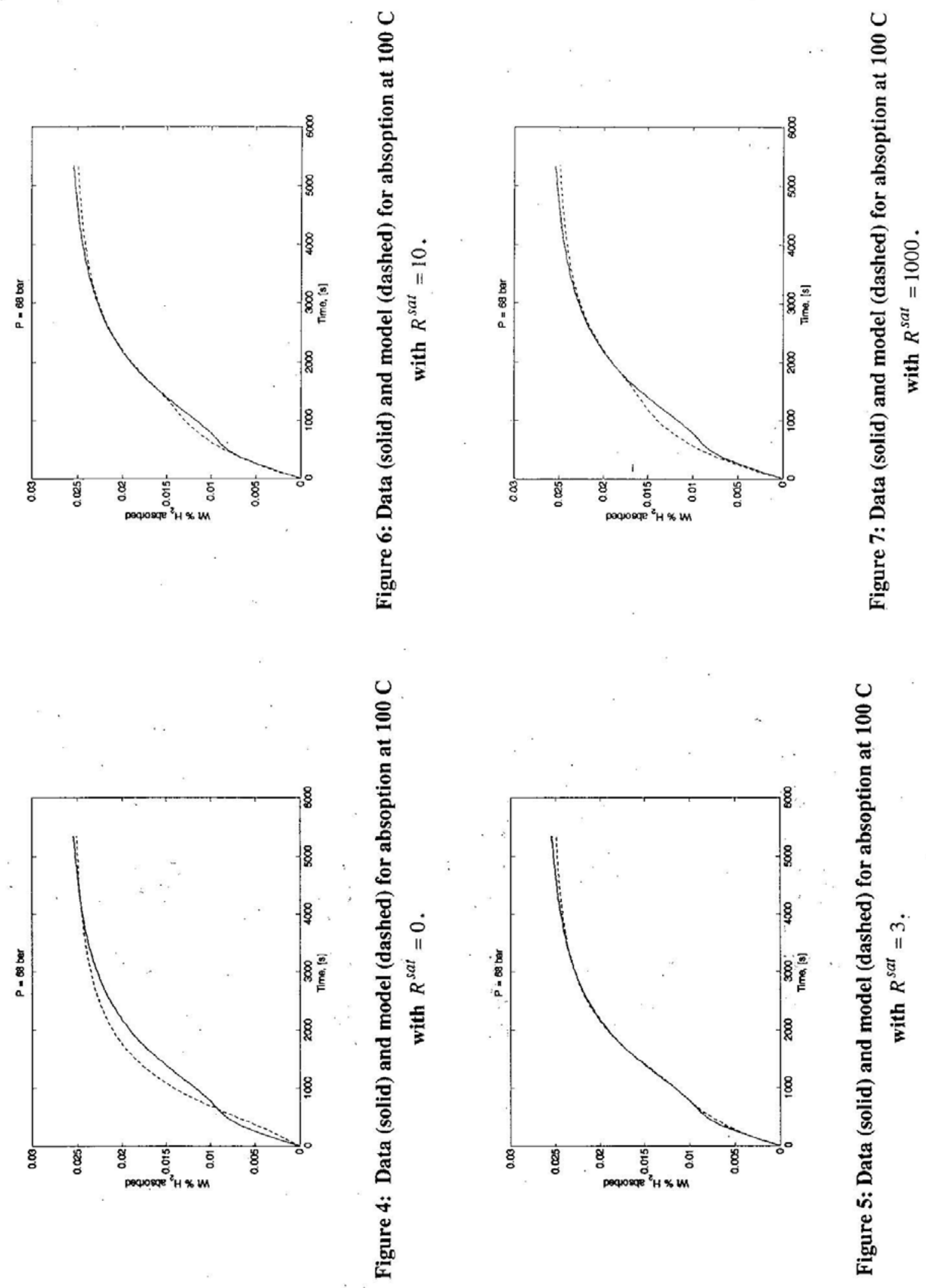

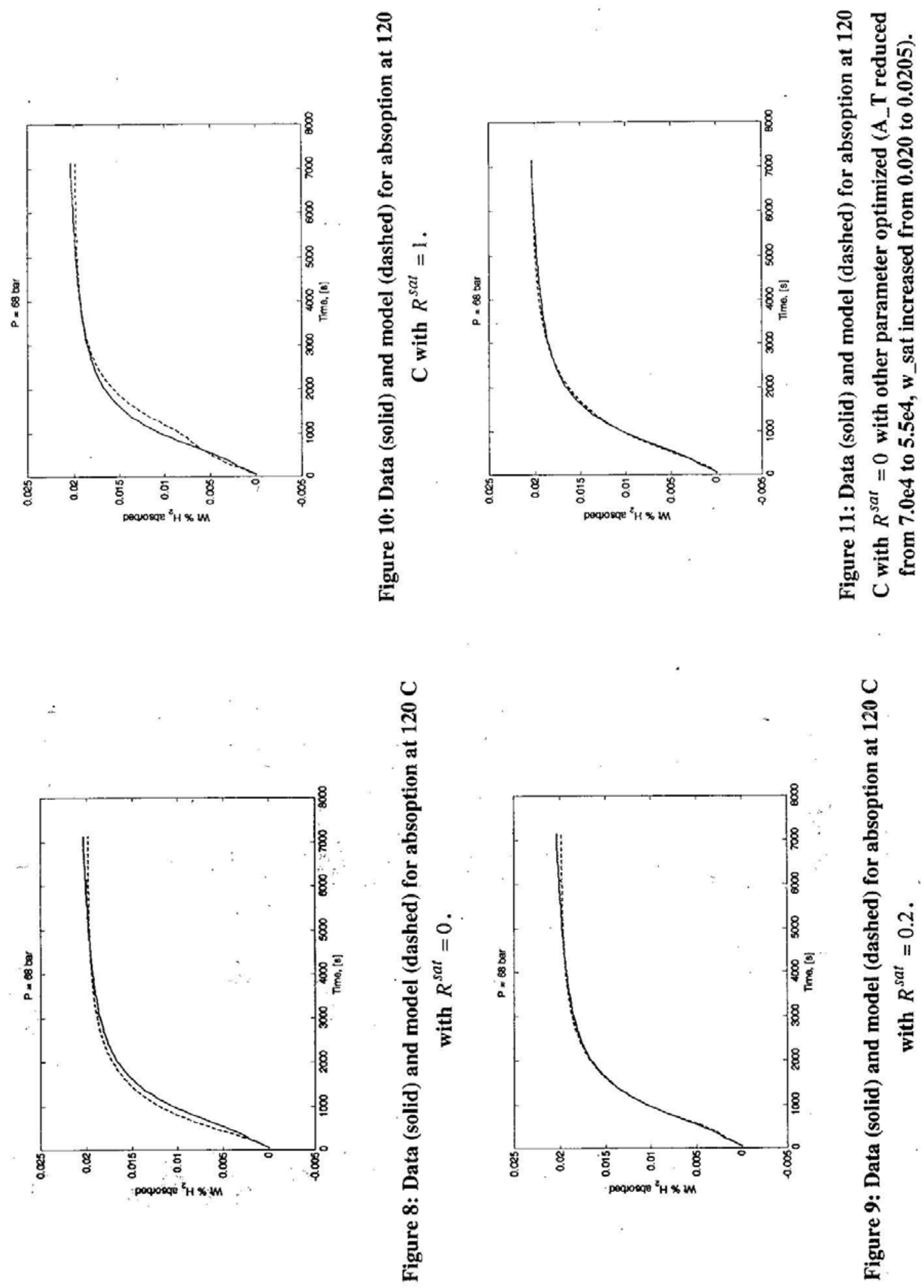
WSRC-TR-2007-00440

Revision 0

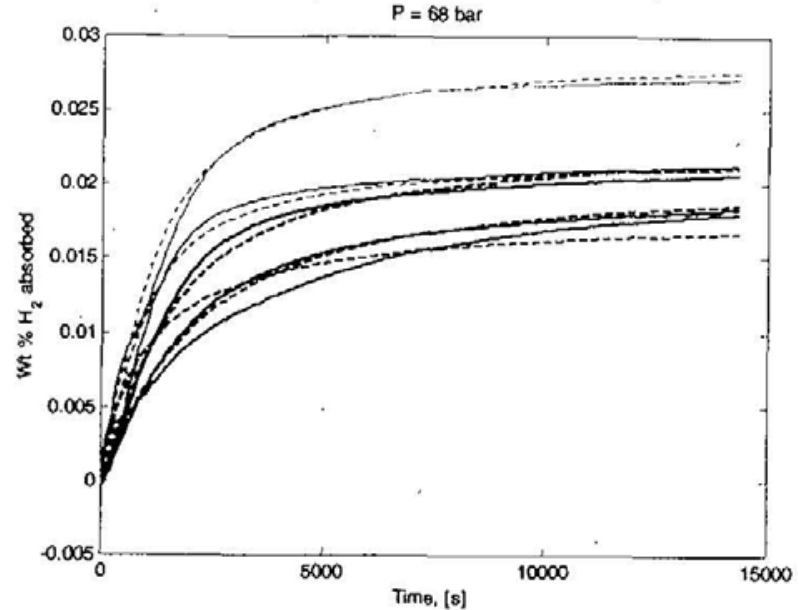

Figure 12: Absorption with starting $\mathrm{C}_{-} 1=1$ and $\mathrm{T}$ dependent C__1_sat $\left(r \_s a t(T)=1\right.$ so $\left.C \_2 \_s a t=0\right)$. The dashed lines are the model with red $=80 \mathrm{C}$; blue $=90 \mathrm{C}$; cyan $=100 \mathrm{C}$; green $=120 \mathrm{C}$; and magenta $=140 \mathrm{C}$.

Table 2: MATLAB coding giving model parameter values.

T_sat_C $=\left[\begin{array}{lllllll}0 & 80 & 90 & 100 & 120 & 140 & 300\end{array}\right] ; \quad \%$ temperatures associated with w_iso

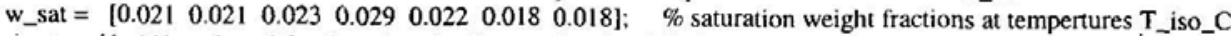

r_sat $=\left[\begin{array}{llllllllll}1 & 1 & 1 & 1.0 & 1 & 1 & 1\end{array}\right]$; $\quad \%$ ratio of C_1_sat / C_l_sat_max

r_sat_threshold $=1-(0.056-0.0187) . /(0.056-\mathrm{w}$ ssat $)$; \% restriction level for $r$ sat. $\mathbf{I}-(0.056-0.0187) / 0.056=0.333$

r_sat $=\max \left(r_{-}\right.$sat, r_sat_threshold $) ; \quad \%$ check for values of r_sat that will maintain C_2_sat $<1$.

T_sat_K = T_sat_C + 273;

i_r $=1$ : \% directional reaction 1, dehydriding of $\mathrm{Na3AlH6}$ to $\mathrm{NaH} \quad-r_{4}$ param $\left(i \_r, 1\right)=-6150 ; \quad \%$ A or delta $H / R$, slope in van't Hoff plot

param $\left(i \_r, 2\right)=16.22 ; \quad \%$ B or -delta $S / R$, intercept in van't Hoff plot

param(i_r,3 $=6.0 \mathrm{e} 12 ; \quad \%$ A_ $T$, lcading coefficient in temperature factor, time unit of seconds

param $\left(i \_r, 4\right)=110000 ; \quad \%$ E, thermal activation energy, $\mathrm{J} / \mathrm{mol}$ of $\mathrm{H}_{-} 2$

param $\left(i \_r, 5\right)=1.0 ; \quad \%$ chi, exponent on reactant weight fraetion

i_r $=2$; \% directional reaction 2 , hydriding of $\mathrm{NaH}$ to Na3AlH6 $\left(-r_{2}\right)$

param $\left(i_{\_} r, 1\right)=-6150 ; \quad \% A$, not used, value for i_ $r=1$ used....

param $\left(i \_r, 2\right)=16.22 ; \quad \% B$, not used, value for $i \_r=1$ used

param(i_r,3) $=1.5 \mathrm{es:} \%$ A_T .

$\operatorname{param}($ i_r,4) $=70000 ; \quad \% \mathrm{E}$

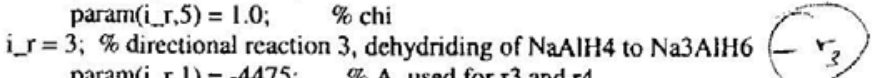

param $\left(i \_r, 1\right)=-4475$; \% $A$, used for $r 3$ and $r 4$

param $\left(i \_r, 2\right)=14.83 ; \quad \% B$, used for $r 3$ and $r 4(14.83)$

param $\left(i \_r, 3\right)=4.0 \mathrm{e} 12 ; \quad$ \% A_T

param(i_r,4) $=110000 ; \quad \% \mathrm{E}$

param $\left(i_{-} r, 5\right)=2.0 ; \quad \%$ chi

i_r $=4$; \% directional reaction 4 , hydriding of Na3AlH6 to NaAlH4,$- r_{\text {. }}$

param $\left(i_{\_} r, 1\right)=-4475 ; \quad \% A$, not used, value for $i_{\_} r=3$ used

$\Delta H / R$

param $\left(i \_r, 2\right)=14.83 ; \quad \% B$, not used, value for $i \quad r=3$ used $(14.83$ )

param(i_r.3) $=1.0 \mathrm{e} 8 ; \quad \%$. A_T

param(i_r.4) $=80000 ; \quad \% \mathrm{E}$

param(i_r.5) $=2 ; \quad \%$ chi

$\stackrel{E}{x}$ 
WSRC-TR-2007-00440

Revision 0

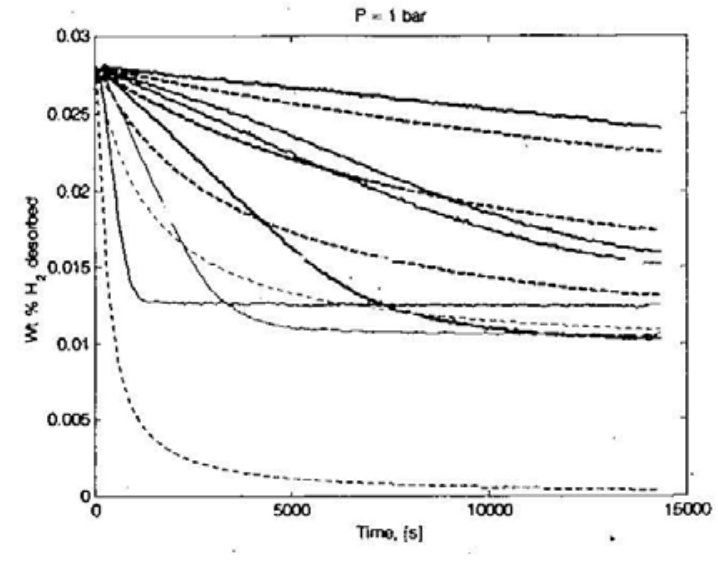

Figure 13: Desorption from as milled condition (assume C_1_sat $=0.5$ ). Dashed lines are model. Temperatures are black $=70 \mathrm{C}$; red $=80 \mathrm{C}$ (two experiments); blue $=90 \mathrm{C}$; cyan $=100 \mathrm{C}$; yellow $=110 \mathrm{C} ;$ green $=120 \mathrm{C}$;

Note that the equilibrium pressure for the lower van't Hoff line using a modified Equation 20 and parameters in Table 2 is

$$
P_{e}(T)=\exp \left(\frac{A}{T}+B\right)=\exp \left(\frac{-6150}{T}+16.22\right)
$$

Solving for the transition temperature for the desorption pressure of $1 \mathrm{~atm}$,

$$
T=\frac{-6150}{\ln \left(P_{e}(T)\right)-16.22}=\frac{-6150}{\ln (1 \mathrm{~atm})-16.22}=379 \mathrm{~K}=106 \mathrm{C}
$$

Thus, we would expect significant differences in capacity for temperatures above $106 \mathrm{C}$ versus those below it. This is reflected in the model predictions of Figure 13 (yellow and green lines) but not in the experimental data. In fact, after $8,000 \mathrm{~s}$, the desorbed capacity at $90 \mathrm{C}$ is greater than at $120 \mathrm{C}$. Additional experimentation and modeling is required to understand this effect.

The modifications to the kinetics model were made to the ABAQUS subroutines and check with a simple isothermal test problem. The user subroutine "powder_user2.for" was developed from the previous "powder_user.for" file based on additional modeling and parameter estimation in MATLAB. The implementation of changes required adding parameters to calculate saturation compositions and also the addition of these saturation levels to the hydriding reaction rate equations. Simple simulations were conducted in ABAQUS to verify that the implementation was accurate. These were nearly isothermal simulations of a cube $0.1 \mathrm{~m}$ in size. A slight temperature difference was produced by imposing a convective boundary condition which was 1 degree $\mathrm{C}$ higher than the initial temperature to avoid numerical problems of taking to small of a time step in transient thermal analyses. Such a small time $(100 \mathrm{~s})$ is needed to integrate the reaction equations. 
WSRC-TR-2007-00440

Revision 0

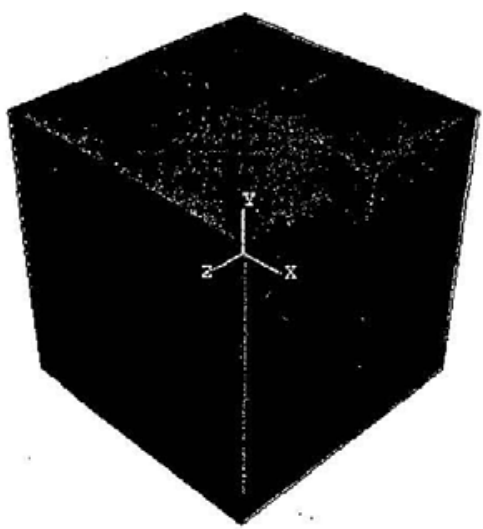

Figure 14: 0.1 meter cube used to test implementation of model in ABAQUS.

The results below are very similar to the comparison of data with the MATLAB implementation as expected. After these simulations were run, code was added to the user subroutine HETVAL to check whether the composition factors were positive. A simulation at $140 \mathrm{C}$ was then rerun and the results did not changed at all. This is expected since the value of $r_{-}$sat was 1 for all temperatures so that C_2_sat $=0$ and therefore there would not be any negative composition factors for an isothermal history starting with $C_{-} 1=1$. Note that the checks for negative composition factors were in the MATLAB code used to fit the parameters. Therefore, though the code was modified, it is expected that the results for the other temperatures besides $140 \mathrm{C}$ will also agree as in the figure.

The results in Figure 15 show good agreement with Figure 12 indicating the coditig of equations including their integration is accurate, at least for these conditions.

ABAQUS Comparison, $0.1 \mathrm{~m}$ Cube

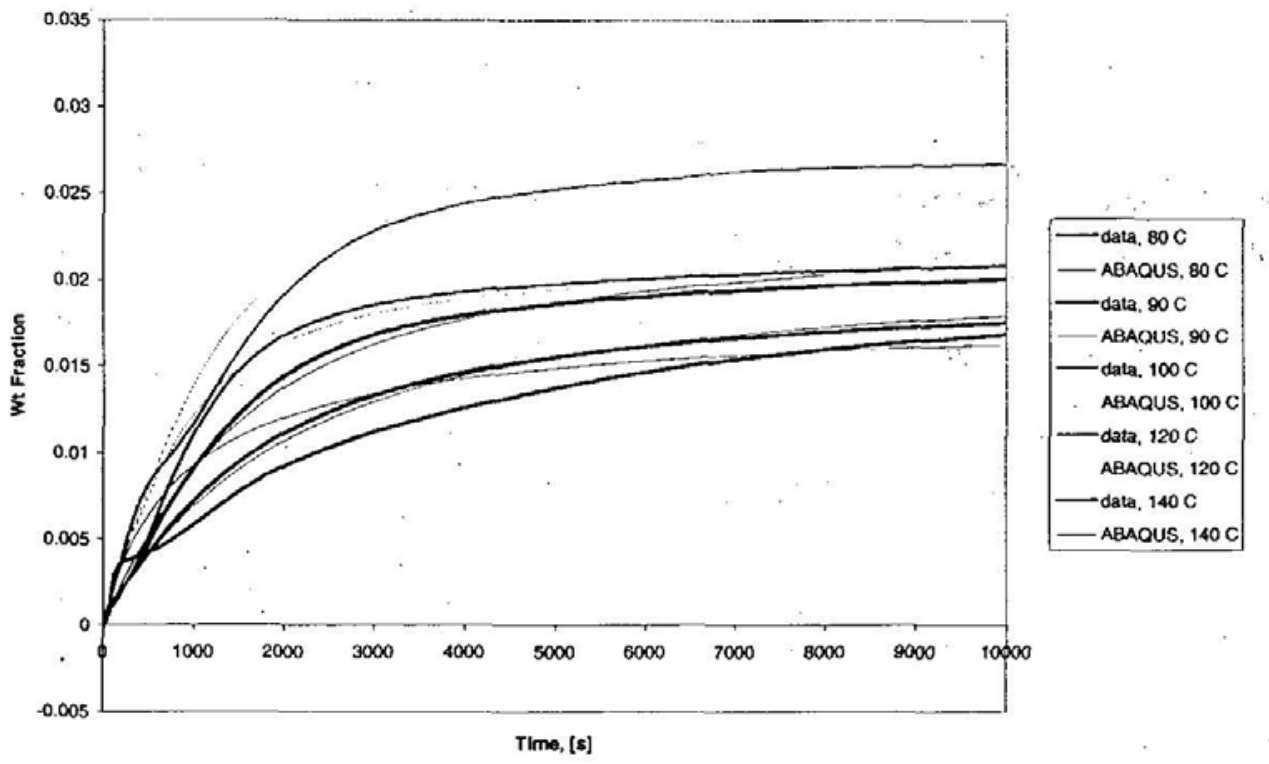

Figure 15: Results for absorption conditions. 


\section{Attachment 3}

\section{DOE Technical Targets for On-Board Hydrogen Storage Systems}

\begin{tabular}{|c|c|c|c|c|}
\hline Storage Parameter & Units & 2007 & 2010 & 2015 \\
\hline $\begin{array}{l}\text { System Gravimetric } \\
\text { Capacity: Usable, specific- } \\
\text { energy from } \mathrm{H}_{2} \text { (net useful } \\
\text { energy/max system mass) }^{a}\end{array}$ & $\begin{array}{c}\mathrm{kWh} / \mathrm{kg} \\
\left(\mathrm{kg} \mathrm{H}_{2} / \mathrm{kg} \text { system) }\right.\end{array}$ & $\begin{array}{c}1.5 \\
(0.045)\end{array}$ & $\begin{array}{c}2 \\
(0.06)\end{array}$ & $\begin{array}{c}3 \\
(0.09)\end{array}$ \\
\hline $\begin{array}{l}\text { System Volumetric } \\
\text { Capacity: Usable energy } \\
\text { density from } \mathrm{H}_{2} \text { (net useful } \\
\text { energy/max system volume) }\end{array}$ & $\begin{array}{c}\mathrm{kWh} / \mathrm{L} \\
\left(\mathrm{kg} \mathrm{H}_{2} / \mathrm{L} \text { system }\right)\end{array}$ & $\begin{array}{c}1.2 \\
(0.036)\end{array}$ & $\begin{array}{c}1.5 \\
(0.045)\end{array}$ & $\begin{array}{c}2.7 \\
(0.081)\end{array}$ \\
\hline $\begin{array}{l}\text { Storage system cost } \\
\text { (\& fuel cost) }\end{array}$ & $\begin{array}{c}\text { \$/kWh net } \\
\left(\$ / \mathrm{kg} \mathrm{H}_{2}\right) \\
\text { \$/gge at pump }\end{array}$ & $\begin{array}{c}6 \\
(200) \\
---\end{array}$ & $\begin{array}{c}4 \\
(133) \\
2-3\end{array}$ & $\begin{array}{c}2 \\
(67) \\
2-3\end{array}$ \\
\hline $\begin{array}{l}\text { Durability/Operability } \\
\text { - Operating ambient temperature } \\
\text { - Min/max delivery temperature } \\
\text { - Cycle life (1/4 tank to full) } \\
\text { - Cycle life variation } \\
\text { - Min delivery pressure from tank; } \\
\text { FC= fuel cell, I=ICE } \\
\text { - Max delivery pressure from tank }\end{array}$ & $\begin{array}{c}{ }^{\circ} \mathrm{C} \\
{ }^{\circ} \mathrm{C} \\
\text { Cycles } \\
\% \text { of mean (min) at \% confidence } \\
\text { Atm (abs) } \\
\text { Atm (abs) }\end{array}$ & $\begin{array}{c}-20 / 50 \text { (sun) } \\
-30 / 85 \\
500 \\
\text { N/A } \\
\\
8 \mathrm{FC} / 10 \text { ICE } \\
100\end{array}$ & $\begin{array}{c}-30 / 50 \text { (sun) } \\
-40 / 85 \\
1000 \\
90 / 90 \\
\\
4 \mathrm{FC} \mathrm{/} 35 \text { ICE } \\
100\end{array}$ & $\begin{array}{c}-40 / 60 \text { (sun) } \\
-40 / 85 \\
1500 \\
99 / 90 \\
\\
3 \mathrm{FC} / 35 \text { ICE } \\
100\end{array}$ \\
\hline $\begin{array}{l}\text { Charging/discharging Rates } \\
\text { - System fill time (for } 5 \mathrm{~kg} \text { ) } \\
\text { - Minimum full flow rate } \\
\text { - Start time to full flow }\left(20^{\circ} \mathrm{C}\right) \\
\text { - Start time to full flow }\left(-20^{\circ} \mathrm{C}\right) \\
\text { - Transient response } 10 \%-90 \% \\
\text { and } 90 \%-0 \%\end{array}$ & $\begin{array}{l}\min _{(\mathrm{g} / \mathrm{s}) / \mathrm{kW}} \\
\mathrm{s} \\
\mathrm{s} \\
\mathrm{s}\end{array}$ & $\begin{array}{c}10 \\
0.02 \\
15 \\
30 \\
1.75\end{array}$ & $\begin{array}{c}3 \\
0.02 \\
5 \\
15 \\
0.75\end{array}$ & $\begin{array}{c}2.5 \\
0.02 \\
5 \\
15 \\
0.75\end{array}$ \\
\hline Fuel Purity ( $\mathrm{H}_{2}$ from storage $)^{J}$ & $\% \mathrm{H}_{2}$ & \multicolumn{3}{|c|}{99.99 (dry basis) } \\
\hline $\begin{array}{l}\text { Environmental Health \& } \\
\text { Safety } \\
\text { - Permeation \& leakage }{ }^{k} \\
\text { - Toxicity } \\
\text { - Safety }\end{array}$ & $\mathrm{Scc} / \mathrm{h}$ & \multicolumn{3}{|c|}{$\begin{array}{c}(\mathrm{g} / \mathrm{h}) / \mathrm{kg} \bar{H}_{2} \text { stored } \\
\text { Meets or exceeds applicable standards }\end{array}$} \\
\hline - Loss of useable $\mathrm{H}_{2}$ & $(\mathrm{~g} / \mathrm{h}) / \mathrm{kg} \mathrm{H}_{2}$ stored & 1 & 0.1 & 0.05 \\
\hline
\end{tabular}

